\title{
The lichen genus Hypogymnia in southwest China
}

\section{McCune $\mathbf{B}^{1}$ and Wang $\mathrm{LS}^{2}$}

\author{
${ }^{1}$ Department of Botany and Plant Pathology, Oregon State University, Corvallis, Oregon 97331-2902 U.S.A. \\ ${ }^{2}$ Key Laboratory of Biodiversity and Biogeography, Kunming Institute of Botany, Chinese Academy of Sciences, \\ Heilongtan, Kunming 650204, China
}

McCune B, Wang LS 2014 - The lichen genus Hypogymnia in southwest China. Mycosphere 5(1), 27-76, Doi 10.5943/mycosphere/5/1/2

\begin{abstract}
A total of 36 species of Hypogymnia are known from southwestern China. This region is a center of biodiversity for the genus. Hypogymnia capitata, H. nitida, H. saxicola, H. pendula, and H. tenuispora are newly described species from Yunnan and Sichuan. Olivetoric acid is new as a major lichen substance in Hypogymnia, occurring only in H. capitata. A key and illustrations are given for the species known from this region, along with five species from adjoining regions that might be confused or have historically been misidentified in this region.
\end{abstract}

Key words - Lecanorales - lichenized ascomycetes - Parmeliaceae - Shaanxi - Sichuan - Tibet Yunnan - Xizang.

\section{Introduction}

The first major collections of Hypogymnia from southwestern China were by HandelMazzetti, from which Zahlbruckner (1930) reported six species now placed in Hypogymnia, and Harry Smith (1921-1934, published piecewise by other authors; Herner 1988). Since the last checklist of lichens in China (Wei 1991), which reported 16 species of Hypogymnia from the southwestern provinces, numerous species of Hypogymnia from southwestern China have been described or revised (Chen 1994, Wei \& Bi 1998, McCune \& Obermayer 2001, McCune et al. 2002, Wei \& Wei 2005, Wei et al. 2010). Southwestern China, including Sichuan, Xizang (Tibet), and Yunnan Provinces, is emerging as the richest area in the world for the genus Hypogymnia, with over 30 species known in the region from about 100 species worldwide. The purpose of this paper is to describe further new species in Hypogymnia from southwestern China, to summarize the current knowledge of the genus in this area, and to provide a comprehensive key for the region.

\section{Materials \& Methods}

We studied Hypogymnia in the field in southwestern China, mainly Yunnan, Sichuan, and Xizang Provinces. We also examined Asian specimens of Hypogymnia from the following herbaria: BM, CANL, DUKE, E, F, GZU, H, H-NYL, HMAS, KUN, LWG, MIN, NY, OSC, PC, S, TNS, UPS, US, and WTU.

We applied standard microscopy and chemical spot test methods. Many specimens were subjected to thin-layer chromatography (TLC), using the standard methods of Culberson (1972) and reference tables of Chicita Culberson (1996, unpublished). Fragments of specimens were extracted in acetone at room temperature, spotted on aluminum-backed silica gel plates (Merck 5554/7 Silica 
gel $60 \mathrm{~F}_{254}$ ), run in solvent systems $\mathrm{A}$ and $\mathrm{C}$ of Culberson (1972), lightly brushed with $10 \% \mathrm{H}_{2} \mathrm{SO}_{4}$, and lightly charred in an oven for about $5 \mathrm{~min}$ at $100^{\circ} \mathrm{C}$. We also used solvent B' of Culberson and Johnson (1982) for critical specimens or when attempting to name unknown substances. No attempt was made to distinguish chloroatranorin from atranorin. Nor do we report fatty acids. Although these have been used to help define species in Hypogymnia (Goward et al. 2010), we have been unable to replicate their fatty acid results, instead finding several unknown and variable fatty acids in species where they report one.

Physodic acid and 3-hydroxyphysodic acid are often accompanied by various low-Rf pale brownish satellite spots in TLC. Vittatolic acid is one of those, and it is often associated with an adjacent unknown. Similarly, 3-hydroxyphysodic acid is often correlated with a third low-Rf spot near vittatolic acid. In $\mathrm{P}+$ orange-red species these low-Rf spots are obscured by the darker spots of protocetraric acid and/or physodalic acid, depending on the solvent system. This masking, along with the usually low concentrations of these substances, make these low Rf associates of physodic acid of limited taxonomic utility. We report vittatolic acid when seen by TLC, but it is no doubt present in some $\mathrm{P}+$ species, even though we were not able to detect it.

Spermatia and ascospores were measured in a more accurate way than in our previous papers, thus the values given here will depart somewhat from our previously published values. (Note: we use the term spermatia rather than conidia because in the genus Hypogymnia, production of apothecia is strongly correlated with production of these mitospores, implying a role in sexual rather than asexual reproduction). Spores were photographed, cut and pasted onto a single canvas, then measured with the line tool in PhotoShop with View | Info displayed. These raw values were converted to micrometers using a conversion factor calibrated from a stage micrometer. Comparison with previous ascospore measurements indicated no bias; however, we determined that because of refraction error we had chronically underestimated spermatia widths (typically 0.6-0.8 visually vs. 0.9-1.1 $\mu \mathrm{m}$ from photos).

In addition to the morphological and anatomical characters traditionally used in Hypogymnia, we introduce a character not previously reported in the genus, but that appears to deserve further study: the reaction of the hypothecium to polarized light. Terminology for the layering below the hymenium is rather variable among authors, so we define our terms here. All Hypogymnia species have a differentiated subhymenium, a thin layer of horizontal hyphae immediately below the hymenium. This layer is always hyaline, POL- (dark in polarized light), and about 6-14 $\mu \mathrm{m}$ thick. Immediately below the subhymenium is what we term the hypothecium. The upper part of the hypothecium is a compact tissue that can contain POL+ crystals. In other species these crystals are lacking, sparse, or concentrated in the base of the hypothecium. The distribution and abundance of POL+ crystals appears to be a useful species-level character in Hypogymnia. Below the hypothecium is the medullary part of the thalline exciple, which is always somewhat occluded by crystals and POL+ grayish white, and generally somewhat looser than the hypothecium. Unfortunately we discovered this character late in our study, so it is not given for a few species for which fertile specimens were no longer available to us.

The color of the lobe interiors of Hypogymnia can be a very useful character. Lobes are generally hollow in Hypogymnia, and we call the upper interior surface of this open space the "ceiling" and the lower surface the "floor" of the cavity. Be sure to check this character well back ( $1 \mathrm{~cm}$ or more) from the tips. The ceilings and floors of almost all Hypogymnia are initially white at the extreme tips. In most species the ceiling rapidly darkens away from the tip, while in others it is persistently white or white with only scattered dark hyphae. The floor of the lobe cavity quickly darkens away from the lobe tip in almost all Hypogymnia species.

In many species the lobe tips are often perforate, as in $H$. irregularis, $H$. stricta, and $H$. vittata. Because lobe tips often become axils as a lobe branches, species with perforate lobes also tend to have perforate axils. Perforations (holes) are typically circular to elliptical and have smooth, non-ragged margins, unlike most holes caused by mechanical tears or herbivory. A subset of the perforate species have "rimmed holes" (McCune et al. 2003), where the rolled-over edge of a hole forms a raised rim around the hole. Most specimens in this group have at least a few holes with 
poorly formed rims. This makes it desirable to examine several holes before concluding that a specimen belongs to the group with rimmed holes.

The perforations in Hypogymnia mostly follow one of two developmental patterns. In one the perforations are terminal on the lobe tips. When the lobe tip branches dichotomously, the perforation becomes axillary and the new apices elongate. Then the new apices can develop perforations. This pattern leads to many terminal and axillary holes, but only a few holes in the lower surface. In some species the perforations are slow to develop, so that lobe tips mainly have pinholes, while large holes are seldom seen until the tip has become an axil. Even in species that are keyed as having perforate axils and lobe tips, the fraction of lobes developing perforations is quite variable, but typically in the range of 5-75\%.

In the second developmental pattern the holes form on the lower surface just behind the lobe tips (subterminal) or at the lobe tips. This results in a series of holes laid down on the lower surface, but with few truly terminal or axillary holes. Examples are mostly Asian species, including $H$. arcuata, $H$. hengduanensis, and $H$. delavayi. The holes may be so close as to commonly fuse, as in $H$. arcuata or the extreme case, $H$. fragillima, where the lower surface is typically more hole than tissue.

The terms "phyllidia" and "lobules" have variable meanings in the lichen literature; for our purposes, we consider them synonymous and use the term lobules as a more or less determinate, dorsiventral, asexual propagules. We use "budding" to refer to adventitious side branches that are often constricted at the base, but larger than lobules. These can continue to grow into sizeable lobes and may or may not function as asexual propagules.

Lobe arrangement is often a useful character in Hypogymnia, but the terminology can be applied in various ways, so we define our usage. Lobes can be appressed, such that the lower surface is in broad contact with the substrate. In contrast, other species soon develop suberect or pendulous lobes, such that the lower surface is largely free of the substrate. Many species are initially appressed but the lobes become imbricate, meaning that the lobes are shingled on one another, the tip of the lobe below extending farther than the one above. In species with appressed lobes, the lobes are usually contiguous, that is with the sides of the lobes in nearly continuous contact with adjacent lobes. In contrast, many species have more open branching open. such that the sides of the lobes are largely free of one another.

Texture of Hypogymnia species shows some variation, which we term either cartilaginous or papery. By "papery" we mean thin and soft to the touch, (for example $H$. diffractaica, $H$. hypotrypa and H. magnifica in Asia and H. rugosa in North America), while most species have a somewhat thicker tougher feel (cartilaginous).

\section{Results and Discussion}

\section{Key to Species of Hypogymnia in SW China and the Himalayas}

Species not yet known from SW China and the Himalayas, but known from adjoining regions in Asia, are indicated by square brackets [...]. These species are not given descriptions after the key, but for these the key includes a summary statement of distribution and in some cases supplemental characters to aid identification.

1a Thallus yellowish green, containing usnic acid Group 1

$1 \mathrm{~b}$ Thallus gray green to white or brown, lacking usnic acid as a major substance (i.e. not detectable visually or by TLC)

2a Thallus sorediate or isidiate or with laminal lobules Group 2

$2 \mathrm{~b}$ Thallus lacking soredia, isidia, and laminal lobules, though sometimes with lateral bud-like branches that resemble lobules

3a Lower surface with rimmed holes (i.e. with a differentiated slightly raised rim) .. Group 3 $3 b$ Lower surface perforate or not, but if perforate, then holes lacking a differentiated rim 
4a Medulla P+ orange or red [Note: Some Menegazzia species lack holes in the upper surface. These typically contain stictic and menegazzaic acids and will key here if mistaken for a Hypogymnia. They are, however, KC-, lacking physodic acid.] ....

Group 4

4b Medulla P-

Group 5

\section{Group 1 \\ Thallus yellowish, containing usnic acid}

1a Soredia lacking.

H. flavida

$1 \mathrm{~b}$ Soredia present.

H. hypotrypa

\section{Group 2}

1a Thallus isidiate

\section{Sorediate or Isidiate or Laminally Lobulate}

2a True isidia present, cylindrical or subspherical

3a Isidia cylindrical, clavate, or pear-shaped; diffractaic acid present ( $\mathrm{CK}+$ yellow, $\mathrm{KC}-)$, physodic acid lacking.

H. hengduanensis

$3 \mathrm{~b}$ Isidia subspherical to cylindrical, often somewhat compound or branched, often bursting; diffractaic acid absent (CK-), physodic acid present (KC+ orange or red). Lobes nearly contiguous to separate; isidia laminal and marginal; branching typically frondose with dense, narrow, perpendicular side lobes. Corticolous; reported from Sri Lanka, India, Papua New Guinea, Japan.

[H. zeylanica $]$

$2 \mathrm{~b}$ True isidia lacking, rather, the "isidia" globose laminal buds or lobules

4a Lobes becoming frondose with abundant narrow side lobes; lobules mainly marginal; main lobes 2-4 mm broad; pruina absent; containing physodic and 3-hydroxyphysodic acids, \pm 2'-O-methylphysodic acid; medulla $\mathrm{K}+$ slowly reddish brown, $\mathrm{UV}+$ weakly whitish

H. delavayi (in part)

$4 \mathrm{~b}$ Lobes often with side lobes but rarely frondose; lobules marginal or laminal; main lobes mostly $<2 \mathrm{~mm}$ broad; thallus with white pruinose patches when exposed; propagules pruinose on the tips; containing alectoronic acid; medulla K-, UV++ distinctly white lobulate form of $\boldsymbol{H}$. pruinosa

$1 b$ Thallus sorediate or schizidiate

5a Soredia lining burst lobe tips, often becoming lip-shaped

6a Lower surface lacking roundish holes; lobes usually without perpendicular adventitious side branches; solarized thalli melanizing to blackish or blue-blackish

H. physodes

$6 \mathrm{~b}$ Lower surface and lobe tips with roundish holes; lobes sometimes with perpendicular adventitious side branches; solarized thalli melanizing to brownish or dark brown

7a Medulla $\mathrm{P}+$ orange (containing physodalic and protocetraric acids); lobes typically short and broad (internodes about 2-5(9) mm long; lobes (0.7)1.5-3(4) mm broad)

H. subarticulata

7b Medulla P- (lacking physodalic and protocetraric acids); lobes generally elongate and slender, rarely $>2 \mathrm{~mm}$ broad

H. vittata

$5 \mathrm{~b}$ Soredia laminal or terminal, but not lining burst lobe tips

8a Soralia almost exclusively terminal, either on short side lobes or the main lobes

9a Lobes with open branching; lower surface with large perforations; thallus containing olivetoric acid $(\mathrm{C}+\mathrm{red}, \mathrm{KC}+\mathrm{red})$

H. capitata

9b Lobes contiguous; lower surface imperforate but lobe tips sometimes with minute perforations; thallus containing physodic acid (C-, KC-)

H. bitteri (in part, see below)

8 b Soralia partly or wholly laminal

10a Lobes patchily pruinose along the margins and lobe tips; medulla $\mathrm{P}+$ orange red (physodalic and protocetraric acids)

H. subfarinacea 
10b Lobes not pruinose; lobes $\mathrm{P}+$ or $\mathrm{P}$ -

11a Lower surface with rimmed holes; medulla $\mathrm{P}+$ orange red (physodalic and protocetraric acids present)

H. laxa

11b Lower surface perforate or not, but holes lacking a differentiated rim; medulla $\mathrm{P}$ -

12a Soredia forming initially along edges of schizidia (flakes of cortex + algal layer) on the upper surface; thallus containing 3-hydroxyphysodic acid (medulla $\mathrm{K}+$ slowly reddish brown)

13a Lobes 2-5 mm wide, usually blunt-tipped (broadly obtuse), but sometimes with narrower tapered tips

H. sinica

13b Lobes mostly 1-2 mm wide, often with tapered tips

14a Lobes with abundant lateral budding and perpendicular side branches; southern Asia.

H. pseudobitteriana

14b Lobes with few or no buds and adventitious branches. Northeast Asia

[H.pseudophysodes]

$12 \mathrm{~b}$ Soredia otherwise, derived from erupting isidia-like warts or the cortex dissolving into a mass of powdery or granular soredia; thallus containing 3hydroxyphysodic acid or not (medulla $\mathrm{K}$ - or $\mathrm{K}+$ slowly reddish brown). Circumboreal south to Himalayas and in the American cordillera

[H. bitteri]

\section{Group 3}

1a Medulla $\mathrm{P}+$ orange or red

\section{No soredia or isidia, with rimmed holes}

2a Lobes narrow to medium wide, free or imbricate, smoothly elongate

3a Spores mostly > $10 \mu \mathrm{m}$ long; lobe margins and tips lacking pseudocyphellae; thallus containing physodic, physodalic, and protocetraric acids

H. pendula

$3 \mathrm{~b}$ Spores < $10 \mu \mathrm{m}$ long; lobe margins and tips often with whitish pseudocyphellae; thallus lacking physodic and physodalic acids, containing diffractaic acid with 1'-methyl hypothamnolate and squamatic (major), hypothamnolic (submajor), usnic, barbatic, and elatinic (minor) and baeomycesic (trace) acids;

H. pseudocyphellata

$2 \mathrm{~b}$ Lobes narrow or broad, congested, inflated with a constricted base or with periodic constrictions

4a Thallus lacking physodalic acid, containing virensic acid (medulla P+ slowly yelloworange) and physodic acid; spores ca 7.0-8.0 × 5.0-5.5 $\mu \mathrm{m}$

H. congesta

$4 \mathrm{~b}$ Thallus containing physodalic acid, lacking virensic acid (medulla usually $\mathrm{P}+$ orange red); spores (6)7-9(11.5) ×(5.5)6-.5(10) $\mu \mathrm{m}$

H. bulbosa, $\mathrm{P}+$ chemotype

$1 \mathrm{~b}$ Medulla P- or pale yellowish

5a Lobes narrow, mostly $<1.5 \mathrm{~mm}$ broad, lax, often drooping; medulla $\mathrm{KC}-$, $\mathrm{CK}+$ yellow to orange (diffractaic acid as the major substance).

H. diffractaica

5 b Lobes commonly $>1.5 \mathrm{~mm}$ broad (mostly 1-3 mm broad), congested, suberect or slightly pendulous; medulla $\mathrm{KC}+$ reddish

6a Spores < $10 \mu \mathrm{m}$ long; thallus containing physodic acid

H. bulbosa, P- chemotype

$6 \mathrm{~b}$ Spores ellipsoid, large, $15-18 \times 12-15 \mu \mathrm{m}$; thallus containing 4- $O$-demethylbarbatic acid

( = norbarbatic acid $)$

H. macrospora

\section{Group 4}

\section{No soredia or isidia; holes not rimmed; P+ red}

1a Upper cortex with black bands, lines, or patches, or completely blackened; lobes 0.5-2.5(4) mm broad

.H. alpina 
1b Upper cortex white to grey or greenish grey, black markings usually sparse or absent (except for black pycnidia), but occasionally sun-browned or blackened or with black-margined lobes; lobe width various

2a Lobes distinctly inflated in appearance, slightly to strongly uneven in diameter, mostly > 2 $\mathrm{mm}$ broad

H. magnifica

$2 \mathrm{~b}$ Lobes slender, \pm even in diameter, and usually $<2 \mathrm{~mm}$ broad

3a Lower surface with gaping holes near the lobe tips, almost as broad as the lobes

4a Lobes often tapering and with rather acute tips; lobes epruinose. Holes often exposing the white ceiling of the lobe tips (however, the lobe cavities are dark farther back); upper surface typically pale greenish gray; on bark and wood, rarely on other substrates (moss-covered rock, soil); Taiwan, Japan; reports from North America, Australia, and New Zealand are apparently incorrect.

[H. pseudoentermorpha]

$4 \mathrm{~b}$ Lobe tips relatively even, with blunt tips; lobes occasionally lightly pruinose

H. lijiangensis

$3 b$ Lower surface of lobe tips with smaller holes or entire; upper surface commonly brown to dark brown

H. laccata

\section{Group 5}

No soredia or isidia; holes not rimmed; P-

1a Lobe tips and lower surface imperforate

2a Upper surface mid to dark brown, glossy; lobes mostly contiguous and appressed, but sometimes with separate lobes with planar branching; ceiling white to \pm darkening; floor white to dark; thallus lacking 3-hydoxyphysodic acid; medulla K-

H. nitida

2b Upper surface gray green to white, sometimes brownish, matte or glossy; lobes completely appressed, the lobes contiguous to somewhat imbricate; ceiling of cavity white or dark; thallus containing 3-hydroxyphysodic acid; medulla $\mathrm{K}+$ slowly red brown. H. metaphysodes

$1 b$ Lobe tips and/or lower surface with sparse to abundant holes

3a Lobe tips with subtle to pronounced white pruinose patches or with continuous pruinose strips along the lobe crests

4a Medulla containing alectoronic acid; thallus rosettiform; lobes usually closely contiguous, strongly inflated and compressed and contorted from crowding; spermatia cylindrical or with submedial swelling....

H. pruinosa

4b Medulla containing physodic and 3-hydroxyphysodic acids; thallus loosely rosettiform to more irregular; lobes subcontiguous to imbricate; spermatia weakly bifusiform

5a Perforations numerous and conspicuous in lobe tips, axils, and lower surface, often elongating.....

H. pruinoidea

$5 b$ Perforations sparse and relatively inconspicuous H. pseudopruinosa

3 b Lobe tips lacking pruina or nearly so

6a Holes in lower surface frequently offset from the midline of the lobe, sometimes lateral, and sometimes forming a staggered series near the lobe tips.... H. irregularis (see below)

$6 \mathrm{~b}$ Holes in lower surface \pm centered on the midline of the lobe, usually just a single hole centered on the lobe tip or axil

7a Ceiling of cavity white, whitish, light brownish, or light grayish, rarely dark; containing physodic, 3-hydroxyphysodic, and 2'-O-methylphysodic acids

8a Lobe tips usually recurved; distribution mainly in NE Asia; lobes slender (mostly $<1.5 \mathrm{~mm}$ broad); ceiling of cavity white near the tips and often well back from the tips but ultimately darkening

9a Lower surface heavily perforate with large holes that fuse into a continuous gap occupying more area than the intact lower surface; medulla K-, lacking 3hydroxyphysodic acid. NE Asia.

[H. fragillima $]$ 
9b Lower surface heavily to moderately perforate; medulla $\mathrm{K}+$ slowly reddish brown, containing 3-hydroxyphysodic acid

H. arcuata

$8 \mathrm{~b}$ Lobe tips seldom recurved; distribution various; lobes narrow or broad; ceiling of cavity various

10a Lobes $0.5-1.5(3) \mathrm{mm}$ broad, appressed but sometimes with lobe tips ascending

11a Lobes $0.5-1.5 \mathrm{~mm}$ broad; containing physodic and 3-hydroxyphysodic acids. Japan ....

[H. nikkoensis]

$11 \mathrm{~b}$ Lobes $0.5-3 \mathrm{~mm}$ broad; containing physodic and 2'- $O$-methylphysodic acids. Known from one site in Yunnan (L. S. Wang 82-735)............H. sp.

$10 \mathrm{~b}$ Lobes often $>1.5 \mathrm{~mm}$ broad or, if narrow, then lobes becoming free from the substrate

12a Upper surface smooth to weakly rugose, in some areas developing faint to prominent transverse cracks across the upper cortex; lower surface black, glossy....

H. stricta

12b Upper surface becoming distinctly verrucose; lower surface brown to black, matte or glossy

H. delavayi

$7 \mathrm{~b}$ Ceiling and floor of cavity always dark, except at the immediate lobe tip; chemistry various

13a Lobes $0.5-1.5 \mathrm{~mm}$ broad, appressed to imbricate; physodic acid present, lacking

2'-O-methylphysodic and 3-hydroxyphysodic acids

14a On rock and moss over rock; lobes imbricate, cushion forming; laminal lobules common; apothecia and pycnidia unknown; texture papery....

H. saxicola

14b On bark or wood, rarely on mossy rock; lobes initially appressed and contiguous, becoming imbricate and somewhat separate, mat forming; laminal lobules lacking; apothecia and pycnidia common; texture cartilaginous. NE Asia on the coast

[H. sachalinensis]

13b Lobes (0.5)1.5-4 mm broad, often separating and becoming \pm free; chemistry various

15a Lobes appressed to imbricate; spores narrowly elliptical, about 2:1 (10-12 $\times$ $4.5-5 \mu \mathrm{m})$

H. tenuispora

15b Lobes appressed, imbricate, or free, but spores always relatively broad, about $1.1: 1$ to $1.3: 1$

16a Lobes broad, short to elongate; perforations on the lower surface large, centered on the midline of the lower surface, and well-spaced; perpendicular bud-like side lobes infrequent or absent .....H. thomsoniana

$16 \mathrm{~b}$ Lobes narrow or broad, but mostly elongate and slender; perforations on the lower surface small and numerous, variously placed relative to the midline of the lower surface, sometimes lateral; perpendicular bud-like side lobes frequent

H. irregularis

\section{The species}

A description is given for all species from southwest China and others with revised species concepts or previously incomplete descriptions. The lower surface of all species, unless otherwise indicated, is black (brown at the margins), wrinkled, and lacking rhizines. The apothecial disks are always some shade of brown. The epihymenium is always a clear light brown, without granules and POL-, unless stated otherwise. The subhymenium is always hyaline, about $6-14 \mu \mathrm{m}$ thick. Pycnidia are always black, immersed in the upper surface to slightly protruding. The upper cortex spot tests are $\mathrm{K}+$ yellow, $\mathrm{P}+$ pale yellow, $\mathrm{K}-, \mathrm{KC}-$, unless otherwise indicated. Chemotypes are summarized in Fig. 1. New taxa are given full-page plates while other species are illustrated alphabetically by epithet in groups of four. Type specimens are listed for those collected in China or nearby areas. 


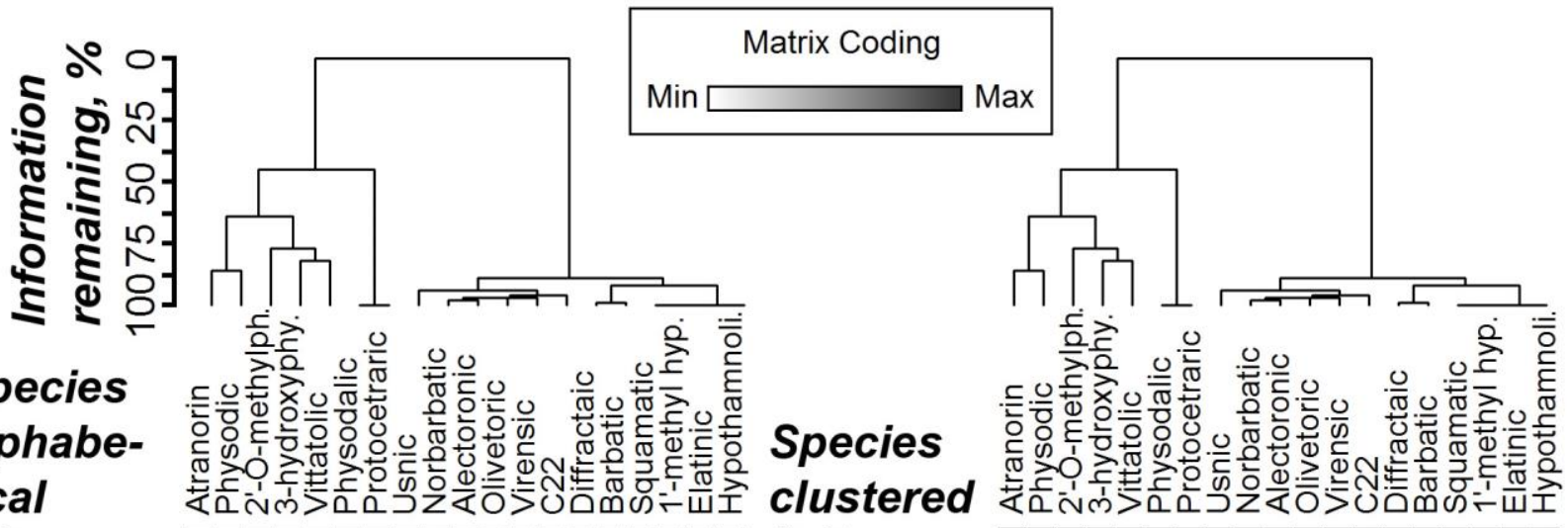

ipina

arcuata

austerodes

bitteri

bulbosa

capitata

congesta

delavayi

diffractaica

flavida

fragillima

hengduanensis

hypotrypa

irregularis

laccata

laxa

lijiangensis

macrospora

magnifica

metaphysodes

nitida

pendula

physodes

pruinoidea

pruinosa

pseudobitteria

pseudocyphel.

pseudophysod.

pseudopruinos.

saxicola

sinica

stricta

subarticulata

subfarinacea

subpruinosa

tenuispora

thomsoniana

vittata

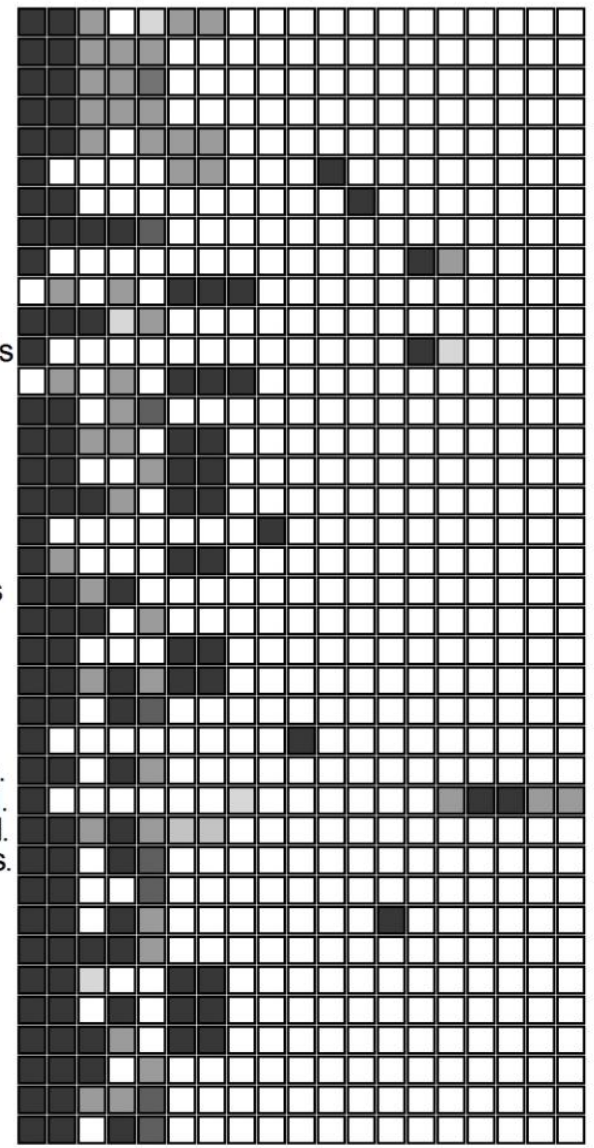

flavida

hypotrypa

laccata

lijiangensis

subpruinosa

physodes

subfarinacea

laxa

pendula

subarticulata

magnifica

alpina

bulbosa

fragillima

nitida

tenuispora

congesta

arcuata

bitteri

thomsoniana

austerodes

irregularis

saxicola

pruinoidea

pseudopruinos.

vittata

pseudobitteria

sinica

delavayi

stricta

metaphysodes

pseudophysod.

capitata

macrospora

pruinosa

diffractaica

hengduanensis

pseudocyphell.

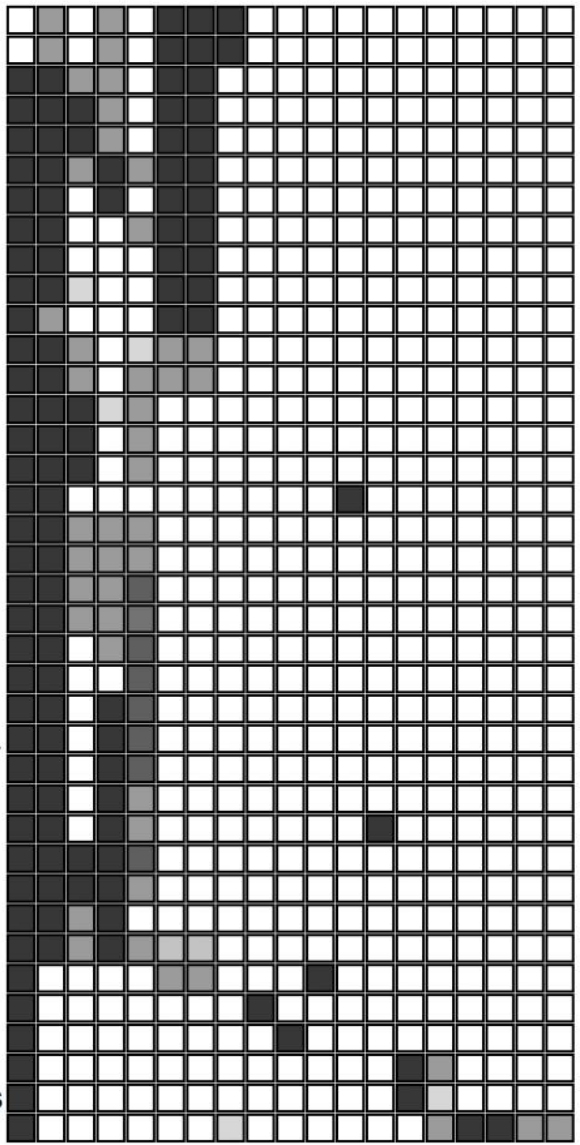

Fig. 1 - Chemotypes of Hypogymnia species in SW China and adjoining areas, with substances clustered by co-occurrence patterns. Dark boxes indicate usual presence of a substance (either major or minor); gray boxes indicate accessory substances. Left: One-way clustering with species alphabetical but substances grouped with a dendrogram to show similarities among substances, according to co-occurrence among species. Right: Two-way clustering, the species grouped by similarity in chemical content (dendrogram not shown); substance clustering as in left panel. Agglomerative cluster analysis used Ward's method and Euclidean distances. The dendrogram is scaled by the error sum of squares expressed as a percentage of the total. The relationships shown are phenetic (indicating similarity relationships) rather than phylogenetic.

Hypogymnia alpina Awasthi, Kavaka 12(2):91. 1984.

Fig. 2a.

Synopsis - Upper surface brown to dark brown, uniformly blackening or blackish mottled, perforations occasional to frequent, appressed to suberect, cavity white above and dark below OR tan to gray above and below; lacking soredia and isidia. 
Description - Thallus to $10 \mathrm{~cm}$ diam, appressed to suberect; branching mostly isotomic dichotomous, lateral budding and narrow perpendicular adventitious lobes infrequent; lobes imbricate, mostly 1-2(3) $\mathrm{mm}$ broad, strongly inflated, separate on the thallus periphery but subcontiguous to contiguous internally; upper surface smooth to weakly rugose, greenish gray to brown or dark brown, with black mottling or uniformly blackening, often glossy, epruinose; lower surface black, usually glossy, dark brown near the lobe tips, occasionally perforate; lobe tips and axils commonly perforate, the holes lacking a differentiated rim; medulla hollow, ceiling of lobe cavity white to grayish, floor grayish to dark brown; soredia and isidia lacking; apothecia sessile to substipitate, the receptacle urn- or funnel-shaped; disk to $4 \mathrm{~mm}$ diameter; hypothecium two-layered (in addition to subhymenium), the lower part POL+ and the upper part POL-; ascospores simple, hyaline, 8/ascus, 5-10 $\times 4-6 \mu \mathrm{m}$; spermatia rod-shaped to weakly bifusiform, 4-8-6.5 $\times 0.8-1.2$ $\mu \mathrm{m}$.

Chemistry - Atranorin, physodic, and accessory physodalic, protocetraric, and 2'-Omethylphysodicacids, rarely with vittatolic acid; medulla $\mathrm{K}-, \mathrm{KC}+$ orange red, $\mathrm{P}+$ or (less often) $\mathrm{P}-$.

Substrate - Commonly on soil and rock, also on bark and wood; subalpine and alpine.

Known distribution - Widespread in the Himalayan and Hengduan Mountains; northern India, Nepal, Sichuan, Xizang (Tibet), and Yunnan; see map in McCune (2012).

Notes - Hypogymnia laccata is similar to $H$. alpina in chemistry and also solarizes to dark brown, but $H$. laccata tends to form appressed rosettes rather than separate lobes, though some separate lobes are common. Furthermore, H. laccata is less strongly blackened, develops a rugose upper surface, is normally corticolous, and is less conspicuously perforate.

Hypogymnia alpina was previously confused with $H$. delavayi but differs from that species in many ways (McCune 2012).

Selected material examined - See McCune (2012).

Hypogymnia arcuata Tchab. \& McCune, Bryol. 104:146. 2001.

Fig. 2b.

Synopsis - Lobe tips arcuate, curved upwards (recurved); lobes somewhat flattened; lower surface perforate with large holes; similar to H. fragillima but lower surface less perforate than in that species and lobes shorter; spores small, subspherical; soredia and isidia lacking.

Description - Thallus loosely appressed to suberect, to $6(10) \mathrm{cm}$ long, often confluent into mats; texture cartilaginous; branching mostly isotomic dichotomous, budding occasional; upper surface smooth, whitish gray to pale greenish gray, dark mottles none or rare, black border not visible; lobes separate, 0.5-1.5(2) mm broad, outline even; lobe width:height ratio 1.5:1-3.0:1; lobe tips sparsely perforate, lower surface heavily perforate; medulla hollow, ceiling of cavity grayish to white, floor of cavity dark to grayish; soredia, isidia, and lobules lacking; apothecia rare, substipitate, to $6 \mathrm{~mm}$ diameter or more; receptacle funnel-shaped; septum in stipe absent; hypothecium POL-; spores subspherical to shortly ellipsoidal, 4.5-5.5(6.0) $\times 3.5-4.5 \mu \mathrm{m}$; pycnidia infrequent, spermatia rod shaped to weakly bifusiform, 5-6.5 $\times 0.8-1.0 \mu \mathrm{m}$.

Chemistry - Atranorin, physodic acid, and accessory 3-hydroxyphysodic (major, usually present), 2'-O-methylphysodic, and vittatolic acids; medulla usually $\mathrm{K}+$ slowly red brown, $\mathrm{C}-\mathrm{KC}+$ pink-orange, $\mathrm{P}$-.

Substrate - On bark and wood, occasionally on mossy rock.

Known distribution - Primorsky Region of Russia; China (Jilin, Shaanxi, Sichuan, and Yunnan Provinces), Korean Peninsula; widespread but apparently not common.

Notes $-H$. arcuata is similar to $H$. fragillima but with shorter lobes, less abundantly perforate lower surface; often misidentified as $H$. duplicata, $H$. delavayi, or $H$. enteromorpha in the Asian literature. Heavily perforate $H$. irregularis can appear similar to $H$. arcuata. Hypogymnia irregularis, however, has frequent adventitious lobes that are narrower than the main lobes, while H. arcuata is more consistently isotomic dichotomous. See also discussion in Tchabanenko \& McCune (2001).

Selected material examined - CHINA. Heilongjiang, Dailing, Liangshui Forest Centre, $47.017^{\circ} \mathrm{N} 129.033^{\circ} \mathrm{E}, \mathrm{X}$. L. Chen 3984 (CANL). Jilin, Antu County, Mountain, Changbai Shan, 
northern slope, $42.5^{\circ} \mathrm{N} 128.5^{\circ} \mathrm{E}, 1700 \mathrm{~m}$, Golubkova s.n. (CANL); Changbai Mountains, The Skylake (=Tianchi), $41^{\circ} \mathrm{N} 128^{\circ} \mathrm{E}, 2080 \mathrm{~m}$, Zhao 3504 (CANL). Liaoning, Kuandian County, Baishilazi Natural Reserve, $40.883^{\circ} \mathrm{N} 124.783^{\circ} \mathrm{E}, 1240 \mathrm{~m}, \mathrm{X}$. L. Chen 2748 (CANL). Shaanxi, Taibai Shan, Mingxing Si et Doumo Gong, 2660 m, J. C. Wei, Lich. Sinensis Exs. 11 as $H$. enteromorpha f. inactiva (S, UPS, US); Chieh Hsiu (Jiexiu) District, Mienshanye, 2300 m, Smith 5259, 5261 (UPS); Sept in monte Thaepeisan, Giraldi 195 (BM). Sichuan: Nanping County, Jui Zhai Gou, Bo Jin Yan, 33 ${ }^{\circ} \mathrm{N} 103.833^{\circ} \mathrm{E}, 2050 \mathrm{~m}$, L. S. Wang 83-1463 (KUN); Yanyuan County, Bei-lin village, $27.583^{\circ} \mathrm{N} 101.67^{\circ} \mathrm{E}, 3750 \mathrm{~m}$, L. S. Wang 83-1459 (KUN); Gansu: Min Shan,470 m, Hummel 14195 (S); Yunnan: Dali, top of Long Quan Feng Mountain, $25.717^{\circ} \mathrm{N} 100.133^{\circ} \mathrm{E}, \mathrm{H}$. C. Wang 4364c (KUN); Luquan County, Jiaozixue Mt., 26.083 ${ }^{\circ} \mathrm{N} 103.867^{\circ} \mathrm{E}, 3700 \mathrm{~m}, \mathrm{~L}$. S. Wang 9616733 (KUN).

Hypogymnia austerodes (Nyl.) Räsänen, Ann. Bot. Soc. Zool.-Bot. Fenn. Vanamo 18(1):13. 1943.

Parmelia austerodes Nyl., Flora 64(33):537. 1881.

Fig. 2c.

Synopsis - Thallus rosettiform with appressed, contiguous lobes, solarizing to brown, with laminal granular to isidiose soredia; lobes imperforate.

Description - Thallus appressed, to $10(16) \mathrm{cm}$ broad; texture cartilaginous; branching variable, budding usually present; upper surface smooth to rugose, greenish gray to brown, dark mottles often present; lobes 0.5-2(2.5) mm broad, contiguous, black border sometimes present; lobe width:height ratio 1:1-15:1; lobe tips and axils rarely perforate, lower surface entire; medulla hollow, ceiling of cavity white, floor of cavity dark to grayish; soredia present, laminal, developing by gradual deterioration of the upper cortex or from hemispherical to spherical corticate or partly corticate warts on the upper surface, isidia occasionally present but primarily as a transitional state towards coarsely granular soredia, lobules often present; apothecia rare, substipitate, to $5 \mathrm{~mm}$ diam, receptacle urn- or funnel-shaped, stipe loosely filled with white hyphae; ascospores 5.5-7.3 × 4.9$5.2 \mu \mathrm{m}$; pycnidia occasional; spermatia weakly bifusiform, 4.6-5.2 $\times 0.6-1.0 \mu \mathrm{m}$.

Chemistry - Atranorin, physodic acid (major), 3-hydroxyphyodic acid (major, accessory), and accessory 2'- $O$-methylphysodic and vittatolic acids; medulla $\mathrm{K}+$ slowly red brown or $\mathrm{K}-$, $\mathrm{C}-$, $\mathrm{KC}+$ orange, $\mathrm{P}-$.

Substrate - Bark, wood, tundra sod, or mosses or detritus over rock.

Known distribution - Widespread in northern hemisphere, tundra to boreal and montane; rare in SW China and the Himalayas (India; McCune et al. 2012).

Notes - See discussion of $H$. austerodes vs. H. bitteri in McCune et al. (2012) and Hansen and McCune (2010).

Selected material examined - CHINA. Sichuan: Upper Yalong basin, Chola Shan, DegeGarze, $31.867^{\circ} \mathrm{N} 99.117^{\circ} \mathrm{E}, 4390$ m, G. \& S. Miehe 94-406-17/11 (GZU); Xiaojin County, Rilong Village, Sigunianshan Mountain, $30.2442^{\circ} \mathrm{N} 102.7829^{\circ} \mathrm{E}, 3600 \mathrm{~m}$, L. S. Wang 01-20578 (KUN). Xizang: Nyainqentanglha Shan, $29.63^{\circ} \mathrm{N} 94.7^{\circ} \mathrm{E}, 4250 \mathrm{~m}$, Obermayer 7413 (GZU).

Hypogymnia bitteri (Lynge) Ahti, Ann. Bot. Fenn. 1:20. 1964.

Synopsis - Thallus rosettiform; lobes contiguous, appressed or nearly so, solarizing to brown, with terminal and laminal soralia; similar to $H$. austerodes but with soralia on short, narrow upturned lateral lobes, and often with small perforations in the lobe tips; containing atranorin and physodic acid with accessory 3-hydroxyphysodic, 2'-O-methylphysodic, and vittatolic acids.

Known distribution - Broadly distributed but not yet known from SW China, more common northward in Asia.

Hypogymnia bulbosa McCune \& L.S.Wang, Bryologist 106:227. 2002.

Fig. 2d.

Type - CHINA. Yunnan: Caojian County, Zi Ben Shan, on Picea stump, 12 Jun 2000, L. S. Wang 00-18864 (KUN). 

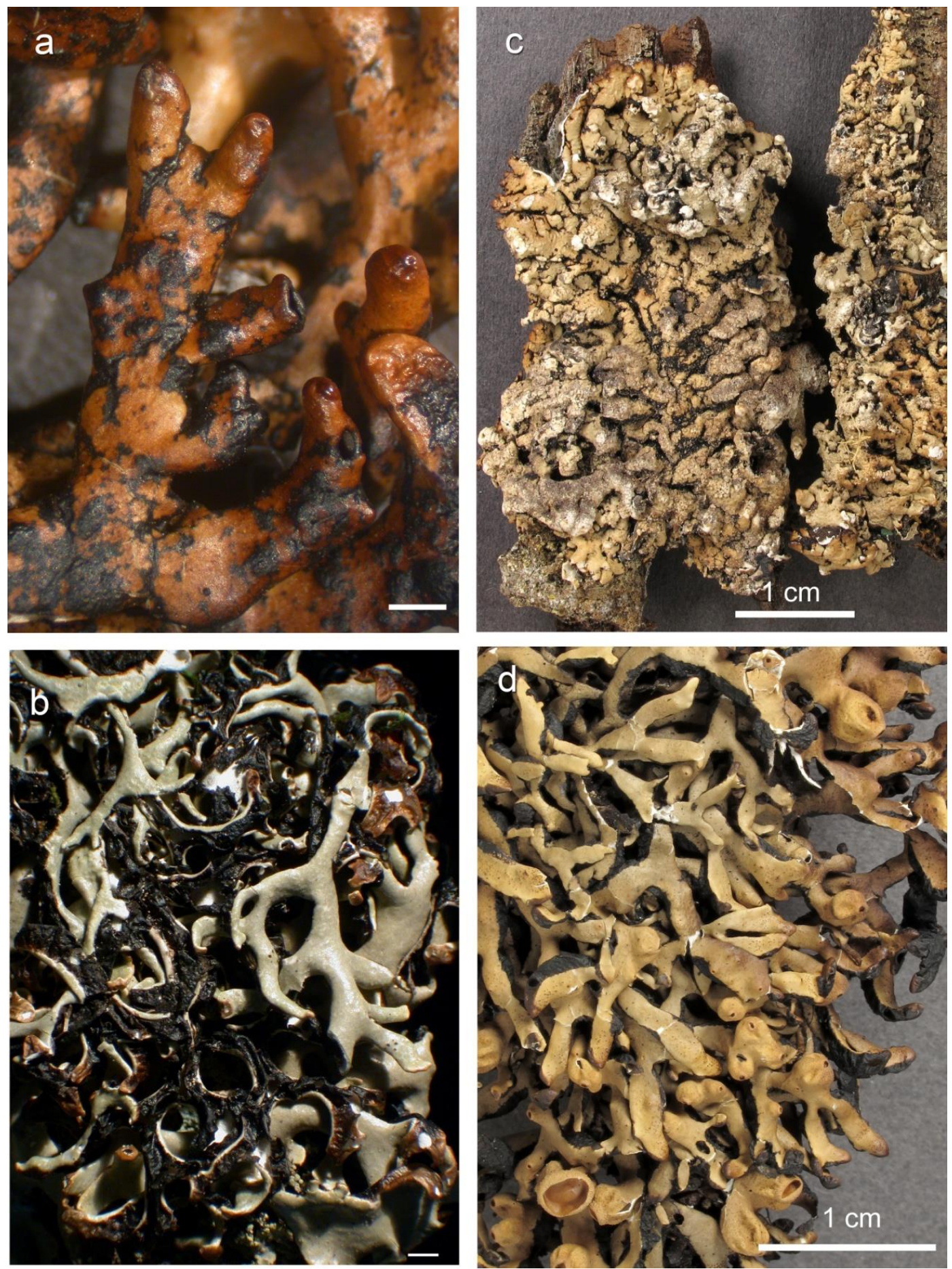

Fig 2 - a Hypogymnia alpina, lobes (L. S. Wang 85-0262). b H. arcuata, habit (McCune 24855). c H. austerodes, habit (L. S. Wang 01-20578). d H. bulbosa, habit (Ahti 46473). Scale bars $1 \mathrm{~mm}$ unless otherwise indicated.

Synopsis - Lobes with abundant adventitious budding, strongly constricted at base and often shaped like a broadly curved prow of a boat; holes rimmed, mainly terminal and axillary; thallus usually P+ but sometimes P-.

Description - Thallus suberect, to $8(10) \mathrm{cm}$ broad; texture cartilaginous; branching variable, adventitious budding abundant, these short lobes strongly constricted at base and often boat shaped (i.e. lobe segments slightly keeled, upturned and constricted at the ends, with lower surface inflated in the middle of the segment); upper surface smooth to weakly rugose, greenish gray to brown, epruinose, dark mottles sometimes present, black border sometimes present; lobes 1-2.5(3) mm 

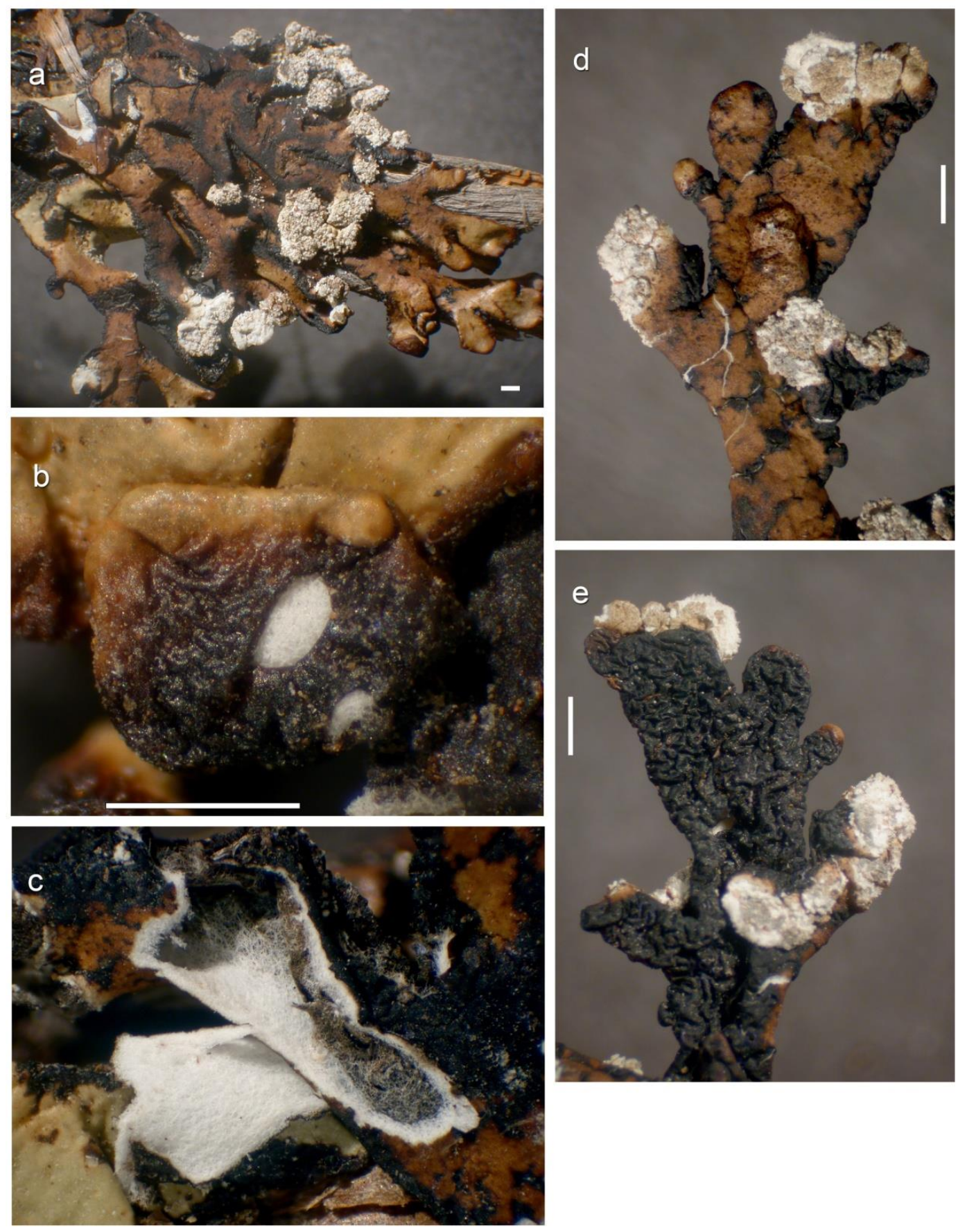

Fig. 3 - Hypogymnia capitata. a Habit (Obermayer 8297). b Perforations (Miehe 94-416-00.06). c Lobe cavity (Obermayer 8297). d Lobe upper surface and soralia (Miehe 94-416-00.06). e. Lobe lower surface (Miehe 94-416-00.06). Scale bars $1 \mathrm{~mm}$ unless otherwise indicated.

broad, separate to imbricate; lobe outline pinched and swollen; lobe width:height ratio 0.7:1-2:1, lobe tips and axils perforate, lower surface sparsely perforate, the holes rimmed; medulla hollow, ceiling and floor of cavity dark; soredia and isidia lacking; lobules occasional; apothecia common, substipitate to stipitate, to $12(15) \mathrm{mm}$ in diameter; receptacle urn- or funnel-shaped, stipe hollow; hypothecium POL-; ascospores $6.2-9.0 \times 5.4-7.0 \mu \mathrm{m}$; pycnidia common; spermatia weakly bifusiform, $4.7-6.0 \times 0.8-1.1 \mu \mathrm{m}$. 

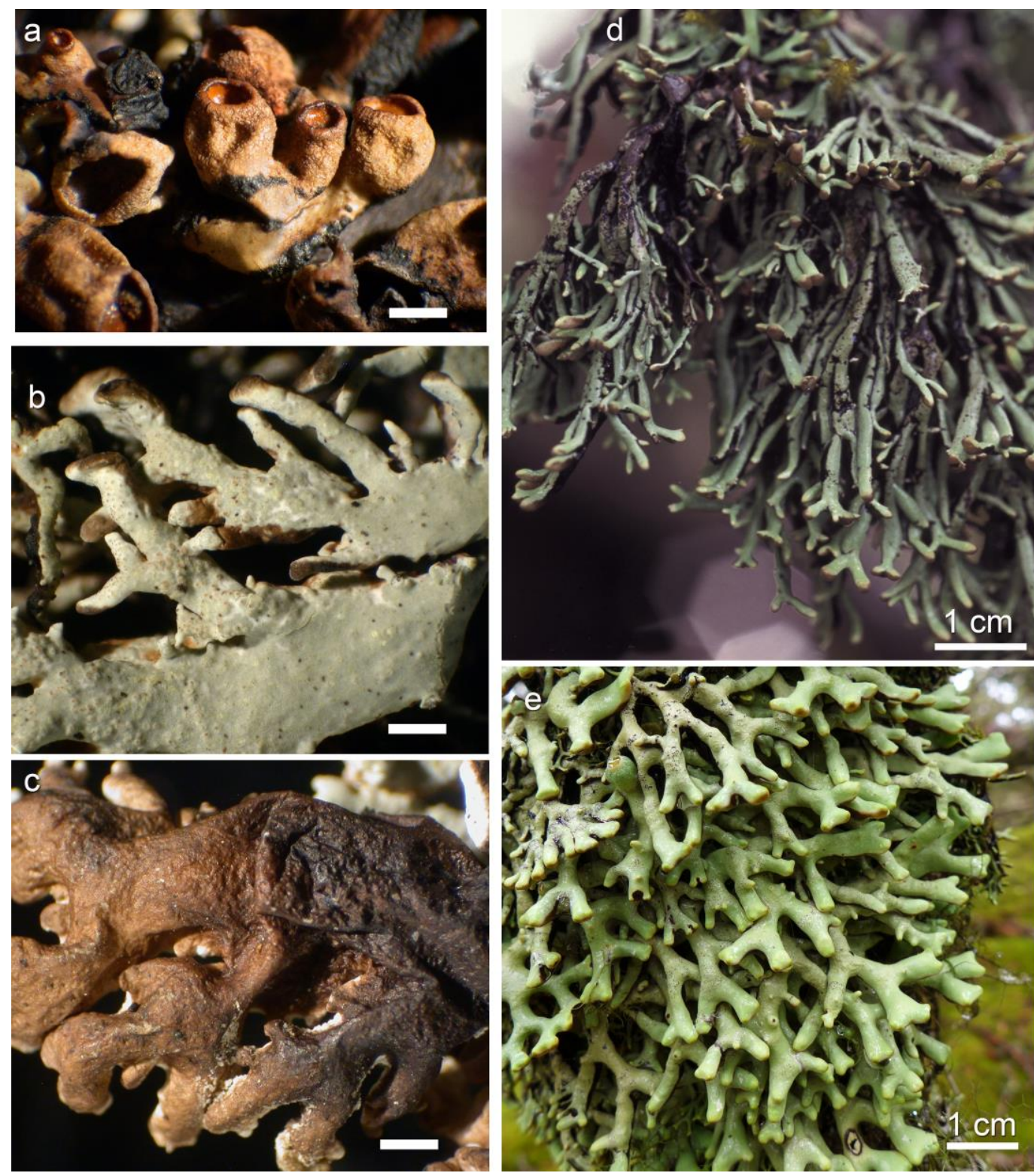

Fig. 4 - a Hypogymnia congesta apothecia (L. S. Wang 82-415). b H. delavayi lobes (McCune 26736). c $H$. delavayi lower surface (McCune 26736; holes not visible in this view). d $H$. diffractaica, habit (L. S. Wang 00-20411). e H. flavida, habit (L. S. Wang 13-38786). Scale bars 1 $\mathrm{mm}$ unless otherwise indicated.

Chemistry - Atranorin, physodic acid (major), physodalic acid (major, giving a P+ medullary reaction, but sometimes rather weak or absent by TLC and giving a P- medulla), and protocetraric acid (minor with physodalic acid), 2'-O-methylphysodic (minor, accessory), rarely with 3hydroxyphyodic acid; cortex $\mathrm{K}+$ yellow, $\mathrm{C}-, \mathrm{KC}-, \mathrm{P}+$ pale yellow; medulla $\mathrm{K}-$, rarely $\mathrm{K}+$ reddish brown, $\mathrm{C}-, \mathrm{KC}+$ orange or red, $\mathrm{P}+$ deep yellow to orange or red, rarely $\mathrm{P}-$.

Substrate - On bark and wood, including Abies, Picea, Rhododendron, Salix, and stumps.

Known distribution - SW China (Yunnan and Sichuan Provinces) and Taiwan.

Notes - Hypogymnia bulbosa is a fairly common species in the high-elevation Abies forests of the Hengduan Mountains. Previously thought to be restricted to SW China, here we report it as new to Taiwan. Both specimens from Taiwan were the P- chemotype.

Selected material examined - See McCune et al. (2002). TAIWAN. Hualien County, Taroko NP, Hohuan Shan, exposed mountain ridge, 3000 m, 12 Oct 2001, Aptroot 53692 (F); Miaoli County, Shei-Pa National Park, 25 km ENE of Tungshi, near Tahsuehshan, 1600 m, 8 Oct 2001, Aptroot $51931(\mathrm{~F})$. 
Etymology - The epithet "capitata" refers to the capitate terminal soralia.

Type - CHINA. Sichuan: Upper Yalong basin, Chola Shan, Dege-Garze, Manigango, on

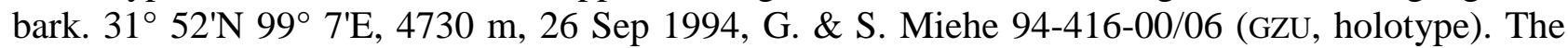
holotype contains two individuals labeled $a$ and $b$, both with olivetoric acid + atranorin + unknowns with olivetoric acid.

Synopsis - Soralia terminal and capitate on brownish, \pm free lobes, lobe cavities with white ceilings and white to dark floors, lobes sparsely perforate below; so far the only Hypogymnia species with olivetoric acid as a major substance.

Description - Thallus appressed to pendulous and separate to somewhat imbricate, to $4 \mathrm{~cm}$ or more broad; texture cartilaginous; branching variable, budding occasionally present; upper to pale greenish gray to more often brown, epruinose, dark mottles present, black border on the lobes not evident; lobes contiguous to separate, smooth then becoming rugose; lobe outline even; lobe width 0.8-2.5(4.0) $\mathrm{mm}$; lobe width:height ratio 1:1-8:1; lower surface sparsely perforate with roundish to ellipsoid holes, the holes not rimmed; medulla hollow, ceiling white and floor white to grayish; soredia powdery, in terminal capitate soralia; apothecia not seen; pycnidia common, brown to black, plane to slightly raised; spermatia cylindrical, straight to slightly curved, mostly without swellings but some with a terminal swelling or a submedial swelling, 5.8-7.8 $\times 0.8-1.2 \mu \mathrm{m}$.

Chemistry - Atranorin and olivetoric acid (major, constant), with accessory physodalic and protocetraric acids; also present are minor unknown satellite compounds of olivetoric acid. The type lacks physodalic and protocetraric acid, but these are present in the only other specimen known. Cortex $\mathrm{K}+$ yellow, $\mathrm{C}-, \mathrm{KC}-, \mathrm{P}+$ pale yellow; medulla $\mathrm{K}-, \mathrm{C}+$ red, $\mathrm{KC}+$ red, $\mathrm{C}-, \mathrm{P}-\mathrm{or} \mathrm{P}+$ orange-red.

Substrate - Hypogymnia capitata occurs on bark in high-elevation conifer forests. In one case it occurred in a streamside conifer forest. Because only two sites are known, little is known about its habitat requirements.

Known distribution - So far known only from Sichuan Province, China.

Notes - Two other Hypogymnia species also produce terminal soralia on lobes that are openly branched, but neither one is found in the study area. Hypogymnia submundata is known from Far East Russia and Japan, while H. tubulosa is widely distributed in the northern hemisphere. Hypogymnia bitteri also produces terminal soralia, and like $H$. capitata the upper surface readily solarizes to brown, but its appressed contiguous lobes and rosettiform habit distinguish it at a glance for the others. Dark lobe interiors (checking ca. $1 \mathrm{~cm}$ or more back from a lobe tip) separate $H$. submundata from $H$. tubulosa and $H$. capitata, both of which typically have white ceilings and white to darkening floors. Hypogymnia tubulosa can be separated from $H$. capitata by its regular dichotomous branching, absence or near absence of mottling on the upper surface, and imperforate lobes. In contrast, $H$. capitata has more variable branching, black mottling on the upper surface, and sparse perforations in the lower surface.

These three species can also be separated chemically. Hypogymnia submundata and $H$. tubulosa contain physodic and 3-hydroxyphysodic acids as major substances, while $H$. capitata is unusual for the genus in lacking physodic acid and containing olivetoric acid. Note that while both substances are $\mathrm{KC}+\mathrm{red}$, physodic acid is $\mathrm{C}$ - and olivetoric acid $\mathrm{C}+$ red. Furthermore, the medulla of $H$. submundata and $H$. capitata are often $\mathrm{P}+$ orange (physodalic and protocetraric acids), while the medulla of $H$. tubulosa is always P-.

Another unusual feature of $H$. capitata is that the spermatia are typically cylindrical rather than weakly bifusiform, as in most species of Hypogymnia. The spermatia of $H$. capitata are, however, somewhat variable: some spermatia have a slight swelling at just one end, or offset a bit from the center.

Additional specimen examined - CHINA. Sichuan: Tibetan fringe mountains (=Hengduan

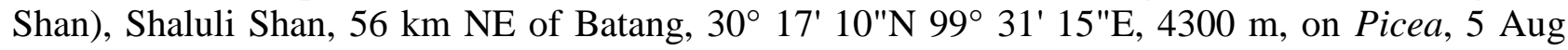
2000, Obermayer 8297 (GZU). 
Type - CHINA. Yunnan: Wei Xi County, Wei Den Village, Lu Ma Deng Ya Kou, 3000 m, 26 May 1982, L. S. Wang 82-415 (KUN).

Synopsis - Thallus densely apotheciate with short, congested fertile lobes and rimmed holes; spores 7-8 × 5-5.5 $\mu \mathrm{m}$; virensic acid present.

Description - Thallus appressed to suberect, to $8 \mathrm{~cm}$ broad or long; texture cartilaginous; branching variable, budding present; upper surface smooth to weakly rugose, brown to brownish gray, epruinose, dark mottles sometimes present, black border sometimes present; lobes 1.7-3.5(4) $\mathrm{mm}$ broad, separate to centrally contiguous; lobe outline pinched and swollen; lobe width:height ratio $0.7: 1-5: 1$; lobe tips and axils often perforate, lower surface perforate, the holes rimmed; medulla hollow, ceiling and floor of cavity dark; soredia and isidia lacking; lobules often present; apothecia common, substipitate to stipitate, to $6(8) \mathrm{mm}$ in diameter; receptacle urn- or funnelshaped, stipe hollow; ascospores 7.0-8.0 $\times 5.0-5.5 \mu \mathrm{m}$; pycnidia common; spermatia rod shaped to weakly bifusiform, $5.0-6.0 \times 0.8-1.1 \mu \mathrm{m}$.

Chemistry - Atranorin, physodic acid (major), virensic acid (major), possible trace 2'- $O$ methylphysodic acid; cortex K+ yellow, C-, KC-, P+ pale yellow; medulla K-, C-, KC-, P+ slowly yellow orange (often weak).

Substrate - On bark and wood of conifers; also on bamboo.

Known distribution - So far known only from Wei Xi County in Yunnan Province.

Notes - This species is unique in the genus Hypogymnia in having virensic acid as a major constituent. Virensic acid gave us pale violet gray spots by TLC, with the same Rf as physodic acid in solvent A (class 3), but at the upper end of Rf class 5 in solvents $\mathrm{B}^{\prime}$ and $\mathrm{C}$; falling between norstictic and diffractaic acids in $\mathrm{C}$.

Material examined - No additional specimens beyond the two cited in McCune et al. (2002) are known.

Hypogymnia delavayi (Hue) Rassadina, Bot. Mater. Gerb. Bot. Inst. V. A. Komarova 11:5. 1956.

Parmelia delavayi Hue, Bull. Soc. Bot. France 34:21. 1887.

Fig. 4b.

H. yunnanensis Y.M.Jiang \& J.C.Wei, Acta Mycol. Sin. 9:293. 1990.

Type - CHINA. Yunnan: dans la bois de Mao-kou-tchong, au dessus Tapin-tze, 2000 m, 15 May 1885, A. Delavay 1599 (PC!).

Synopsis - Branching weakly to strongly pinnately; adventitious lobes present; upper surface slightly to strongly verrucose; cavity ceiling white, floor white to dark; lower surface often brown rather than black, usually conspicuously perforate; medulla $\mathrm{P}-, \mathrm{K}+$ slowly red brown, $\mathrm{KC}+$ orange red. This species has swollen, rather closely set lobes with abundant marginal budding of lobules, in places almost pectinate.

Description - Thallus appressed, to $15 \mathrm{~cm}$ diam; branching variable but often somewhat pinnate; lobes commonly (0.5)1-3(10) $\mathrm{mm}$ broad, short and strongly inflated or elongate, contiguous centrally, separate or contiguous at the margins; lateral budding and narrow perpendicular adventitious lobes often abundant, but sometimes nearly absent; upper surface becoming distinctly verrucose, in many cases the verrucae black capped with pycnidia or incipient apothecia, otherwise white to greenish gray, dark mottles none or rare, black border sometimes present; lower surface near lobe tips brown to dark brown, less often black, matte or rarely glossy, usually perforate; holes in lower surface large, gaping, conspicuous, also common in lobe tips and axils, lacking a differentiated rim; ceiling of lobe cavity white; floor of lobe cavity white to brown; soredia and isidia lacking; apothecia common, sessile to substipitate, the receptacle urn- or funnelshaped, stipe hollow; disk to 8(13) mm diameter; hypothecium POL+, ascospores 5.5-7.5 $\times$ 4-5 $\mu \mathrm{m}$; pycnidia common; spermatia rod-shaped to weakly bifusiform, 5.1-8.4 × 0.8-1.3 $\mu \mathrm{m}$.

Chemistry - Atranorin, physodic acid (major), 3-hydroxyphysodic acid (major), and 2'-Omethylphysodic acids (minor accessory, usually present), rarely with vittatolic acid; medulla $\mathrm{K}+$ slowly reddish brown, C-, KC+ orange-red, P-. 
Substrate - On bark and wood. $3200 \mathrm{~m})$

Known distribution - Apparently endemic to SW China, mainly at middle elevations (below

Notes - Previously applied in India to what is now known as H. alpina (McCune 2012) the name $H$. delavayi actually pertains to what was later described as $H$. yunnanensis. The name $H$. delavayi was also misapplied in the Russian lichen flora (Rassadina 1971) to other species with perforations at the lobe tips and on the lower surface, including what are now known as $H$. sachalinensis and $H$. arcuata.

Hypogymnia diffractaica McCune, Bryologist 106:228. 2002.

Fig. 4c.

Type - CHINA. Sichuan: Jiulong County, Tang Gu Xiang, 3000 m, on Rhododendron; 11 Sep 1996, L. S. Wang 96-16604 (KUN!).

Synopsis - Lobes narrow and separate with arcuate tips, often browning; holes rimmed; lower surface expanded and puffed out; lobe cavity ceilings and floors dark; spores 6.2-7.5 × 5.0-6.5 $\mu \mathrm{m}$.

Description - Thallus suberect, drooping, or pendulous, to $10 \mathrm{~cm}$ long; texture papery; lobes elongate and free; branching variable, budding common; upper surface smooth, white to greenish gray or brown, epruinose, dark mottles present, black border sometimes present, lobes 0.8-1.7(2.2) $\mathrm{mm}$ broad, separate to imbricate; lobe outline even to nodulose; lobe width:height ratio 0.7:1-1.5:1; lobe tips and axils sometimes perforate, lower surface perforate, the holes rimmed; medulla hollow, ceiling and floor of cavity dark; soredia and isidia lacking; lobules occasional; apothecia occasional, substipitate to stipitate, to 6(7) $\mathrm{mm}$ in diameter; receptacle urn or funnel shaped, stipe hollow; hypothecium POL-; ascospores $6.2-7.5 \times 5.0-6.5 \mu \mathrm{m}$; pycnidia common; spermatia rod shaped to weakly bifusiform, $4.6-4.9 \times 0.8-1.1 \mu \mathrm{m}$.

Chemistry - Atranorin, diffractaic acid (major), barbatic acid (minor accessory); medulla K-, $\mathrm{C}-, \mathrm{KC}-, \mathrm{CK}+$ yellow to orange, $\mathrm{P}-$.

Substrate - On bark and wood, including Abies and Rhododendron.

Known distribution - SW China (Yunnan and Sichuan Provinces) in high elevation AbiesRhododendron forests.

Notes - Hypogymnia hengduanensis and $H$. diffractaica are similar in their pendulous narrow lobes and lax branching and both have diffractaic acid as the major medullary substance. Together they form an isidiate/non-isidiate species pair.

Material examined - See list in McCune et al. (2002).

Hypogymnia flavida McCune \& Obermayer, Mycotaxon 79:24. 2001.

Fig. 4d.

H. hypotrypa (Nyl.) Rassad. sensu Asahina

Type - CHINA. Yunnan: Luquan County, Jiaozixue Mt. north of Kunming, forest of Abies georgei and Rhododendron, upper slopes of mountain, 3700 m, on Abies, Sep 2000, McCune 25622 (holotype, OSC; isotypes, Dupla Graecensia Lichenum 160, Obermayer (2002)).

Synopsis - Lobes large, neatly dichotomous, with yellowish tinge of usnic acid, perforate below; soredia lacking.

Description - Thallus appressed to suberect, to 10(20) $\mathrm{cm}$ broad or long; texture papery; branching mostly isotomic dichotomous, budding absent or rare; upper surface smooth, yellowish green to brownish, often with dark mottles or black stripes; lobes contiguous or separate, black border often present; lobe outline even to \pm nodulose; lobe width 3-6(10)mm; lobe width:height ratio $1: 1-5: 1$; lobe tips and axils perforate, lower surface perforate; medulla hollow, ceiling of cavity dark, floor of cavity dark; soredia, isidia, and lobules lacking; apothecia common, substipitate to stipitate, to $10(17) \mathrm{mm}$ diam, receptacle urn- or funnel-shaped, stipe hollow; hypothecium POL-; ascospores 5.5-7.5 $\times 4.8-5.5 \mu \mathrm{m}$, pycnidia common, spermatia rod shaped to weakly bifusiform, $5.3-6.3 \times 1.0-1.3 \mu \mathrm{m}$.

Chemistry - Usnic acid (major), physodalic acid (major), physodic acid (major, accessory, about $25 \%$ of specimens), 3-hydroxyphysodic (accessory, $<10 \%$ of specimens), and protocetraric 
acid (minor); cortex $\mathrm{K}-, \mathrm{KC}+$ yellow, $\mathrm{C}-$, $\mathrm{P}-$; medulla $\mathrm{K}$ - (rarely $\mathrm{K}+$ slowly reddish brown), $\mathrm{KC}$ - or occasionally $\mathrm{KC}+$ orange red, $\mathrm{C}-, \mathrm{P}+$ orange red.

Substrate - On bark and wood, rarely on mossy rock; usually on conifers, but frequently also on Rhododendron, less often on Quercus and other hardwoods.

Known distribution - East Asia, including Nepal, China (many provinces), and Taiwan, but as yet unknown from Russia and Japan.

Notes - The historical application of $H$. hypotrypa to esorediate material is incorrect (McCune \& Obermayer 2001). Esorediate material should be referred to $H$. flavida, while $H$. hypotrypa is sorediate.

Material examined - See McCune and Obermayer (2001); additional specimens cited in Obermayer (2004). Also: CHINA. Yunnan: Jianchuan Co., Lao Juen Shan, 26 37'N, 99 44'E, 4050 m, L. S. Wang 13-38786 (KUN).

Hypogymnia fragillima (Hillmann) Rassad., Bot. Materialy (Notul. System. e Sect. Cryptog. Inst. Bot. nomine V. L. Komarovii Acad. Sci. URSS) 11:8. 1956.

Fig. 5a.

Parmelia fragillima Hillmann, Repert. Spec. Nov. Regni Vegetabilis 45:172. 1938. Holotype destroyed in Berlin; neotype in TNS chosen by Yoshida (2001).

Synopsis - Lower surface heavily perforate showing white ceiling near tips, the perforations covering half or more of the lower surface; upper surface unusually smooth and shiny; lobes even and narrow, arcuate-recurved, with regular isotomic branching.

Description - Thallus erect to suberect, to $5 \mathrm{~cm}$ broad or long; texture cartilaginous; branching isotomic dichotomous, budding absent or rare; upper surface smooth, white to greenish gray or brown, dark mottles none or rare; lobes separate, arcuate, black border not visible; lobe outline even; lobe width $0.7-1.5(2) \mathrm{mm}$; lobe width:height ratio 1:1-4:1; lobe tips and axils perforate, lower surface heavily perforate, such that the area of the intact part is normally less than that of the perforations, often forming a ladder-like structure; medulla hollow, ceiling of cavity white, darker inward, floor of cavity dark to grayish; soredia, isidia, and lobules lacking; apothecia not seen; pycnidia rare; spermatia not seen.

Chemistry - Atranorin (major), physodic (major), 2'-O-methylphysodic (minor), and vittatolic (minor accessory) acids; rarely with 3-hydroxyphysodic acid; medulla $\mathrm{K}-, \mathrm{C}-, \mathrm{KC}+$ orange red, $\mathrm{P}-$.

Substrate - Bark and wood.

Known distribution - NE Asia; so far unknown from SW China.

Selected material examined - CHINA. Heilongjiang: Dailing, Liangshuigou, Pinus koraiensis, 400 m, J. C. Wei 2015, Lich. Sin. Exs.7 (US). JAPAN. Hokkaido, Prov. Kushiro, trail from Taro-ko to top of Mt. O-akan, $565 \mathrm{~m}$, Ohmura 1282 (TNS). RUSSIA. Khabarovskiy: $30 \mathrm{~km}$ WSW of De Kastri, 135 m, Spribille 31157 (GZU). Primorsky: 1 km N of Peschany Pass, southern Sikhote-Alin, 680 m, McCune 24903 (OSC). Sakhalin Island: 11 km S Krasnopolye, Uglegorke River valley, McCune 25031 (OSC).

Notes - Hypogymnia fragillima is most closely related to $H$. arcuata. See table in Tchabanenko and McCune (2001) comparing these two and H. duplicata. Both H. arcuata and $H$. fragillima are species of northeast Asia, while $H$. duplicata is endemic to western North America. Hypogymnia arcuata is distinguished by the less frequently confluent holes in the lower surface, more broadly divergent branching, occasional presence of apothecia, and the presence of 3hydroxyphysodic acid.

Hypogymnia hengduanensis J.C.Wei, Acta Mycol. Sin. 3:214. 1984.

Fig. 5b.

H. hengduanensis ssp. kangdingensis J.C.Wei, Acta Mycol. Sin. 3:215. 1984.

H. kangdingensis (J.C.Wei) Chen \& J.C.Wei, Fungi \& Lichens of Shennongjia, p. 429. 1989.

Type - CHINA. Sichuan: Kangding County, Yulinkong, Gomba La, on Betula trunk, 3700 m, 19 Oct 1934, H. Smith 14078 (holotype, UPS; isotype, HMAS-L!).

Synopsis - True isidia present, cylindrical to coralloid or sometimes globose, lobes erect to more often trailing, with rimmed holes in the lower surface; apothecia rare. 
Description - Thallus erect or trailing, to 10(19) cm long; texture cartilaginous; branching mostly isotomic dichotomous, budding occasional; upper surface smooth to weakly rugose, greenish gray to brown, dark mottles sometimes present, black border often present; lobes 0.61.5(2.2) $\mathrm{mm}$ broad, separate; lobe outline even to \pm nodulose; lobe width:height ratio 0.5:1-2:1; lobe tips and axils rarely perforate, lower surface perforate, the holes rimmed; medulla hollow, ceiling and floor of cavity dark; soredia lacking; isidia cylindrical to coralloid, sometimes globose; lobules occasional; apothecia rare; hypothecium sparsely POL+; asci and ascospores not seen; pycnidia occasional; spermatia not seen.

Chemistry - Atranorin and diffractaic acid (both constant, major), rarely with barbatic acid (accessory, minor); medulla $\mathrm{K}-, \mathrm{C}-, \mathrm{KC}-, \mathrm{CK}+$ yellow to orange, $\mathrm{P}-$.

Substrate - On bark and wood, including Betula and Rhododendron.

Known distribution - SW China with rare disjuncts in Taiwan and Japan (McCune 2009) and India (Upreti \& Divakar 2008, McCune et al. 2012).

Notes - McCune et al. (2002) considered H. kangdingensis to be a minor morphological variant of $H$. hengduanensis, falling within the normal intraspecific variability observed in Hypogymnia. Chemically, H. kangdingensis and H. hengduanensis are identical. Hypogymnia kangdingensis was originally described as a subspecies of $H$. hengduanensis, later elevated to the species level.

Material examined - See specimens cited in McCune et al. (2002). Additional specimens: CHINA. Sichuan: Hengduan Mountains, Da Xue Shan, $57 \mathrm{~km} \mathrm{~S} \mathrm{Kangding,} 29.5764^{\circ} \mathrm{N}$ $101.9988^{\circ} \mathrm{E}, 2990 \mathrm{~m}$, Obermayer 8724 (GZU). Xizang: Nyainqentanglha Shan, $345 \mathrm{~km}$ E of Lhasa, $29.633^{\circ} \mathrm{N} 94.7^{\circ} \mathrm{E}, 4250 \mathrm{~m}$, Obermayer 7411 (GZU). Yunnan: Dali County, trail to Cang Shan, Abies delavayi - Rhododendron forest, $25.685^{\circ} \mathrm{N} 100.102^{\circ} \mathrm{E}, 3500 \mathrm{~m}$, McCune 26801 (OSC); Lijiang County, Yulong Shan, Abies forestii groves and rocky grasslands, Ahti 46483 (KUN); Yulongshan, $27.1^{\circ} \mathrm{N} 100.233^{\circ} \mathrm{E}, 3000 \mathrm{~m}$, Moberg 32161 (UPS).

Hypogymnia hypotrypa (Nyl.) Rassad., Novosti sistematiki nizshikh rasteniui 1967:297. (Notul. System. e Sect. Cryptog. Inst. Bot. nomine V. L. Komarovii Acad. Sci. URSS) $1967 . \quad$ Fig. 5c.

Parmelia hypotrypa Nyl., Synopsis Lich. I:403. 1860.

P. hypotrypella Asahina, Acta Phytotax. Geobot. 14:34. 1950. Lectotype in TNS designated by Yoshida (2001).

H. hypotrypella (Asah.) Rass., Bot. Mater. Otd. Spor. Rast. 13:23. 1960.

Type - INDIA. Sikkim: Lachen, reg. alpina, 12,000 ft, J. D. Hooker 2016 (BM); lectotype selected by Awasthi (1984).

Synopsis - Thallus large, appressed to imbricate with broad lobes, neatly dichotomous branching, upper surface yellowish-tinged from usnic acid, with sparse to abundant laminal soredia that often form along the edges of schizidia.

Description - Thallus appressed to suberect, to 15(30) $\mathrm{cm}$ broad or long; texture papery; branching isotomic dichotomous, budding absent or rare; upper surface smooth to weakly rugose, yellowish green to brownish, sometimes with dark mottles, black border sometimes present; lobes contiguous or separate, 3-7(10) $\mathrm{mm}$ broad; lobe outline even to \pm nodulose; lobe width:height ratio 2:1-4:1; lobe tips and axils perforate, lower surface perforate; medulla hollow, ceiling of cavity dark, floor of cavity dark; soredia present (though sometimes subtle or incipient in young thalli), laminal, typically developing along edges of schizidia; apothecia rare, substipitate to stipitate, to 10 $\mathrm{mm}$ diam, receptacle urn- or funnel-shaped, stipe hollow; ascospores not seen, pycnidia uncommon, spermatia rod shaped to weakly bifusiform, 4.7-5.8 $\times 1.0-1.2 \mu \mathrm{m}$.

Chemistry - Usnic acid (major), physodalic acid (major), physodic acid (major, accessory, $14 \%$ of 64 specimens), 3-hydroxyphysodic (accessory, 6\% of specimens), and protocetraric acid (minor); cortex $\mathrm{K}-, \mathrm{KC}+$ yellow, $\mathrm{C}-$, $\mathrm{P}-$; medulla $\mathrm{K}$ - (rarely $\mathrm{K}+$ slowly reddish brown), $\mathrm{KC}-$ or occasionally $\mathrm{KC}+$ orange red, $\mathrm{C}-, \mathrm{P}+$ orange red.

Substrate - On bark and wood, occasionally on mossy rock. 
Known distribution - China, India (Sikkim), Japan, Korea, Nepal, Russia (Khabarovsk, Sakhalin), Taiwan.

Notes - McCune \& Obermayer (2001) discussed the historical confusion between $H$. hypotrypa and $H$. hypotrypella. Sorediate $(H$. hypotrypa) and esorediate $(H$. flavida) specimens of the big yellowish Asian Hypogymnia are mostly rather easy to separate. But sometimes soredia are only weakly developed in $H$. hypotrypa. Early developmental stages of soredia can, however, usually be found even in small specimens of $H$. hypotrypa.

Soredia are formed in several ways: (1) gradual bumpiness and dissolution of the upper cortex into granules, (2) warts bursting apically forming a mound of granules, and (3) cracks in the upper cortex that becoming granular edged. These cracks are usually short and irregular, initiating flakes of the cortex and algal layer (schizidia) that begin to detach from the medulla. These flakes are often marginally sorediate. Soralia that develop in the first two ways often become thickly mounded in discrete, often capitate soralia. Fertile $H$. hypotrypa specimens are rare.

Material examined (see also Obermayer 2004) - CHINA. Gansu: ("Kansu orientali"), Dschom ad rip. pluv. Tao-che., $36.07^{\circ} 103.85^{\circ}$, Potanin s.n. (UPS); Min-Shan Range, Tsana, vid Drakana, ovre Tebbu, $36.07^{\circ} 103.85^{\circ}, 505$ m, D. Hummel 14194 (S). Hupeh: $30.58^{\circ} \mathrm{N} 114.28^{\circ} \mathrm{E}, \mathrm{A}$. Henry 6939 (FH). Shaanxi: Mei Xian County, Ying To Village, Tai Bei Mt, $34.2^{\circ} \mathrm{N} 107.7^{\circ} \mathrm{E}, 2800$ m, D. C. Zhang 4656 (KUN); Taibai Shan, Doumu Gong, 33.95¹07.78, 2680 m, J. C. Wei 2481 (Lich. Sinenses Exs. 6; E, S, UPS, US). Sichuan: East Litang, Picea-Abies-Rhododendron forest, $30.00^{\circ} \mathrm{N} 100.883^{\circ} \mathrm{E}, 4000 \mathrm{~m}$, Obermayer 3197 (GZU); Emei County, Emeishan, Leidongping, $29.5197^{\circ} 103.3325^{\circ}, 2430 \mathrm{~m}$, Mietzsch 5748d (F); Er Mei Mt, 29.50 $\mathrm{N} 103.33^{\circ} \mathrm{E}, 2900 \mathrm{~m}$, Y. S. Min 696c (KUN); from Ping Wu Co to Jui Zhai Guo, $29.53^{\circ} \mathrm{N} 104.00^{\circ} \mathrm{E}, 3100 \mathrm{~m}$, L. S. Wang 862514b (KUN); Hu Ding Pref, Xinxing County, Gongga Mt, Yen Zi, 29.67 N 102.00 $\mathrm{E}, 3950 \mathrm{~m}$, Yuan Yu 1373 (KUN); Hueli County, Long Zhou Mt, TV tower, 26.67 ${ }^{\circ} \mathrm{N} 102.0^{\circ} \mathrm{E}, 3250 \mathrm{~m}$, L. S. Wang 97-17911 (KUN); Jiulong County, Jiulong to Liu Ba Xiang, 29.25 N 101.5 ${ }^{\circ}$, $4200 \mathrm{~m}$, L. S. Wang 96-17514b (KUN); Liu Ba Xiang, $29.25^{\circ} \mathrm{N} 101.50^{\circ} \mathrm{E}, 3100 \mathrm{~m}, \mathrm{~L}$. S. Wang 96-16454b (KUN); Tang Gu Xiang, $29.167^{\circ} \mathrm{N} 101.5^{\circ} \mathrm{E}, 3000 \mathrm{~m}, \mathrm{~L}$. S. Wang 96-17456, 96-17459 (KUN); Kangding County, Li Qiu to Sha De Xiang, $29.583^{\circ} \mathrm{N} 101.4167^{\circ} \mathrm{E}, 3200 \mathrm{~m}$, L. S. Wang 96-17533 (KUN); Luding County, Gongga Mt, $29.417^{\circ} \mathrm{N} 101.833^{\circ} \mathrm{E}, 3000 \mathrm{~m}$, L. S. Wang 96-17246a (KUN); Gongga Mt, Hai Luo Gou, 29.83 ${ }^{\circ} \mathrm{N} 102.33^{\circ} \mathrm{E}, 3000 \mathrm{~m}$, L. S. Wang 96-16238, 96-17029, 96-16977 (KUN); Ma Er Kang Pref., Wang Jia Zhai Gou, 31.917 N 102.167E, 3800 m, X. J. Li 1062a (KUN); Mu Li County, Ka La Village, Shao Xian Liang Zi, $28.083^{\circ} \mathrm{N} 101.333^{\circ} \mathrm{E}, 3800 \mathrm{~m}$, L. S. Wang 83-1741 (KUN); San Qu Ba Song Ya Kou, 27.83 N 101.00 E, 4250 m, L. S. Wang 83-2101 (KUN); Nanping County, Jui Zhai Gou, Bo Jin Yan, 33.00 ${ }^{\circ} \mathrm{N} 103.83^{\circ} \mathrm{E}, 2050 \mathrm{~m}$, L. S. Wang 862626 (KUN); Tian Er Lake, $33.00^{\circ} \mathrm{N} 103.83^{\circ} \mathrm{E}, 2980 \mathrm{~m}$, L. S. Wang 86-2695 (KUN); reg. bor., Dongrego, below Huang-lung-ssu (Huanglongsi), 30.67¹04.07 , H. Smith 5237, 5241 (UPS); reg. bor., Huang-chen-kuan (Huangshengguan), 30.67 $104.07^{\circ}, 3400 \mathrm{~m}, \mathrm{H}$. Smith 5125 (UPS); Shalui Shan, $30 \mathrm{~km}$ NE Batang, S Yidun, $30.267^{\circ} \mathrm{N} 99.417^{\circ} \mathrm{E}, 3800 \mathrm{~m}$, Obermayer 3203, 3219, 3324 (GZU); Tibetan fringe Mts, Daxue Mt, SE Zhedou Shanko Pass, $30.015^{\circ} \mathrm{N} 101.858^{\circ} \mathrm{E}, 3570 \mathrm{~m}$, Obermayer 9806 (UPS); Cogsum to Sumdo, $29.55^{\circ} \mathrm{N} 100.29^{\circ} \mathrm{E}, 4300 \mathrm{~m}$, Obermayer 9742, 9764 (UPS); Wolong Nature Reserve, $30.9^{\circ} \mathrm{N} 103.1^{\circ} \mathrm{E}, 3200 \mathrm{~m}$, L. S. Wang 96-16012 (KUN); Xiaojin County, Chang Ping Gou, $31^{\circ} \mathrm{N} 102.5^{\circ} \mathrm{E}, 3300 \mathrm{~m}$, L. S. Wang 96-17764 (KUN); Rilong Village, Sigunianshan, $30.2442^{\circ} \mathrm{N} 102.7829^{\circ} \mathrm{E}, 3600 \mathrm{~m}$, L. S. Wang 01-20579, 01-20591 (KUN). Sikang: Kangting (Tachienlu) Distr: Yulingkong, Gomba La, $30.07^{\circ} \mathrm{N} 101.95^{\circ} \mathrm{E}, 3700 \mathrm{~m}, \mathrm{H}$. Smith 14060 (UPS). Xizang: near bend of Tsangpo R., $\mathrm{N}$ of Gyala Peri, $29.95^{\circ} \mathrm{N} 94.892^{\circ} \mathrm{E}, 3000-3400 \mathrm{~m}$, Obermayer 69346982 (GZU); Himalaya Range, slopes W of Kuru River valley, $28.3^{\circ} \mathrm{N} 90.95^{\circ} \mathrm{E}$, 4150-4250 m, Obermayer 4826, 4860, 4891, 4893 (GZU); $40 \mathrm{~km}$ SW Mainling, $29.05^{\circ} \mathrm{N} 93.933^{\circ} \mathrm{E}$, 4000 m, Obermayer 6126, 6127, 6151 (GZU); Nyainqentanglha Shan, Lake Basum Tso, $30.00^{\circ} \mathrm{N}$ $93.942^{\circ} \mathrm{E}, 3500 \mathrm{~m}$, Obermayer 7616,7242 (GZU); Gyala Peri, $29.60^{\circ} \mathrm{N} 94.73^{\circ} \mathrm{E}, 3700 \mathrm{~m}$, Obermayer 7261, 7393, 7394, 7464, 7513, 7543, 7553 (GZU); Nyainqentanglha Shan, bend of Tsangpo River, $29.908^{\circ} \mathrm{N} 94.875^{\circ} \mathrm{E}, 3350 \mathrm{~m}$, Obermayer 7345, 7346, 7347 (GZU); Ta-tsien-lu, $28.20^{\circ} \mathrm{N} 85.083^{\circ} \mathrm{E}, 3352 \mathrm{~m}$, Elenkin 8 (BM). Yunnan: Binchuan County, Ji-zhu Mt, $25.967^{\circ} \mathrm{N}$ 

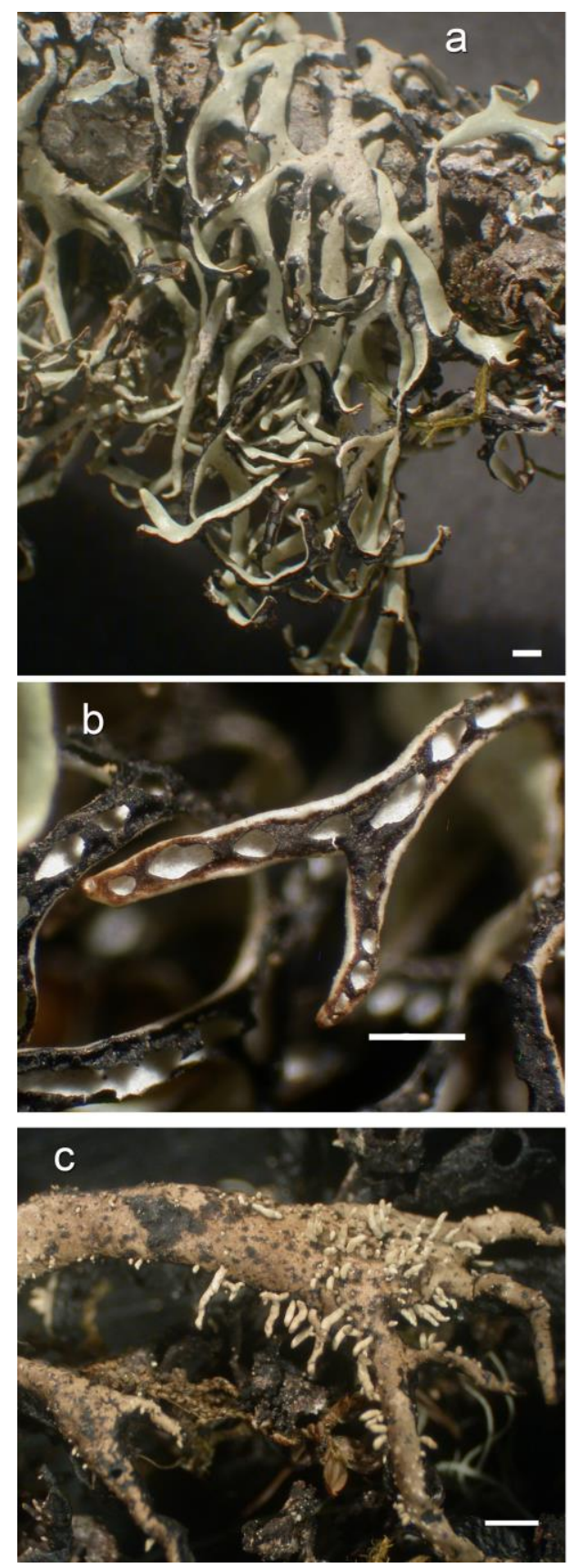
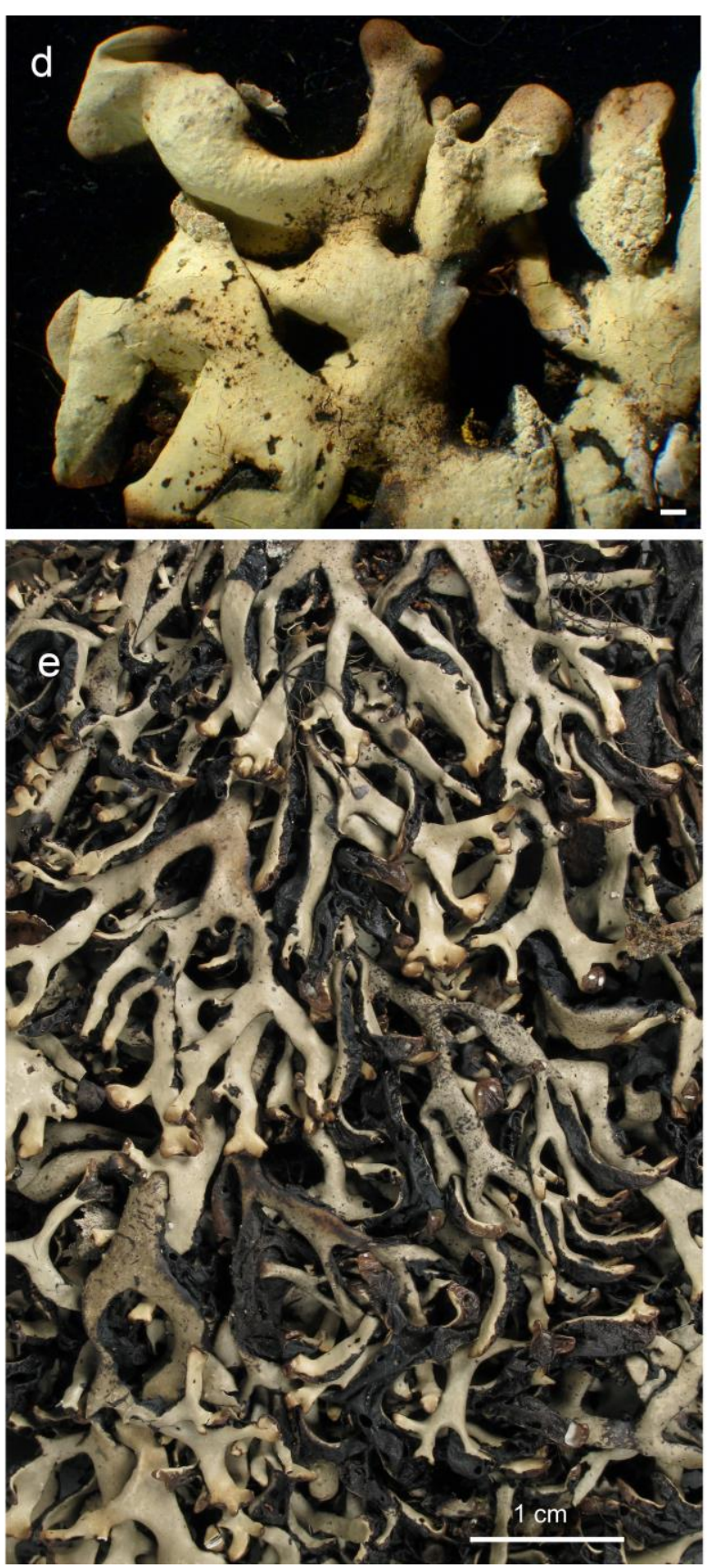

Fig. 5 - a Hypogymnia fragillima, habit (Spribille 31157). b H. fragillima, perforations on lower surface (Spribille 31157). c H. hengduanensis, isidiate lobes (L. S. Wang 00-19996). d $H$. hypotrypa, lobes (McCune 26701). e H. irregularis, habit (McCune 25517). Scale bars $1 \mathrm{~mm}$ unless otherwise indicated.

$100.45^{\circ} \mathrm{E}, 3000 \mathrm{~m}, \mathrm{~L} . \mathrm{S}$. Wang 96-15958 (KUN); Deqin County, Bei Ma Xue Shan, Ya Kou, $28.38^{\circ} \mathrm{N} 99.00^{\circ} \mathrm{E}, 3600 \mathrm{~m}$, Kirkpatrick 58 (KUN); Mei Li Xue Mt, Yu Ben Village, $28.4^{\circ} \mathrm{N} 98.8^{\circ} \mathrm{E}$, 3200 m, L. S. Wang 94-15193 (KUN); Gong Shan County, Qinatong, Songtaxue Mt, $28.188^{\circ} \mathrm{N}$ $98.532^{\circ} \mathrm{E}, 3300 \mathrm{~m}$, L. S. Wang 00-19611 (KUN); Qiqi to Dongshaofang, $27.703^{\circ} \mathrm{N} 98.495^{\circ} \mathrm{E}, 3000$ m, L. S. Wang 00-19029b (KUN); Jianchuan County, San Jiang Bin Liu area, $26.6625^{\circ} \mathrm{N}$ 99.7217 ${ }^{\circ} \mathrm{E}, 3110 \mathrm{~m}$, McCune 26701 (OSC); Shi Bao Shan Park, $75 \mathrm{~km} \mathrm{~S}$ of Lijiang, $26.3589^{\circ} \mathrm{N}$ $99.8403^{\circ} \mathrm{E}, 2490 \mathrm{~m}$, McCune 26738 (OSC); Lijiang County, Tie Jia Mt, $26.783^{\circ} \mathrm{N} 100.083^{\circ} \mathrm{E}$, L. S. Wang $11462(\mathrm{KUN})$; Yulong Shan, west side of Baishui, $27.133^{\circ} \mathrm{N} 100.233^{\circ} \mathrm{E}, 2925 \mathrm{~m}$, Ahti 46598 (KUN); Hei-ba-shuei, $27.133^{\circ} \mathrm{N} 100.25^{\circ} \mathrm{E}, 2750 \mathrm{~m}$, L. S. Wang 15864 (KUN); Yulong Shan, $27.1^{\circ} \mathrm{N} 100.23^{\circ} \mathrm{E}, 3000 \mathrm{~m}$, Moberg 7858, 7897, 7933 (UPS); Tieja Shan, $26.933^{\circ} \mathrm{N}$ 
$100.167^{\circ} \mathrm{E}, 2750 \mathrm{~m}$, Moberg 32246b (UPS); Lijiang Pref., along Bei Sui River, $27.133^{\circ} \mathrm{N}$ $100.25^{\circ} \mathrm{E}, 3000 \mathrm{~m}$, L. S. Wang 85-374 (KUN); $2400 \mathrm{~m}$, L. S. Wang 98-18440 (KUN); Luquan County, Jiaozixue Mt, $26.083^{\circ} \mathrm{N} 102.133^{\circ} \mathrm{E}, 3700-4000 \mathrm{~m}$, L. S. Wang 96-17214, 00-20409, 812307b, 92-12898 (KUN); McCune 25525, 25619 (OSC); Wei Xi County, Ye Zhi Village, Ba Di, $27.717^{\circ} \mathrm{N} 99.05^{\circ} \mathrm{E}, 3800 \mathrm{~m}, \mathrm{~L} . \mathrm{S}$. Wang 82-1817b (KUN); Zhongdian County, Daxueshan, Ya Kou, $28.667^{\circ} \mathrm{N} 99.834^{\circ} \mathrm{E}, 4260 \mathrm{~m}, \mathrm{C}$. C. Hu $2734(\mathrm{KUN}) ; 28.567^{\circ} \mathrm{N} 99.817^{\circ} \mathrm{E}, 3800 \mathrm{~m}$, L. S. Wang 0120828 (KUN); Xiaoxueshan Mt, $28.317^{\circ} \mathrm{N} 99.75^{\circ} \mathrm{E}, 3650 \mathrm{~m}, \mathrm{~L}$. S. Wang 01-20868 (KUN); Bi-tahai Lake, $27.833^{\circ} \mathrm{N} 100^{\circ} \mathrm{E}, 3500 \mathrm{~m}$, L. S. Wang 15121 (KUN). TAIWAN. Hualien County, Taroko NP, Hohuan Shan, $24.15^{\circ} \mathrm{N} 121.28^{\circ} \mathrm{E}, 3000 \mathrm{~m}$, Aptroot 52906, 53684 (F); Hohuan Shan, near field station, $24.156^{\circ} \mathrm{N} 121.288^{\circ} \mathrm{E}, 3200 \mathrm{~m}$, Aptroot 52658 (F); unknown county, Mt. Nan-Fu-Ta-San, 2800 m, Kurokawa 1188 (TNS); Nantou County, Yu Shan (Mt. Morrison), Tartaka Saddle, 3000 m, M. J. Lai 10342 (US); Mt. Pa-tung kuan, 3280 m, Nakanishi 13676 (TNS); Taichung County, between Ssu-yuan \& To-chia-tun Shan, Nanhuta Shan, 2825 m, Kashiwadani 36017, 36043 (TNS).

Hypogymnia irregularis McCune, Mycotaxon 115:485. 2011.

Fig. 5d.

Type - CHINA. Yunnan: 3700 m, Sep 2000, McCune 25576 (holotype: KUN, isotypes: H, HMAS-L, OSC, UPS, US).

Synopsis - Lobes free, short or long, often arcuate-tipped; long, slender, adventitious lobes often abundant; lobes $0.5-4 \mathrm{~mm}$ broad and internodes often 1-2 cm long; lobes somewhat pinched and swollen or smooth in outline; ceiling of cavity grayish brown to black; floor brownish black; similar to $H$. vittata but no soredia and perforations on lower surface are irregularly arranged or staggered.

Description - Thallus appressed to pendulous, to 10(30) $\mathrm{cm}$ long, branching variable, including both isotomic and anisotomic portions, lateral budding often present; texture cartilaginous; upper surface smooth to weakly rugose, white to pale greenish gray, sometimes with dark mottles, sometimes with black borders, epruinose; lobes 0.5-3(4) $\mathrm{mm}$ wide, separate to imbricate, often arcuate-recurved, width even to slightly expanding distally and near the nodes, sometimes \pm pinched at the nodes; lobe width:height ratio $0.5: 1$ to $2: 1$; perforations present on many lobe tips, axils, and lower surfaces, the holes not rimmed; medulla hollow, both the ceiling and floor of the cavity soon darkening to brown or dark brown; soredia and isidia lacking; lateral budding or lobules occasional; apothecia common, substipitate to stipitate, to $9 \mathrm{~mm}$ broad, the receptacle urn or funnel shaped; stipe hollow; hypothecium POL+ in a thin layer at the base; ascospores small, subglobose, 5.0-6.0 $\times 4.0-5.0 \mu \mathrm{m}$; pycnidia common, brown to black; spermatia weakly bifusiform, $4.0--6.6 \times 0.8-0.9 \mu \mathrm{m}$.

Chemistry - Atranorin and physodic acid, often with 3-hydroxyphysodic acid or vittatolic acid; medulla $\mathrm{K}$ - or $\mathrm{K}+$ slowly red brown, $\mathrm{KC}+$ orange red, $\mathrm{P}-$.

Substrate - On bark and wood of both conifers (especially Abies, Juniperus, Picea, Pinus, and Tsuga) and hardwoods (Rhododendron, Quercus, Sorbus, and dwarf bamboo).

Known distribution - Very common and often locally abundant in SW China; infrequent disjuncts in Taiwan and Japan.

Notes - Hypogymnia irregularis often shows an extreme range in lobe width and length, all in the same thallus. The arrangement of the perforations appears to form a complete series, from a staggered arrangement of semi-lateral holes to a linear arrangement of holes centered on the lobes. The spores are, however, consistent across this series, being small and subspherical, averaging 5-6 $\times 4-5 \mu \mathrm{m}$.

Material examined - See list in McCune (2011).

Hypogymnia laccata J.C.Wei \& Y.M.Jiang, Acta Phytotax. Sin. 18(3):387. 1980.

Fig. 6a.

Type - CHINA. Xizang: Zuogong, 4400 m, 31 Aug 1976, Y. C. Zong and Y. Z. Liao 506 (HMAS-L!).

Synopsis - Upper surface readily solarizing to brown; lobes typically appressed and contiguous, though somewhat separate and imbricate lobes are common; lobe cavity with grayish to 
white ceiling and dark floor, lobe tips and lower surface sparsely perforate, lobes becoming strongly rugose; cortex tough.

Description - Thallus appressed to $8(13) \mathrm{cm}$ diam; texture cartilaginous; branching variable, budding occasional; upper surface white to greenish gray or brown, dark mottles often present, becoming rugose, sometimes slightly pruinose on the tips; lobes contiguous to imbricate, black border sometimes present; lobes 1-2.5(3) mm wide; lobe width:height ratio 1:1-3:1; lobe tips and axils sometimes perforate, lower surface rarely perforate; medulla hollow, ceiling of cavity brownish to white, floor of cavity dark; soredia and isidia lacking but marginal and laminal lobules occasionally present; apothecia common, substipitate, to 3(8) $\mathrm{mm}$ diam; receptacle urn- or funnel shaped, stipe hollow; hypothecium POL+; ascospores not seen; pycnidia common, partially external, black, and warty; spermatia rod-shaped to weakly bifusiform, 4.8-6.6 $\times 0.9-1.1 \mu \mathrm{m}$.

Chemistry - Containing atranorin (major), 2'- $O$-methylphysodic acid (minor accessory), physodic acid (major), physodalic acid (major), 3-hydroxyphysodic acid (major, accessory), protocetraric acid (minor); medulla $\mathrm{K}$ - or $\mathrm{K}+$ slowly red brown, $\mathrm{KC}+$ orange red, $\mathrm{P}+$ orange red.

Substrate - On bark and wood of conifers (especially Juniperus), also Rhododendron and Salix.

Known distribution - Apparently endemic to SW China (Sichuan, Yunnan, and Xizang Provinces), only at high elevations (3900-4750 m).

Notes - The epithet presumably refers to the brown varnish-like hue of the upper surface. Frequently this darkens to a deep coffee-brown color. The type contains 3-hydroxyphysodic acid while many other specimens do not.

Ascospores are reportedly 4-6 $\times 2-3.5 \mu \mathrm{m}$, based on the description of the type (Wei \& Jiang 1980). This is exceptionally narrow for Hypogymnia. We have been unable to confirm these spore dimensions, because the hymenia have been barren in the specimens examined.

Material examined - CHINA. Sichuan: Mu Li County, Ya Zhuei forest station, Jiang Du, $27.83^{\circ} \mathrm{N} 101.33^{\circ} \mathrm{E}, 3400 \mathrm{~m}$, L. S. Wang 83-1568a (KUN); Mu Li County, San Qu Ba Song Ya Kou, $27.83^{\circ} \mathrm{N} 101.00^{\circ} \mathrm{E}, 4250 \mathrm{~m}$, L. S. Wang 83-2106, 83-2115, 83-2129, 83-2150 (KUN); Yanyuan County, Daling Village, Huo Lu Mt, $27.5^{\circ} \mathrm{N} 101.5^{\circ} \mathrm{E}, 4150 \mathrm{~m}$, L. S. Wang 83-1208, 831217, 83-1224 (KUN). Xizang: Ningjing Shan, $9 \mathrm{~km} \mathrm{~W}$ of Markam (=Gartog), $29.667^{\circ} \mathrm{N} 98.533^{\circ} \mathrm{E}$, 4300 m, Obermayer 3670 (GZU); Zogang, 4400 m, T. C Zong 506 (HMAS). Yunnan: Deqin County, Bei Ma Xue Shan, 28.38 ${ }^{\circ}$ 99.00ㄹ, 4200 m, L. S. Wang 93-13548, 93-13467, 94-15268a (KUN); Meilishi village, Suola Ya-Kou, $28.633^{\circ} \mathrm{N} 98.613^{\circ} \mathrm{E}, 4550-4750 \mathrm{~m}$, L. S. Wang 00-19739, 00-19757, 00-19761 (KUN); Luquan County, Jiaozixue Mt., N of Kunming, $26.1^{\circ} \mathrm{N} 102.867^{\circ} \mathrm{E}$, 3900-4200 m, McCune 25554, 25567 (OSC); Zhongdian County, Wengshuei Village, Daxueshan, $28.575^{\circ} \mathrm{N} 99.834^{\circ} \mathrm{E}, 4200 \mathrm{~m}, \mathrm{~L}$. S. Wang 00-19730, 00-19961, 00-19990 (KUN); eastern slopes Bei Ma Shan, below East Pass, $28.326^{\circ} \mathrm{N} 99.088^{\circ} \mathrm{E}, 4100 \mathrm{~m}$, Watson 63 (E).

Hypogymnia laxa McCune, Bryologist 106:231. 2002.

Fig. 6b.

Type - CHINA. Yunnan: Luquan County, Jiaozixue Shan, 3750 m, Sep 2000, McCune 25599 (OSC).

Synopsis - Lobes suberect to pendulous with laminal soredia and schizidia, suberect to pendulous; lower surface with rimmed holes; lobe cavities dark; apothecia unknown.

Description - Thallus initially adnate, becoming suberect to trailing, sometimes forming planar fans of lobes, to $6(8) \mathrm{cm}$ broad or long; texture cartilaginous or papery; branching variable, budding present; upper surface smooth to rugose, light gray to greenish gray, epruinose, dark mottles sometimes present, black border sometimes present; lobes 1-3(4) mm broad, separate to centrally contiguous; lobe outline pinched and swollen; lobe width:height ratio 0.3:1-2.0:1; lobe tips and axils rarely perforate, lower surface perforate, the holes rimmed; medulla hollow, ceiling and floor of cavity dark; soredia laminal, initially forming at the edges of cortical flakes (schizidia) and cracks; isidia none; lobules often present; apothecia unknown; pycnidia unknown. 
Chemistry - Atranorin, physodic acid (major), physodalic acid (major), protocetraric acid (minor), vittatolic acid (minor accessory), rarely with 3-hydroxyphysodic acid; cortex $\mathrm{K}+$ yellow, $\mathrm{C}-, \mathrm{KC}-, \mathrm{P}+$ pale yellow; medulla $\mathrm{K}$ - or $\mathrm{K}+$ slowly red brown, $\mathrm{C}-, \mathrm{KC}+$ orange red, $\mathrm{P}+$ orange red.

Substrate - On bark and wood, including Abies, Pinus, and Rhododendron.

Known distribution - SW China (Yunnan and Sichuan Provinces).

Notes - This species might be confused with robust forms of $H$. pseudophysodes, but differs in the presence of rimmed holes, while $H$. pseudophysodes always has unrimmed holes. Their habit differs as well, with $H$. pseudophysodes having narrow lobes $(0.7-2(3) \mathrm{mm})$ and a more rosettiform, appressed thallus, while in $H$. laxa the lobes are 1-3(4) mm broad, more irregular and lax, frequently trailing from the substrate.

Material examined - See list in McCune et al. (2002). Additional specimen: CHINA. Yunnan: Jianchuan County, ridge on trail to Laojuen Shan, $26.6317^{\circ} \mathrm{N} 99.7183^{\circ} \mathrm{E}, 3980 \mathrm{~m}$, McCune 26733 (OSC).

Hypogymnia lijiangensis J.B.Chen, Acta Mycologica Sinica 13:109.

Fig. 6c.

Type - CHINA. Yunnan: Lijiang area, Baishui, 3050 m, 8 Aug 1981, X. Y. Wang 6991 (HMAS, holotype!).

Synopsis - Branching open, isotomic, with few adventitious branches, lobe cavity dark, lobe tips occasionally lightly pruinose lower surface with large holes; soredia and isidia lacking.

Description - Thallus appressed, to $6 \mathrm{~cm}$ broad; texture cartilaginous; branching isotomic dichotomous, budding absent or rare; upper surface smooth to rugose, white to greenish gray, occasionally lightly pruinose, dark mottles sometimes present; lobes separate to centrally subcontiguous, black border present; lobe outline even to +/- nodulose; lobe width 1.5-2.4(3) mm; lobe width:height ratio 1:1-3:1; lobe tips and axils perforate, lower surface heavily perforate; medulla hollow, both ceiling and floor of cavity dark; soredia, isidia, and lobules lacking; apothecia sessile to substipitate, to $5 \mathrm{~mm}$ diam; receptacle urn or funnel shaped, septum in stipe absent; hypothecium weakly POL+; ascospores 5.5-7.2 4 4.8-5.2 $\mu \mathrm{m}$; pycnidia not seen.

Chemistry - Atranorin, physodic, and physodalic acids (major), protocetraric and 2'- $O$ methylphysodic acids (minor), and accessory 3-hydroxyphysodic acid; medulla $\mathrm{K}$ - or $\mathrm{K}+$ slowly red brown, $\mathrm{KC}+$ orange red, $\mathrm{P}+$ orange red.

Substrate - No information available.

Known distribution - Yunnan and Sichuan Provinces; apparently rare.

Notes - Hypogymnia lijiangensis was described from sterile material. The apothecial and spore characters given above are based on Miehe 94-12-20/06. The species is close to $H$. pseudoenteromorpha Lai and $H$. taiwanalpina Lai, but was not compared with those species by Chen (1994). All three have the same chemistry and are similar in morphology and apothecial characters. One apparent differentiating feature is the occasional light pruina on some of the lobe tips of $H$. lijiangensis, while the other two species are epruinose. Also, $H$. pseudoenteromorpha and $H$. taiwanalpina commonly have slender, tapering lobe tips, while the type of $H$. lijiangensis has more even lobe widths, mostly 1.5-2.4(3.0) $\mathrm{mm}$ in diameter.

Hypogymnia pseudoenteromorpha is known from Taiwan and may be just a narrow-lobed form of $H$. taiwanalpina. In the paper where he described them both, Lai (1980) gave no distinguishing characteristics between $H$. taiwanalpina and $H$. pseudoenteromorpha other than the narrower lobes of $H$. pseudoenteromorpha. More study is needed on the relationship between these three species.

Material examined - CHINA. Sichuan: Litang County (= Batang County), Jinsha (Yangtze) tributary, east of Yidun/Yarwa, degraded Picea-Abies forest on S slope, $30.300^{\circ} \mathrm{N} 99.283^{\circ} \mathrm{E}, 4220$ m, G. \& S. Miehe 94-12-20/06 (GZU).

Hypogymnia macrospora (J.D.Zhao) J.C.Wei, Enum. Lich. China, p. 116. 1991.

Fig. 6d.

Parmelia macrospora J.D.Zhao, Acta Phytotax. Sin. 9:143. 1964.

Parmelia subvittata J.D.Zhao, Acta Phytotax. Sin. 9:141. 1964. 

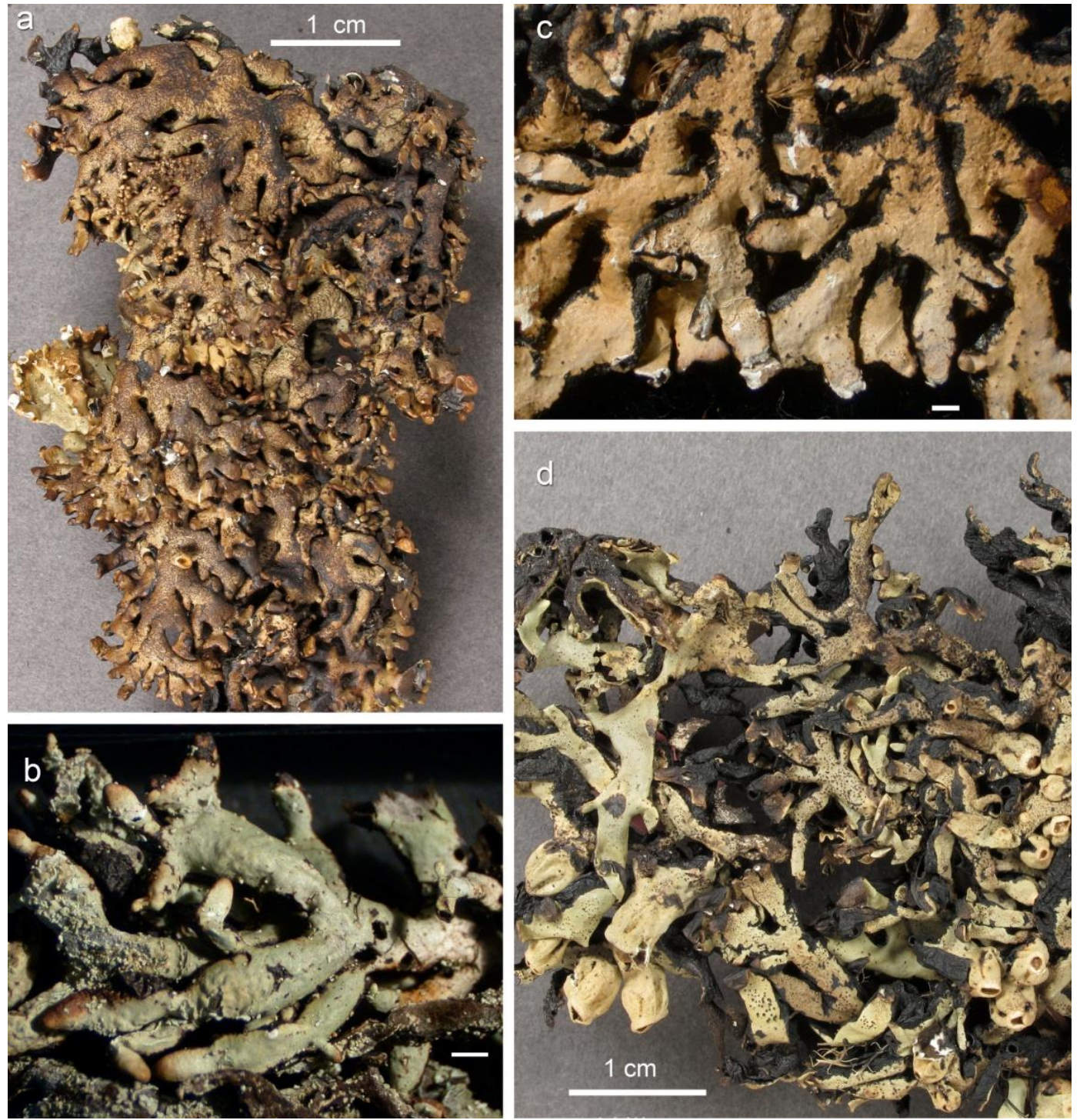

Fig. 6 - a Hypogymnia laccata, habit (McCune 25554). b H. laxa, lobes (McCune 25532). c H. lijiangensis, lobes (holotype, X. Y. Wang 6991). d H. macrospora, habit (L. S. Wang 00-20317). Scale bars $1 \mathrm{~mm}$ unless otherwise indicated.

Hypogymnia subvittata (J.D.Zhao) J.C.Wei, Enum. Lichens in China, p. 118. 1991.

Type - CHINA. Yunnan: Dali County, Longquanfeng, Jul 1941, H. C. Wang 1065 (HMAS$\mathrm{L} !$ as 1065a).

Synopsis - Lobes imbricate, dichotomously branched, with lobules; holes well defined, often with a raised rounded rim; spores unusually large, over twice as large as most Hypogymnia species; hymenium is proportionately taller than in most Hypogymnia.

Description - Thallus appressed to suberect or pendulous, to 10(20) cm broad or long; texture cartilaginous; branching variable, budding present; upper surface smooth then becoming rugose or verrucose, greenish gray to brown, epruinose, dark mottles sometimes present, black border often present; lobes 1-3(5) $\mathrm{mm}$ broad, separate or contiguous to imbricate; lobe outline even to \pm nodulose; lobe width:height ratio 0.5:1-3:1; lobe tips and axils perforate, lower surface perforate, the holes rimmed; medulla hollow, ceiling and floor of cavity dark; soredia and isidia lacking; lobules often present; apothecia common, substipitate, to $15(25) \mathrm{mm}$ in diameter; receptacle urn- to funnel-shaped, stipe hollow, disk strongly concave with the thalline exciple involute; hypothecium POL+; ascospores 14-17.5 × 11.5-14 $\mu \mathrm{m}$; pycnidia common; spermatia cylindrical to weakly bifusiform, 5.0-6.3 × -0.9-1.1 $\mu \mathrm{m}$. 
Chemistry - Atranorin (major) and 4-O-demethylbarbatic acid (= norbarbatic acid, major); medulla K-, C-, KC+ red, P-. bamboo.

Substrate - On bark and wood, including conifers (especially Abies), Rhododendron, and

Known distribution - SW China (Sichuan, Xizang, and Yunnan Provinces).

Notes - At the time of McCune et al. (2002) the only species of Hypogymnia known to have 4- $O$-demethylbarbatic acid (= norbarbatic acid) as the major substance was $H$. macrospora. Surprisingly, this same chemotype has appeared on the opposite side of the globe in the narrow endemic H. madeirensis (Tav.) D. Hawksw. Although H. madeirensis is purported to contain various substances, according to annotation labels, we have found that all specimens examined are uniform in chemistry, containing 4-O-demethylbarbatic (= norbarbatic) acid, physodic acid, and atranorin. Hypogymnia macrospora has the same substances less physodic acid. Despite the similarity in chemistry, the two species appear morphologically unrelated. We therefore interpret the presence of norbarbatic acid in these taxa as convergent evolution.

Material examined - See list in McCune et al. (2002). Additional specimens: CHINA. Xizang: SE Tibet, Tsa rong, Salwin-Kiu Chiang divide, $28.4^{\circ} \mathrm{N} 98.4^{\circ} \mathrm{E}, 4572 \mathrm{~m}$, Forrest 20260 (BM). Yunnan: Dali County, trail to Cang Shan, $25.685^{\circ} \mathrm{N} 100.102^{\circ} \mathrm{E}, 3500 \mathrm{~m}$, McCune 26799, 26800 (OSC); Jianchuan County, ridge on trail to Laojuen Shan, $26.6317^{\circ} \mathrm{N} 99.7183^{\circ} \mathrm{E}, 3980 \mathrm{~m}$, McCune 26730, 26723 (OSC).

Hypogymnia magnifica X.L.Wei \& McCune, Bryol. 113:120. 2010.

Fig. 7a.

Type - CHINA. Yunnan: Lijiang County, Laojuen Mountain, Jiushijiulong Lake, $26.632^{\circ} \mathrm{N}$ 99.728 E, 4100 m, 13 Aug 2000, L.S.Wang 00-20250 (KUN, holotype! Isotypes: HMAS, OSC).

Synopsis - Thalli large (commonly to $30 \mathrm{~cm}$ or more diam) with broad, rather appressed lobes that are contiguous to subcontiguous, whitish color in the field (when dry), sparsely perforate upper and lateral surfaces, lobe cavity with dark ceiling and floor.

Description - Thallus appressed to loosely adnate or somewhat imbricate, to $30 \mathrm{~cm}$ or more broad; texture papery; branching variable, budding present; upper surface smooth to weakly rugose, white to pale greenish gray, epruinose, dark mottles none or scarce, black border sometimes present; lobes contiguous to \pm separate in \pm planar sprays or slightly curled back at the lobe tips; lobe outline even to \pm nodulose; lobe width $1-4(5) \mathrm{mm}$; lobe width:height ratio 0.7:1-4.0:1; upper surface and lateral margins sparsely perforate with roundish to ellipsoid holes; lobe tips and axils often perforate, lower surface sparsely perforate, the holes not rimmed; medulla hollow, ceiling and floor of cavity dark; soredia, isidia, and lobules lacking; apothecia common, stipitate, to $10 \mathrm{~mm}$ or more in diameter; receptacle urn- or funnel shaped; hypothecium POL+; ascospores 6.0-7.8 $\times$ 4.6$5.2 \mu \mathrm{m}$; pycnidia common, spermatia 4.5-6.1 ×0.8-1.1 $\mu \mathrm{m}$. See also Wei et al. (2010).

Chemistry - atranorin and physodalic acid (major), protocetraric acid (minor), with accessory physodic acid; cortex $\mathrm{K}+$ yellow, $\mathrm{C}-, \mathrm{KC}-, \mathrm{P}+$ pale yellow; medulla $\mathrm{K}-, \mathrm{C}-, \mathrm{KC}-$ or $\mathrm{KC}+$ orangered, P+ orange-red.

Substrate - On bark and wood, usually on conifers (Abies, Juniperus).

Known distribution - Yunnan and Sichuan Provinces.

Notes - This locally common and conspicuous species was formerly confused with $H$. taiwanalpina Lai, but separated by Wei et al. (2010) as a new species, H. magnifica. This species is easily distinguished in both the field and laboratory. The large whitish thallus rosettes are distinctive in the field, contrasting with mineral gray to pale greenish gray color of most Hypogymnia in southwest China and elsewhere in the world. Narrow lobed depauperate forms are occasional in SW China, but the usual form is fairly broad-lobed. Hypogymnia magnifica is one of the few Hypogymnia species that commonly develop holes in the upper surface. These are not as regular or frequent as in many species of Menegazzia (though imperforate species of Menegazzia are known). Typically in $H$. magnifica the holes are rather sparse, circular or elliptical, sometimes lateral, sometimes laminal. The best distinctions between Menegazzia and Hypogymnia are, however, the large, thick-walled spores of Menegazzia in combination with the stictic acid group 
chemistry, in contrast with the smaller, thin-walled spores and physodic/physodalic acid group of Hypogymnia.

Material examined - See Wei et al. (2010).

Hypogymnia metaphysodes (Asah.) Rass., Novosti sistematiki nizshikh rasteniui 1967:291. 1967.

Fig. 7b.

Parmelia metaphysodes Asah., Acta Phytotax. Geobot. 14:33. 1950. Lectotype designated by Yoshida (2001).

Synopsis - Lobes small, appressed, contiguous, imperforate, forming neat rosettes; ceiling of cavity white to brown, floor dark; isidia and soredia lacking; spores 6.0-7.5 × 4.5-5.0 $\mu \mathrm{m}$.

Description - (based on Japanese specimens, including holotype) Thallus appressed, to 8(10) $\mathrm{cm}$ broad; texture cartilaginous; branching variable, budding present; upper surface white to greenish gray, smooth to weakly rugose; dark mottles none or rare, black border sometimes present; lobes contiguous, 0.5-2(3) mm wide; lobe width:height ratio 0.8:1-4:1; lobe tips and axils rarely perforate, lower surface rarely perforate; medulla hollow, ceiling of cavity white or dark, floor of cavity dark; soredia, isidia, and lobules lacking; apothecia common, substipitate to stipitate, to 7(13) $\mathrm{mm}$ diam, the receptacle urn- or funnel-shaped; stipe hollow; hypothecium POL-; ascospores 5.6-6.9 × 4.3-5.0 $\mu \mathrm{m}$; pycnidia common, spermatia weakly bifusiform, 5.0-5.5 × 1.0-1.2 $\mu \mathrm{m}$.

Chemistry - Atranorin, physodic, and 3-hydroxyphysodic acids (major), with accessory 2'-Omethylphysodic acid; medulla $\mathrm{K}+$ slowly red brown, $\mathrm{KC}+$ orange red, $\mathrm{P}-$.

Substrate - On conifer bark and wood, less often on hardwoods.

Known distribution - Mainly in Japan; rarely in the Russian Far East (Primorsky); and from SW China. Although previously reported from North America, that material should be referred to H. wilfiana Goward, T. Sprib. \& Ahti (Goward et al. 2010).

Selected material examined - CHINA. Yunnan: Gong Shan County, Yen Niu Gu, $27^{\circ}$ 48.04'N 98 49.5'E, 2950 m, Li Song Wang 00-19362b (KUN). JAPAN. Honshu: Prov. Kai, lower slopes on north side of Mount Fuji, near Okuniwa, 2250 m, McCune26058 (OSC).

Notes - Given that we have seen only one instance of $H$. metaphysodes from SW China, it seems possible that this specimen is an aberrant form of another species. More collections should be sought.

Hypogymnia nitida McCune \& L. S. Wang, sp. nov.

Fig. 8

MycoBank MB 807344

Etymology - The epithet "nitida" refers to the glossy upper surface.

Type - CHINA. Yunnan: Deqin County, Bei Ma Xue Shan, Ya Kou, 4200 m, ca. $28.38^{\circ} \mathrm{N}$ 99.0W, 10 Aug 1993, L. S. Wang 93-13495 (KUN).

Synopsis - Upper surface glossy dark brown with imperforate lobes; lower surface strongly wrinkled and convoluted, with septum in stipe of apothecia; lobe cavity with brownish to white ceilings and dark floors.

Description - Thallus appressed to imbricate or subpendant, to $7(10) \mathrm{cm}$ long; branching variable, with occasional lateral budding; upper surface smooth or becoming rugose, brown to dark brown, glossy though old parts matte, sometimes with black mottling, with or without a black border, epruinose; lower surface black, except brown near the lobe tips, strongly wrinkled and convoluted; lobes hollow, 0.5-2(3) mm wide, contiguous to somewhat separate, even in outline to somewhat pinched and swollen, imperforate, width:height ratio mostly 1:1-4:1, texture cartilaginous; lobe cavity with white to dark ceilings and dark floors, sometimes mostly white; soredia and isidia lacking; lobules rare; apothecia occasional, substipitate to stipitate, to 5(10) $\mathrm{mm}$ diam; stipe initially urn shaped, becoming funnelform; sometimes with transverse septum in stipe, hypothecium POL+ at the base, POL- above; spores ellipsoid, 6.3-7.7 $\times 4.4-5.3 \mu \mathrm{m}$; pycnidia occasional; spermatia rod shaped to weakly bifusiform, 4.8-5.7 $\times 0.9-1.2 \mu \mathrm{m}$. 

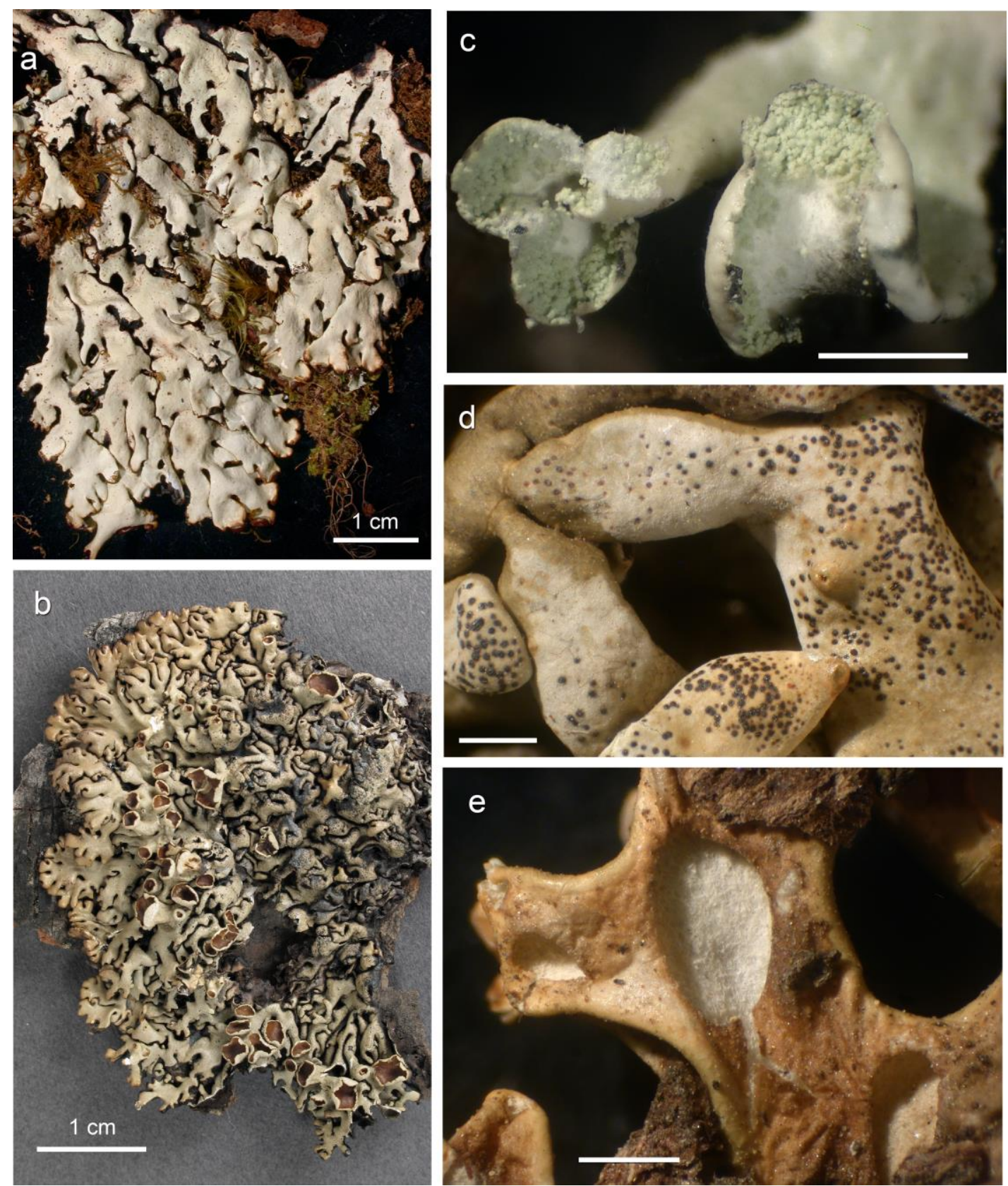

Fig. 7 - a Hypogymnia magnifica, habit (McCune 26718). b H. metaphysodes, habit, (McCune 26058, near type locality in Japan). c H. physodes, soralia (McCune 31241; Canada: British Columbia). d H. pruinoidea, pruinose lobes (holotype, Wei 1728). e H. pruinoidea, perforations in lower surface, Wei 1727). Scale bars $1 \mathrm{~mm}$ unless otherwise indicated.

Chemistry - Atranorin (trace to major), physodic (major), 2'-O-methylphysodic (minor), and vittatolic (minor accessory, usually present) acids; cortex $\mathrm{K}+$ yellow, $\mathrm{P}+$ pale yellow, $\mathrm{C}-, \mathrm{KC}-$ (except the pink-orange medullary reaction showing through); medulla $\mathrm{K}-, \mathrm{C}-, \mathrm{KC}+$ orange red, $\mathrm{P}-$.

Substrate - On conifers, including Larix and Picea.

Known distribution - So far known from NW Yunnan Province (Deqen and Zhongdian Counties); SW Sichuan Province (Mu Li County); perhaps restricted to Hengduan Mountain area proper; so far known from conifer forests at 3700-4200 m.

Notes - Possibly related to $H$. delavayi and $H$. stricta, but the upper surface of $H$. nitida is glossy brown, its lobes are imperforate, and the thallus lacks 3-hydroxyphysodic acid. In contrast, $H$. delavayi and $H$. stricta tend to be pale greenish gray, with perforations developing in the lower surface and axils, and contain 3-hydroxyphysodic acid. The shiny, brown, often appressed lobes 

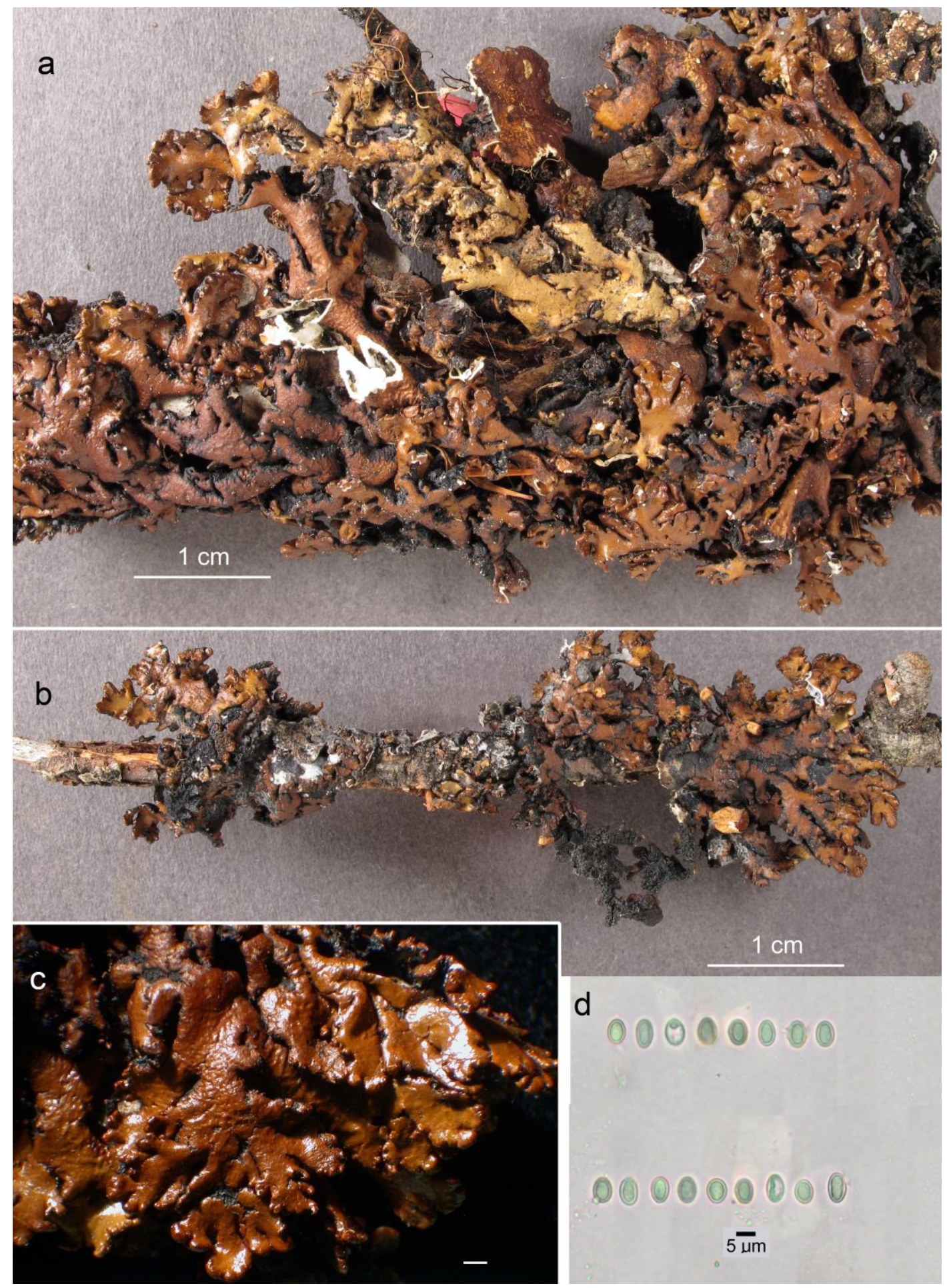

Fig. 8 - Hypogymnia nitida. a Habit (Wang 93-13495). b Habit (Xing 1952b). c Lobes (Wang 9313495; scale bar $1 \mathrm{~mm}$ ). d Ascospores (Wang 83-1793).

and absence of perforations are also reminiscent of $H$. austerodes. That species and its close relative $H$. bitteri are, however, sorediate and do not normally develop separate lobes, nor do they become subpendant. The circumboreal $H$. subobscura is similar in its brown coloration, and approaches $H$. nitida in its slightly more open branching than $H$. austerodes and $H$. bitteri, but differs from $H$. nitida in having frequent but small perforations in the lobe tips.

Additional material examined - CHINA. Sichuan: Hu Ding Pref., Xinxing County, E slope Gongga Mountain, 4000 m, ca. $29.33^{\circ} \mathrm{N} 101.50^{\circ} \mathrm{W}, 27$ June 1982, Xuan Lu s.n. (KUN 1678); Mu 
Li County, Ka La Village, Shao Xian Liang Zi, 3850 m, ca. 28.08 N 101.33W, 22 Aug 1983, L. S. Wang 83-1793 (KUN). Yunnan: Deqin County, Bei Ma Xue Shan, Ya Kou (same as type locality), $4200 \mathrm{~m}$, ca. $28.38^{\circ} \mathrm{N} 99^{\circ} \mathrm{W}, 10$ Aug 1993, L. S. Wang 93-13479 (KUN); Zhongdian County, Shi Ka La Xue Xhan, 3600-3780 m, ca. $27.83^{\circ} \mathrm{N} 99.72^{\circ} \mathrm{W}, 20$ June 1981, Xing Jiang Li 1952b (KUN).

Hypogymnia pendula McCune \& L. S. Wang, sp. nov.

MycoBank MB 807350

Etymology - The name "pendula" refers to the tendency to become pendulous.

Type - CHINA. Yunnan: Jianchuan County, trailhead to Lao Juen Shan, Abies delavayi Rhododendron forest near hotel, $26.6322^{\circ} \mathrm{N} 99.7253^{\circ} \mathrm{E}, 3700 \mathrm{~m}$, on Abies trunk, 18 Oct 2002, McCune 26711 (KUN, holotype).

Synopsis - Similar to H. macrospora, but lobes imbricate to pendulous with open branching and with physodalic, protocetraric, and physodic acids instead of 4-O-demethylbarbatic acid, and therefore $\mathrm{P}+$ orange-red instead of P-.

Description - Thallus pendulous, to 10(12) cm long; texture cartilaginous; branching mostly isotomic dichotomous, budding present; upper surface smooth then becoming rugose or verrucose, whitish to pale greenish gray, epruinose, dark mottles sometimes present, black border often present, lobes $0.5-2.5(3) \mathrm{mm}$ broad, separate or contiguous to imbricate; lobe outline even to \pm nodulose; lobe width:height ratio 0.5:1-3:1; lobe tips and axils perforate, lower surface perforate, the holes rimmed; medulla hollow, ceiling and floor of cavity dark; soredia and isidia lacking; apothecia substipitate, to $15(25) \mathrm{mm}$ in diameter; receptacle urn- to funnel-shaped, stipe hollow, hypothecium POL-; ascospores (10)12-16 × (8)9-12 $\mu \mathrm{m}$; pycnidia common; spermatia cylindrical to weakly bifusiform, $4.0-5.3 \times 0.8-0.9 \mu \mathrm{m}$.

Chemistry - Atranorin and physodic (major), physodalic (major), and protocetraric (minor) acids. Cortex $\mathrm{K}+$ yellow, $\mathrm{C}-, \mathrm{KC}-\mathrm{P}+$ pale yellow; medulla $\mathrm{K}-, \mathrm{C}-, \mathrm{KC}+$ red, $\mathrm{P}+$ orange red.

Substrate - So far known on bark of Abies.

Known distribution - Yunnan Province, Jianchuan and Zhongdian Counties.

Notes - Hypogymnia spores are mostly less than $10 \mu \mathrm{m}$ long, the most notable exceptions being $H$. macrospora and now $H$. pendula. The former is also unusual in having 4-Odemethylbarbatic acid (= norbarbatic acid) as the major substance and rimmed holes in the lower surface. Hypogymnia pendula is similar to $H$. macrospora in most important characters, including the large spores and rimmed holes, but contains a suite of lichen substances not including norbarbatic acid. Furthermore, $H$. pendula has a POL- hypothecium, while that of $H$. macrospora is POL+.

Three well-developed specimens have been found, two from near the trailhead to Lao Juen Shan in Jianchuan County, and one from Zhongdian County. One specimen from Lao Juen Shan has relatively broad lobes, averaging 1-2 mm wide, while the other specimen from there has narrow lobes averaging $1 \mathrm{~mm}$ broad. The pendulous growth form of all three of these specimens, in contrast to the appressed to imbricate form of $H$. macrospora, along with the difference in secondary substances and the difference in hypothecium, prompt us to describe this new species.

All three of these specimens are fertile, but the asci are mostly degenerate and the spores poorly formed, despite the large number of apothecia present. Yet enough spores were found to establish their large size $(12-16 \times 9-12 \mu \mathrm{m})$.

Additional material examined - CHINA. Yunnan: Jianchuan County, trailhead to Lao Juen Shan, Abies delavayi - Rhododendron forest near hotel, $26.6322^{\circ} \mathrm{N} 99.7253^{\circ} \mathrm{E}, 3700 \mathrm{~m}$, on Abies branch, 18 Oct 2002, McCune 26712; Zhongdian County, Tian Chi, on Abies, $27.833^{\circ} \mathrm{N} 99.717^{\circ} \mathrm{E}, 3750 \mathrm{~m}$, 20 Sep 1994, L. S. Wang 94-15531 (KUN).

Hypogymnia physodes (L.) Nyl., Lich. Envir. Paris 39. 1896.

Fig. 7c.

Lichen physodes L., Spec. Plant. p. 1144. 1753.

Synopsis - Soralia lip-shaped beneath the lobe tips, lobes imbricate, imperforate except for incipient soralia; $\mathrm{P}+$ orange red. 

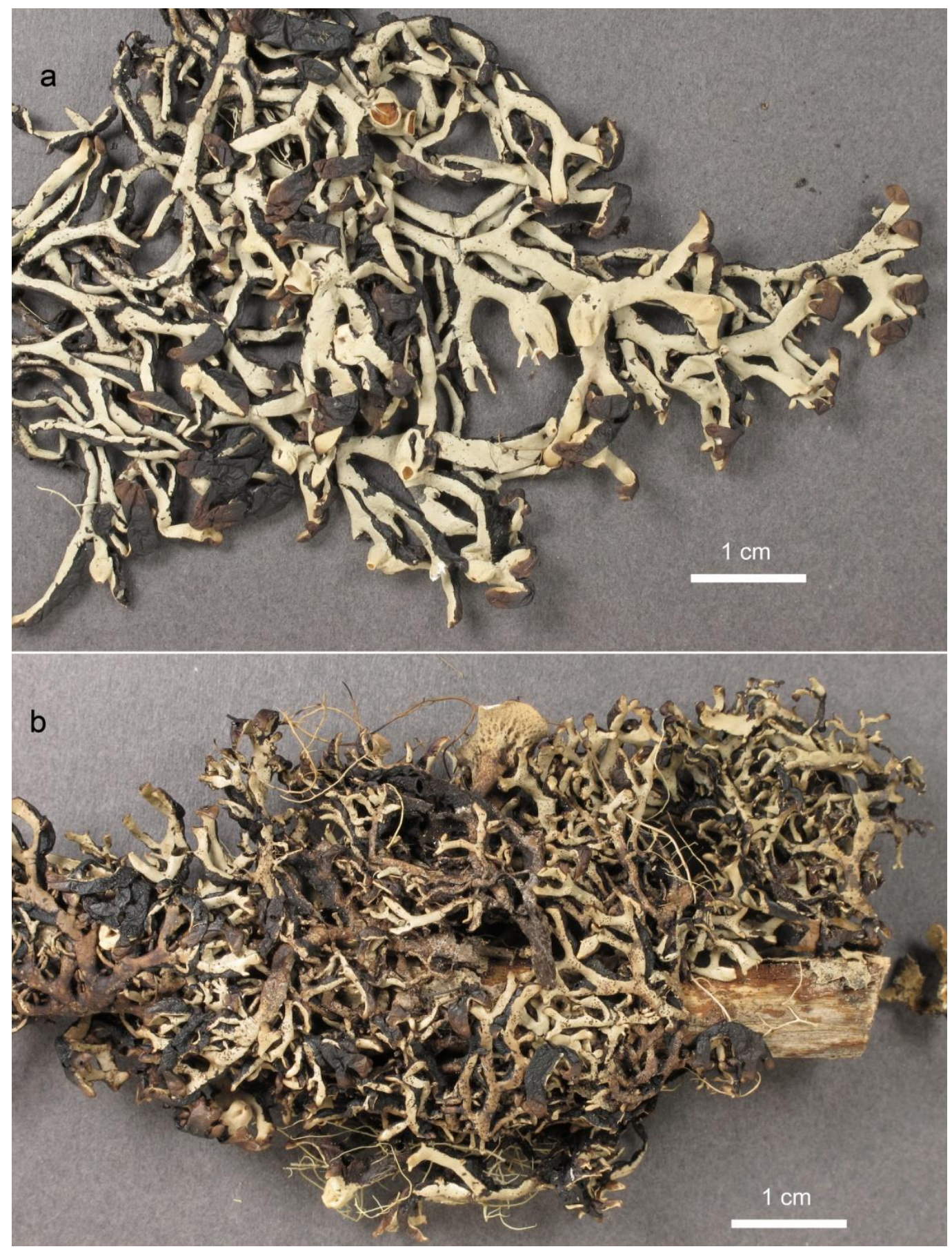

Fig. 9 - Hypogymnia pendula. a Habit (McCune 26711). b Habit of narrow-lobed morph (McCune 26712). Scale bars $1 \mathrm{~mm}$ unless otherwise indicated.

Description - Thallus appressed to suberect, to $6(15) \mathrm{cm}$ broad; branching isotomic dichotomous to irregular, budding occasional; upper surface smooth to occasionally rugose, white, pale gray to greenish gray, solarizing to blackish, not or rarely dark mottled, black border seldom visible from above; lobes contiguous to imbricate or \pm separate, $0.5-2.5(4) \mathrm{mm}$ broad; lobe tips and axils imperforate or irregularly torn at sites of incipient soralia; medulla hollow; ceiling of cavity white or dark, floor of cavity dark; lower surface black, rarely perforate; soredia on the inside of the burst lobe tips, developing labriform soralia; isidia absent, lobules rare; apothecia rare, substipitate to stipitate, to 2(4) $\mathrm{mm}$ in diam; stipe funnel-shaped, hollow; disc brown; thalline exciple becoming sorediate; hypothecium weakly POL+, stronger at the base; ascospores ellipsoid, 6.1-7.9 $\times 4.5-5.6$ $\mu \mathrm{m}$; pycnidia occasional; spermatia narrowly cylindrical to weakly bifusiform, $5.5-7.1 \times 0.9-1.3$ $\mu \mathrm{m}$. 
Chemistry - Atranorin, physodalic, physodic, 3-hydroxyphysodic, and protocetraric acids (all major except minor protocetraric acid), and minor accessories vittatolic and 2'- $O$-methylphysodic acids; cortex $\mathrm{K}+$ yellow, $\mathrm{P}+$ pale yellow, $\mathrm{C}$-, $\mathrm{KC}$ - (except the pink-orange medullary reaction showing through); medulla $\mathrm{K}+$ slowly reddish brown, $\mathrm{C}-, \mathrm{KC}+$ orange red, $\mathrm{P}+$ orange red.

Substrate - Usually on bark or wood of both conifers and hardwoods, occasionally on rock or alpine sod.

Known distribution - Abundant in the temperate to Arctic northern hemisphere, but rare in SW China, much more common in northern and northeastern China.

Notes - This species is easily recognized and seldom misidentified. Hypogymnia vittata is much more common in SW China than $H$. physodes, but the former is $\mathrm{P}$ - and has perforate lobes, while $H$. physodes is $\mathrm{P}+$ orange red and lacks perforations except associated with the soralia. Occasionally esorediate forms are found in cold, exposed habitats including tundra; these forms tend to solarize to blackish rather than dark brown and still have the characteristic chemistry of the species.

SW China material examined - CHINA. Sichuan: Nanping County, forest behind Jiu Zhai Gou, 33. $0^{\circ} \mathrm{N} 103.83^{\circ} \mathrm{E}, 3150 \mathrm{~m}$, L. S. Wang 86-265 (KUN); Upper Dadu He, Dajin Chuang, GanaBarkam, $31.917^{\circ} \mathrm{N} 102.050^{\circ} \mathrm{E}, \mathrm{G}$. \& S. Miehe 94-473-23/03 (GZU). Yunnan: Gong Shan County, Binzhong Luo to Tong Da Ya Kou, $93.683^{\circ} \mathrm{N} 28.092^{\circ} \mathrm{E}, 3700 \mathrm{~m}$, L. S. Wang 99-18549 (KUN).

Hypogymnia pruinoidea X.L. Wei \& J.C.Wei, Lichenol. 44:784. 2012.

Fig. 7d.

Type - CHINA. Shaanxi: Mt. Taibai, 2800 m, 26 Sep 1994, X. L. Wei 1727 (HMAS-L!).

Synopsis - Lobes pruinose, similar to $H$. pruinosa, but developing more elongate, separate lobes and perforations numerous and conspicuous in lobe tips, axils, and lower surface; soredia and isidia lacking, thallus P-.

Description - Thallus appressed to loosely appressed, to $6 \mathrm{~cm}$ broad or long in the limited material available; texture cartilaginous; branching mainly isotomic dichotomous, budding absent or rare; upper surface smooth to rugose, pale greenish gray to brownish, often whitish pruinose in patches; dark mottles rarely present; lobes contiguous to \pm separate or imbricate, black border not visible; lobe width $0.8-2.5(4) \mathrm{mm}$, lobe width:height ratio 0.5:1-3:1; lobe tips and axils prominently perforate, lower surface heavily perforate, the holes large and often oblong; medulla hollow, ceiling of cavity whitish to pale tan or grayish, floor of cavity grayish then darkening; soredia, isidia, and lobules lacking; apothecia unknown; pycnidia common, spermatia weakly bifusiform, $5.7-6.5 \times 0.8-1.0 \mu \mathrm{m}$.

Known distribution - Previously known only from the vicinity of the type locality in the Taibai Mountains in Shaanxi Province, the Sichuan specimen extends its range considerably. There it occurred at an unusually low elevation for Hypogymnia in SW China (2050 m).

Chemistry - Atranorin (minor), physodic, 3-hydroxyphysodic and vittatolic acids. Our TLC of the type specimen showed atranorin (trace), physodic acid (major), 3-hydroxyphysodic (trace) \& vittatolic acid (minor). The specimen from Sichuan also had only a trace of atranorin, but had physodic, 3-hydroxyphysodic, and vittatolic acids as major substances.

Notes - Although at first glance this species appears like a chemical variant of $H$. pruinosa, the thallus appears to be less rosettiform than $H$. pruinosa, and the lobes more elongate and separate. Furthermore the lower surface, branch tips, and axils are perforate with large, gaping, often oblong holes, and are thus more heavily perforate than either $H$. pruinosa or $H$. pseudopruinosa. Otherwise, $H$. pruinoidea and $H$. pseudopruinosa appear identical in morphology and chemistry. So few specimens and sites are known for H. pruinoidea and H. pseudopruinosa, and the species are so similar, that it is difficult to be confident in separating the species.

Material examined - CHINA. Sichuan: Nanping County, Jui Zhai Gou, Bo Jin Yan, ca. $33^{\circ}$ N $103^{\circ}$ 50'E, 2050 m, 24 Sep 1986, L. S. Wang 86-2627 (KUN). 
Hypogymnia pruinosa J.C.Wei \& Y.M.Jiang, Acta Phytotax. Sin. 18:386. 1980.

Fig. 10a.

Type - CHINA. Xizang: Changdu (Qamdo), 1 Jun 1975, Y. C. Zong and Y. Z. Liao 215 (HMAS-L!).

Synopsis - Thalls appressed, often rosettiform, the lobe tips often with a pronounced white pruinose patch; lobes strongly inflated, but compressed and contorted from crowding.

Description - Thallus appressed, to 6(10) $\mathrm{cm}$ broad or long; texture cartilaginous; branching variable, budding occasional; upper surface white to greenish gray, smooth to weakly rugose; dark mottles sometimes present; lobes contiguous to \pm separate, black border not visible; lobe width 0.5 $1.5(2.5) \mathrm{mm}$, inflated but often strongly compressed from crowding; lobe width:height ratio 0.5:14:1; lobe tips and axils perforate, lower surface perforate; medulla hollow, ceiling of cavity white or dark, floor of cavity dark; soredia lacking; isidia rare; lobules occasional; apothecia common, stipitate, to $6(10) \mathrm{mm}$, receptacle urn- or funnel-shaped, stipe hollow; hypothecium POL-; ascospores 6-8 8 4.5-5.4 $\mu \mathrm{m}$; pycnidia common, spermatia rod shaped, 4.8-6.1 $\times 0.8-1.1 \mu \mathrm{m}$.

Chemistry - Atranorin (minor) and alectoronic acid (major) with associated minor satellite compounds; medulla strongly UV+ white, $\mathrm{K}-, \mathrm{KC}+$ orange, $\mathrm{P}-$.

Substrate - On bark and wood, especially Pinus.

Known distribution - Most common in Yunnan Province, also in Sichuan and Xizang. In Yunnan Province the species occurs at lower elevations than most other Hypogymnia species in that province, down to $1900 \mathrm{~m}$.

Notes - See Table 1 for a comparison with other pruinose Hypogymnia species. The pruinosity varies greatly, from heavily and conspicuously pruinose to essentially epruinose. One form has pruinose erect lobules approaching isidia. The species is unusual in having rod-shaped spermatia (sometimes with a slight submedial swelling), in contrast to the weakly bifusiform spermatia that are typical of most Hypogymnia species.

Material examined - CHINA. Sichuan: Er Mei Mountain, $29.50^{\circ} \mathrm{N} 103.33^{\circ} \mathrm{E}, \mathrm{W}$. R. He 1400 (KUN); Kangding County, Hiqiulin Chang, 3300 m, L. S. Wang 96-16307a (KUN); Nanping County, Jui Zhai Gou, Bo Jin Yan, 33.0 ${ }^{\circ}$ N 103.83 E, 2050 m, L. S. Wang 86-2637 (KUN); Shalui Shan, $30 \mathrm{~km}$ NE Batang, S Yidun, 30.267 N 99.417 $\mathrm{E}, 3775 \mathrm{~m}$, Obermayer 3215 (GZU); reg. bor., Lu-lan-huo, on a dry hill, 2300 m, 29 Apr 1922, H. Smith 5294 (UPS). Xizang: way from Bamda to Quarndo (Changtu), 30.70 N 97.25 $\mathrm{E}$, $4050 \mathrm{~m}$, Obermayer 4024 (GZU); Qamdo, Y. C. Zong 215

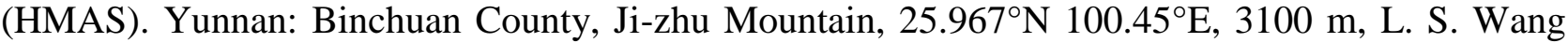
96-17480 (KUN); Chu Xiong County, ridges and slopes above Chu Xiong, $26.000^{\circ} \mathrm{N} 101.435^{\circ} \mathrm{E}$, $2200 \mathrm{~m}$, McCune 26830 (OSC); Deqin County, Jiuzhai Gou, on trunk of Tsuga, $28.50^{\circ} \mathrm{N} 98.917^{\circ} \mathrm{E}$, $4100 \mathrm{~m}, \mathrm{X}$. Y. Wang 7606b (HMAS); Ben Zi Lan, bamboo forest, $28.25^{\circ} \mathrm{N} 99.27^{\circ} \mathrm{E}, 3000 \mathrm{~m}, \mathrm{Li}$ Xin Jiang 2065A (KUN); Jianchuan County, Shi Bao Shan Park, $75 \mathrm{~km} \mathrm{~S}$ of Lijiang, $26.359^{\circ} \mathrm{N}$ $99.840^{\circ} \mathrm{E}, 2490 \mathrm{~m}$, McCune 26739 (OSC); Kunming, Jin-dian, 25.083 ${ }^{\circ} \mathrm{N} 102.267^{\circ} \mathrm{E}, 1900 \mathrm{~m}$, L. S. Wang 83-30a, 83-30b (KUN); Lijiang County, $9 \mathrm{~km} \mathrm{~S}$ of Lijiang City, $26.717^{\circ} \mathrm{N} 100.25^{\circ} \mathrm{E}, 2500$ m, L. S. Wang 85-28, 85-44 (KUN); Bei Pu Lin, Yu Long Shan, 27.083 ${ }^{\circ} \mathrm{N} 100.167^{\circ} \mathrm{E}, 3050 \mathrm{~m}, \mathrm{~J}$. X. Xi 67A (KUN); Tie Jia Shan, 26.7670 ${ }^{\circ} \mathrm{N} 100.0053^{\circ} \mathrm{E}, 2700 \mathrm{~m}$, McCune 26750 (OSC); Tie Jia Shan, $26.767^{\circ} \mathrm{N} 100.033^{\circ} \mathrm{E}, 2800 \mathrm{~m}$, Ahti $46164(\mathrm{KUN})$; Tie Jia Shan, $26.783^{\circ} \mathrm{N} 100.083^{\circ} \mathrm{E}$, L. S. Wang 85-313 (KUN); Yuhaizi, 27.08 ${ }^{\circ} \mathrm{N} 100.25^{\circ} \mathrm{E}, 3200 \mathrm{~m}, \mathrm{~L}$. S. Wang 85-122 (KUN); Gan-he-ba, $27.083^{\circ} \mathrm{N} 100.233^{\circ} \mathrm{E}, 2600 \mathrm{~m}$, L. S. Wang 11424 (KUN); Yu-long-xue-shan, $27.033^{\circ} \mathrm{N} 100.267^{\circ} \mathrm{E}$, 3200 m, L. S. Wang 11546 (KUN); Lijiang County, Tie Jia Shan, $26.933^{\circ} \mathrm{N} 100.167^{\circ} \mathrm{E}, 2750 \mathrm{~m}$,

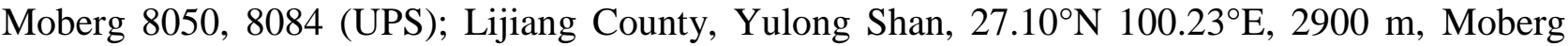
7854 (UPS); Yulong Shan, bark of Pinus yunnanensis, $26.92^{\circ} \mathrm{N} 100.30^{\circ} \mathrm{E}, 3150 \mathrm{~m}$, J. C. Wei 2546 , Lich. Sinenses Exs.12 (E, S, US); Ning Lang County, Yong Ning Luo Sui, $27.667^{\circ} \mathrm{N} 100.75^{\circ} \mathrm{E}$, 2700 m, L. S. Wang 10298 (KUN); Qiaoji County, To Da Qiao, Da Feng Ya Kou, 26.683 $\mathrm{N}$ $103.333^{\circ}$ E, 2500 m, L. S. Wang 96-17160 (KUN); Wu Ding County, Shi-zi Mountain, $25.533^{\circ} \mathrm{N}$ $102.367^{\circ} \mathrm{E}, 4200 \mathrm{~m}, \mathrm{~L}$. S. Wang 11013 (KUN), S. Q. Wang 10995 (KUN); Zhongdian County, Bei Shui Tai, $27.50^{\circ} \mathrm{N} 100.083^{\circ} \mathrm{E}, 3400 \mathrm{~m}, \mathrm{~L}$. S. Wang 94-15521 (KUN); Na Pa, Hai Hou Shan, $27.833^{\circ} \mathrm{N} 99.717^{\circ} \mathrm{E}, \mathrm{X}$. J. Li 1974 (KUN); Tianchi Lake, $27.617^{\circ} \mathrm{N} 99.633^{\circ} \mathrm{E}, 2800 \mathrm{~m}$, L. S. Wang 01-20947 (KUN); Wu Fen Mountain, 27.8 N 99.733 E, 3300 m, Z. W. Lin 4414 (KUN); Xiao 


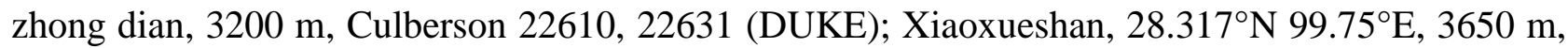
L. S. Wang 01-20870 (KUN).

Hypogymnia pseudobitteriana (Awasthi) Awasthi, Geophytology 1:101. 1971. Fig. 10b.

Parmelia pseudobitteriana Awasthi, Curr. Sci. 26:123. 1957.

Synopsis - Thallus small to medium sized with soft texture and laminal soredia, usually with abundant adventitious budding, often developing into pinnate branching; lobe cavity with white ceiling and dark floor.

Description - Thallus appressed, to $6(11) \mathrm{cm}$ broad or long; texture soft; branching weakly to strongly pinnate, budding present; upper surface smooth to weakly rugose, white to pale greenish gray, dark mottles often present, black border often present; lobes contiguous to \pm separate, 0.1 2(4) $\mathrm{mm}$ wide; lobe outline pinched and swollen; lobe width:height ratio 0.7:1-2:1; lobe tips and axils perforate, lower surface sparsely perforate; medulla hollow, ceiling of cavity pale brownish to more often dark brown, floor of cavity dark; soredia present, laminal, partly on the edges of schizidia, the schizidia often building into thick piles or eroding to expose the medulla; isidia and lobules lacking; apothecia rare, substipitate, to $2 \mathrm{~mm}$ diam in the few cases seen; ascospores 8-10 $\times$ 4-6 $\mu \mathrm{m}$, pycnidia sparse, spermatia cylindrical to weakly bifusiform, $4.5-5.4 \times 0.9-1.1 \mu \mathrm{m}$.

Chemistry - Atranorin, physodic acid (major), 3-hydroxyphysodic acid (major), with accessory vittatolic acid; medulla $\mathrm{K}+$ slowly reddish brown, $\mathrm{KC}+$ orange red, $\mathrm{P}-$.

Substrate - bark and wood, both hardwoods and conifers, including Lithocarpus, Pandanus, Picea, Pinus, Quercus, Rhododendron, and Vaccinium.

Known distribution - Widespread in eastern and southern Asia, including China, India, Philippines, Taiwan, and Thailand; also in Papua New Guinea.

Notes - This species occurs in warmer climates than any other Hypogymnia in Asia. The perforate lobe tips and pinnate branching suggest a close relationship with $H$. vittata. Small or poorly developed specimens can be difficult to separate from H. pseudophysodes; see discussion under that species. The ranges of the two species barely overlap, perhaps only in Taiwan.

Material examined - CHINA. Gueizhou: Jiangkou County, Fanjinshan, $27.95^{\circ} \mathrm{N} 108.83^{\circ} \mathrm{E}$, 2100 m, L. S. Wang 10748 (KUN). Yunnan: Chu Xiong County, ridges and slopes above Chu Xiong, $25.999^{\circ} \mathrm{N} 101.435^{\circ} \mathrm{E}, 2200 \mathrm{~m}$, Wetmore 88717, 88724 (MIN), McCune 26829 (OSC); Dali Prefecture, 2400 m, J. X. Xi 0361 (KUN); Gong Shan County, Qinatong, Songtaxue Mountain, $28.1883^{\circ} \mathrm{N} 98.5317^{\circ} \mathrm{E}, 3300 \mathrm{~m}$, L. S. Wang 00-19677 (KUN); Jianchuan County, Shi Bao Shan Park, $75 \mathrm{~km} \mathrm{~S}$ of Lijiang, 26.359 ${ }^{\circ} \mathrm{N} 99.840^{\circ} \mathrm{E}, 2490 \mathrm{~m}$, McCune 26737 (OSC); Jing-dong County, Ai-lao Mt, Xu-Jia-Ba, $24.55^{\circ} \mathrm{N} 101.033^{\circ} \mathrm{E}, 2500 \mathrm{~m}$, L. S. Wang 94-1443 (KUN); Xui-Jia-Ba, $24.33^{\circ} \mathrm{N} 101.67^{\circ} \mathrm{E}, 2600 \mathrm{~m}$, L. S. Wang 94-14345b, 94-14391 (KUN); Kunming, Jin-dian, 25.083 ${ }^{\circ} \mathrm{N} 102.267^{\circ} \mathrm{E}, 1900 \mathrm{~m}, \mathrm{~L}$. S. Wang 83-30c, 1860 (KUN); Ping Bian County, Da Wei Mt, $22.92^{\circ} \mathrm{N} 103.67^{\circ} \mathrm{E}, 1900 \mathrm{~m}, \mathrm{~L}$. S. Wang 95-15851 (KUN); Tengchong County, Da-Tang Village, Dadizi, $25.754^{\circ} \mathrm{N} 98.706^{\circ} \mathrm{E}, 1700 \mathrm{~m}, \mathrm{~L}$. S. Wang 96-17108 (KUN); Tengchong County, Ma Zhan, Bu Jia Village, $26.867^{\circ} \mathrm{N} 98.50^{\circ} \mathrm{E}, 1500 \mathrm{~m}$, L. S. Wang 96-17024 (KUN); $1900 \mathrm{~m}$, J. X. Xi 583 (KUN); Wu Ding County, Shi-zi Mountain, $25.533^{\circ} \mathrm{N} 102.367^{\circ} \mathrm{E}$, S. Wang 11013 (KUN). TAIWAN. Chiayi County, Alishan Forest Park, $11.5 \mathrm{~km}$ E of Chiai, $23.52^{\circ} \mathrm{N} 120.80^{\circ} \mathrm{E}, 2300 \mathrm{~m}$, Wetmore 87517 (MIN); Alishan, J. Wang-Yang 177 (US); Chiayi County, Arisan, Asahina 23616 (TNS).

Hypogymnia pseudocyphellata McCune \& E. P. Martin, Bryologist 106:233. 2002. Fig. 10c.

Type - CHINA. Yunnan: Zhongdian County, Tian Chi (alpine lake), 27³8'N, 99 $39^{\circ} \mathrm{E}, 3750$ m, 20 Sep 1994, L. S. Wang 94-14916c (KUN).

Synopsis - Lobes appressed to suberect, narrow, separate or imbricate, sublinear, sometimes with white pseudocyphellae on the lobe tips, with rimmed holes and complex chemistry as described below; medulla $\mathrm{P}+$ orange red.

Description - Thallus appressed to suberect, to $5 \mathrm{~cm}$ broad or long; texture papery; branching isotomic dichotomous, budding common; upper surface smooth to weakly rugose, white to greenish 
gray, solarizing to brown, epruinose, dark mottles sparse, black border sometimes present; lobes sublinear, separate, 0.5-1.5(2) mm broad; lobe outline even; lobe width:height ratio 1:1-3:1; lobe tips and axils perforate, lower surface sparsely perforate, the holes rimmed; medulla hollow, ceiling and floor of cavity dark; soredia and isidia lacking; lobules occasional; apothecia occasional, substipitate, urn-shaped; hypothecium POL+; ascospores not seen; pycnidia occasional; spermatia not seen.

Chemistry - Thallus containing atranorin and chloroatranorin (minor), usnic acid (minor), barbatic acid (minor, accessory), elatinic acid (minor, accessory), baeomycesic acid (trace), squamatic acid (major), 1'-methylhypothamnolate (major), and hypothamnolic acid (submajor, accessory) by TLC and HPLC (by J. Elix). We detected all of these substances by TLC except for usnic acid and chloroatranorin. Cortex $\mathrm{K}+$ yellow, $\mathrm{C}-, \mathrm{KC}-, \mathrm{P}+$ pale yellow; medulla $\mathrm{K}-, \mathrm{C}-, \mathrm{KC}-$, $\mathrm{P}+$ orange.

Substrate - On bark and wood, including Abies and Rhododendron.

Known distribution - So far known only from Yunnan Province, SW China at 3700-4100 m.

Notes - The TLC results for this species initially included several unknowns (McCune et al. 2002), but these have been resolved by J. Elix, as reported in McCune et al. (2012). Since the species was first described from two sites in Zhongdian County, three additional sites have been found (Jianchuan and Lijiang Counties). These additional specimens have shown that presence of pseudocyphellae at the lobe tips is not a constant character; they do appear to be associated with development pathway of the rimmed holes at the lobe tips. In some cases they appear as spots paler than the surrounding cortex (Fig. 10d), which then open into the medullary cavity.

Only one fertile specimen is known (L. S. Wang 00-19814), but the apothecia are small and no asci or ascospores were found. The shallow hymenium (ca. $30 \mu \mathrm{m})$ suggests, however, that the spores will be small and typical of Hypogymnia. The large spores of $H$. macrospora and $H$. pendula are associated with a taller hymenium (ca. $60 \mu \mathrm{m})$.

Specimens examined - CHINA. Yunnan: Jianchuan County, ridge on trail to Laojuen Shan, $26.6317^{\circ} \mathrm{N} 99.7183^{\circ} \mathrm{E}, 3980 \mathrm{~m}$, McCune $^{26725}$ (OSC); trailhead to Laojuenshan, $26.6322^{\circ} \mathrm{N}$ $99.7253^{\circ} \mathrm{E}, 3700 \mathrm{~m}, \mathrm{McCune} 26713$ (OSC); Lijiang County, Laujuenshan, Jiushijiulong Lake, Shi Men, $26.6309^{\circ} \mathrm{N} 99.7280^{\circ} \mathrm{E}, 4100 \mathrm{~m}$, L. S. Wang 00-20248 (KUN); Zhongdian County, Wengshuei village, Daxueshan, $28^{\circ} 30.15^{\prime} \mathrm{N} 99^{\circ} 49.06^{\prime} \mathrm{E}, 3800$ m, L. S. Wang 00-19814 (KUN).

Hypogymnia pseudophysodes (Asah.) Rass., Novosti sistematiki nizshikh rasteniui 1967:294. 1967. Fig. 10d. (2001).

Parmelia pseudophysodes Asah., J. Jap. Bot. 26:100. 1951. Lectotype designated by Yoshida

Synopsis - Thallus frequently forming appressed rosettes or lobes becoming imbricate, sorediate along the edges of well-developed schizidia, the schizidia shedding to expose a strip of black medulla along the upper surface, lobes perforate, lobe cavity with dark ceilings and floors.

Description - Thallus appressed to suberect, to $5(7) \mathrm{cm}$ broad or long; texture cartilaginous; branching isotomic dichotomous, often with broadly roundish axils, budding occasional; upper surface smooth or becoming rugose, white to pale greenish gray or brown, dark mottles sometimes present, black border sometimes present; lobes contiguous or separate; lobe outline even to \pm nodulose; lobe width $0.7-2(3) \mathrm{mm}$; lobe width:height ratio $0.5: 1-: 1$; lobe tips and axils perforate, lower surface sparsely perforate; medulla hollow, ceiling of cavity dark, floor of cavity dark; soredia present, laminal, often developing along edges of schizidia, and then often exposing the blackish medulla along the crest of the lobes; isidia and lobules lacking; apothecia occasional, substipitate to stipitate, to 3(5)mm, receptacle urn or funnel shaped, stipe hollow; ascospores 5.0$6.0 \times 4.5--5.5 \mu \mathrm{m}$, pycnidia infrequent, spermatia $5.0-6.1 \times 0.9-1.3 \mu \mathrm{m}$.

Chemistry - Atranorin (major), 2'-O-methylphysodic acid (minor, accessory), physodic acid (major), physodalic acid (major, accessory), 3-hydroxyphysodic acid (major), protocetraric acid (minor, accessory), vittatolic acid (minor, infrequent accessory); medulla $\mathrm{P}+$ orange-red or more often $\mathrm{P}-\mathrm{K}+$ slowly reddish brown, $\mathrm{C}-\mathrm{KC}+$ orange red. 

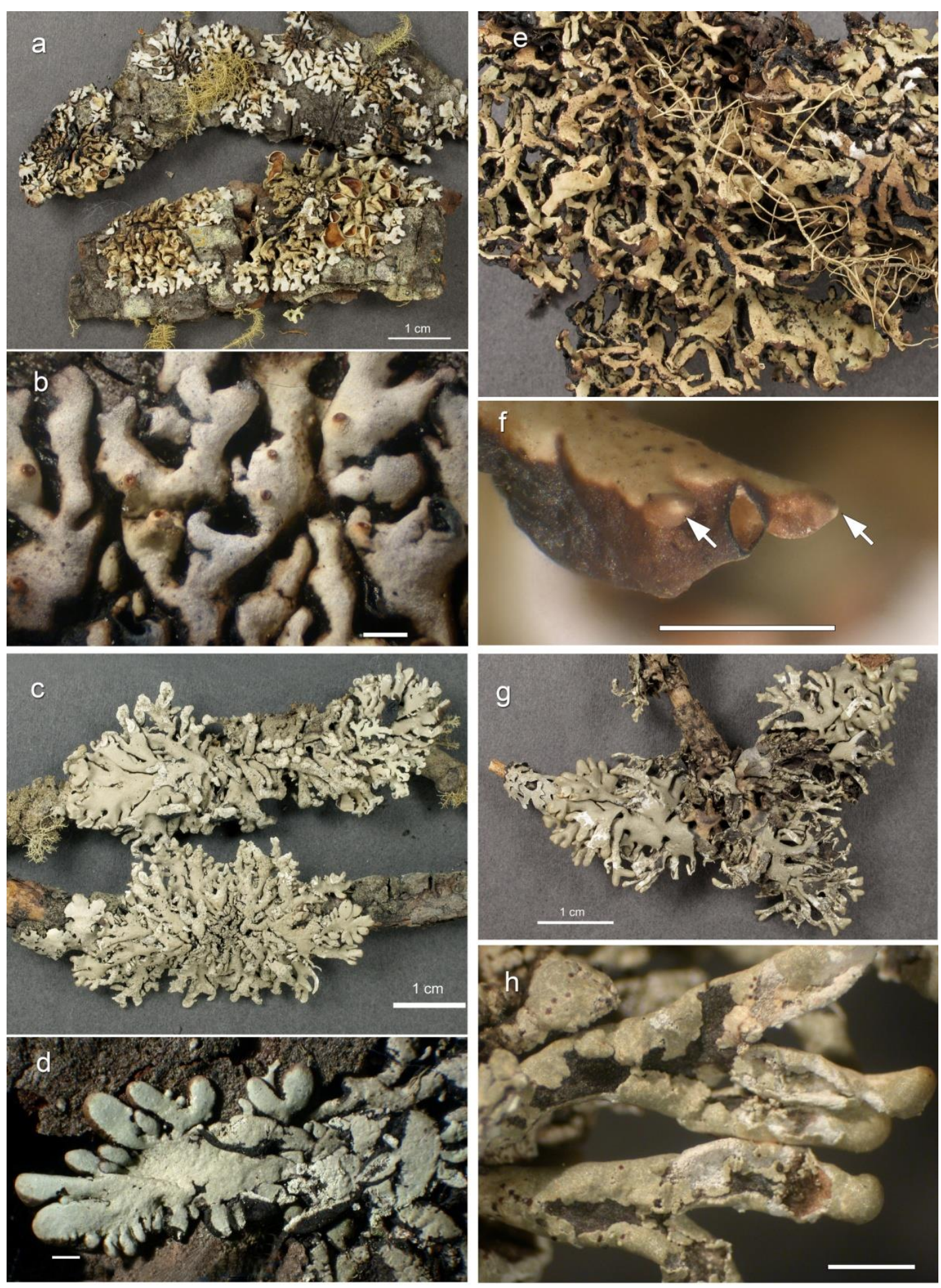

Fig. 10 - a. Hypogymnia pruinosa, habit (McCune 26750). b. H. pruinosa, lobes (McCune 26739). c. H. pseudobitteriana, habit (McCune 26737). d. H. pseudobitteriana, lobes (McCune 26829). e. H. pseudocyphellata, habit (L. S. Wang 00-19814). f. H. pseudocyphellata, lobe tips with pseudocyphellae (arrows) and axillary rimmed hole (L. S. Wang 00-19814). g. H. pseudophysodes, habit (McCune 26057). h. H. pseudophysodes, lobes (McCune 26057). Scale bars $1 \mathrm{~mm}$ unless otherwise indicated. 
Table 1 Comparison of pruinose species of Hypogymnia from Asia. Hypogymnia laccata is not considered to be a pruinose species but is included because of its occasional light pruina on the lobe tips and its strong similarities with $H$. lijiangensis, $H$. pseudopruinosa, and $H$. subpruinosa. $H$. pruinoidea is known from Shaanxi Province, not SW China. Abbreviations: contig. = contiguous lobes (vs. more open branching), $\mathrm{Ph}=$ physodic acid, $\mathrm{Pl}=$ physodalic acid, $\mathrm{Al}=$ alectoronic acid, Oxy $=3$-hydroxyphysodic acid, tr. $=$ trace.

\begin{tabular}{|c|c|c|c|c|c|c|c|c|c|}
\hline Species & Lobes & Ceiling & Spermatia & Pruina & Soredia & $\mathbf{P h}$ & Pl & Al & Oxy \\
\hline pruinosa & contig. & $\begin{array}{l}\text { white to } \\
\text { dark }\end{array}$ & $\operatorname{rod}$ & ++ & - & - & - & + & - \\
\hline subfarinacea & $\begin{array}{l}\text { contig. or } \\
\text { open }\end{array}$ & white & unknown & + & + & + & + & - & + \\
\hline lijiangensis & open & $\begin{array}{l}\text { light to } \\
\text { dark } \\
\text { brown }\end{array}$ & unknown & \pm & - & + & + & - & \pm \\
\hline pruinoidea & $\begin{array}{l}\text { contig. to } \\
\text { imbricate }\end{array}$ & $\begin{array}{l}\text { white to } \\
\text { brownish } \\
\text { or } \\
\text { grayish }\end{array}$ & bifusiform & \pm & - & + & - & - & + \\
\hline pseudopruinosa & contig. & $\begin{array}{l}\text { white to } \\
\text { light } \\
\text { brown }\end{array}$ & bifusiform & \pm & - & + & - & - & $\operatorname{tr}$. \\
\hline subpruinosa & contig. & dark & unknown & + & - & + & + & - & + \\
\hline laccata & contig. & $\begin{array}{l}\text { white to } \\
\text { light } \\
\text { brown }\end{array}$ & bifusiform & \pm & - & + & + & - & \pm \\
\hline
\end{tabular}

Substrate - Bark and wood, mainly of conifers.

Known distribution - Widely distributed in northeast Asia, including Russia and Japan; also reported from NE China (Jilin Province) and Taiwan (Wei 1991; specimens not seen by us).

Notes - This common species of northeast Asia is as yet unknown in southwest China, but we give a full description because of possible confusion with $H$. pseudobitteriana and the possibility of it eventually being found in SW China. Both $\mathrm{P}+$ and $\mathrm{P}$ - chemotypes are known, but most specimens are P-. Similar to $H$. pseudobitteriana in the laminal production of both schizidia and soredia, $H$. pseudophysodes can be distinguished by more isotomic dichotomous branching and the exposure of a black strip of medulla along the lobe crests after schizidia detach. In contrast, $H$. pseudobitteriana has more pinnate branching and less often exposes a blackish medulla on the tops of the lobes. Laminal schizidia and soredia are also characteristic of $H$. farinacea, but that species lacks holes in lower surface and is not known from Asia.

Selected material examined - JAPAN. Honshu: Prov. Shinano, Mt. Asahi-dake, Mt. Kimpu, $2500 \mathrm{~m}$, on trunk of Abies mariesii, Yoshida 3035, Kurokawa \& Kashiwadani, Lich. Rar. et Crit. Exs. 568 (US). Prov. Kai, lower slopes on north side of Mount Fuji, 1600 m, McCune 26057 (OSC). RUSSIA. Kurile Islands: Kunashir, 3 km NW of Yuzhno-Kurilsk near Lake Serebryanoye, Joneson 778 (WTU). Sakhalin Island: $11 \mathrm{~km}$ south of Krasnopolye, Uglegorke River valley, Larix cajanderi - Picea ajanensis forested bog, 100 m, McCune 25030 (OSC).

Hypogymnia pseudopruinosa X.L.Wei \& J.C.Wei, Mycotaxon 94: 155. 2005.

Fig. 11a.

Type - CHINA. Yunnan: Deqen County, Jiuzhai Gou, on trunk of Tsuga, 10 Jun 1983, X. Y. Wang \& J. J. Su 7606 (HMAS-L).

Synopsis - Lobes brownish gray, appressed, lightly pruinose, containing physodic acid and 3hydroxyphysodic acid, lacking soredia and isidia.

Description - Thallus appressed, to $7 \mathrm{~cm}$ broad or long; texture cartilaginous; branching variable, budding occasional; upper surface smooth to rugose, pale greenish gray to brown, black 
border not visible; lobes contiguous to imbricate, 1-2.5(3) $\mathrm{mm}$ wide; lobe width:height ratio 0.3:14:1; lobe tips and axils often perforate, lower surface perforate; medulla hollow, ceiling of cavity brownish to white, floor of cavity dark to grayish; soredia and isidia lacking; lobules rare; apothecia occasional, substipitate, to $2 \mathrm{~mm}$ diam; receptacle urn shaped, stipe hollow; hypothecium POL-; ascospores $6.1-7.5 \times 4-5.2 \mu \mathrm{m}$, pycnidia common, spermatia rod shaped to weakly bifusiform, 5.1$6.8 \times 1.1-1.4 \mu \mathrm{m}$.

Known distribution - Reported only from the type locality in Yunnan Province and the Mt. Taibai region of Shaanxi Province.

Chemistry - Atranorin (minor or trace), physodic (major), 3-hydroxyphysodic (trace), and vittatolic acids (minor). The TLC results are identical to that of $H$. pruinoidea, including the presence of 3-hydroxyphysodic acid as only a trace.

Notes - Hypogymnia pseudopruinosa is most similar with $H$. pruinoidea; see discussion under that species. The thallus is also similar to $H$. pruinosa, which also often has lobes laterally congested and compressed; H. pseudopruinosa has light pruinosity, weakly bifusiform spermatia, and physodic acid, while $H$. pruinosa usually has conspicuous pruina, spermatia that are rod-shaped or with a submedial swelling, and alectoronic acid.

The holotype and original descriptions (both Latin and English) of H. pseudopruinosa are mixtures of two species. The largest piece, which is illustrated in Plate I.A of Wei and Wei (2005), contained two thalli of different species, one tightly appressed against the other. The upper, smaller thallus is $H$. laccata. It is glossy brown, completely epruinose, with white to grayish ceilings of the lobe cavities, and with tag TLC 10-1. It is P+ orange and accords with the chemical description Wei and Wei (2005). The thallus being overgrown is H. pseudopruinosa, as lectotyped by Wei and Wei (2012). That piece is matte, blackish brown, and in poor condition. It does, however, have pruinose lobe tips (Wei and Wei 2005, Plate I.B.). The pruinose parts of this specimen have a medulla that is $\mathrm{P}$ - and contains physodic acid and atranorin.

Material examined - CHINA. Shaanxi: Mei County, Taibaishan, X. L. Wei 11139, 11143, 11150 (HMAS-L).

Hypogymnia saxicola McCune \& L. S. Wang, sp. nov.

Fig 12 MycoBank MB 807351

Etymology - The epithet "saxicola" refers to the saxicolous substrate preference for this species, unusual for Hypogymnia.

Type - CHINA. Yunnan: Luquan County, Jiaozixue Mountain, north of Kunming, on top of shoulder of mountain, outcrops and Rhododendron and Juniperus scrub in subalpine, $4200 \mathrm{~m}$, rock crevices in cliff, McCune 25561, Sep 2000 (holotype: KUN, isotype: OSC).

Synopsis - Thallus forming imbricate to suberect cushions on mossy rock; lobes slender (to $1.5 \mathrm{~mm}$ broad), smooth-surfaced, fragile, glossy brown, pointed lobes; branch axils and lower surface perforate, lobe cavity with dark ceilings and floors; medulla P-, K- or K+ slowly brownish red.

Description - Thallus appressed to suberect, to $10 \mathrm{~cm}$ or more broad; branching variable, including both isotomic and anisotomic portions, lateral budding present; texture papery, fragile; upper surface pale greenish gray to more often brown or dark brown, often with black mottling, without black borders, smooth, epruinose; lobes 0.5-1.4(3) $\mathrm{mm}$ wide, separate to imbricate, width even to slightly expanding distally and near the nodes; lobe width:height ratio mostly $1: 1$ to $2: 1$; perforations present on many lobe tips, axils, and lower surfaces, the holes not rimmed; medulla hollow, both the ceiling and floor of the cavity soon darkening to brown or dark brown; soredia and isidia lacking; lateral budding and lobules common, the lobules often pointed or teardrop shaped. Apothecia and pycnidia unknown. Photobiont chlorococcoid.

Chemistry - Containing atranorin and physodic acid (major) and vittatolic acid (minor); cortex K+ yellow, C-, KC-, P- or pale yellow; medulla K-, KC+ reddish, P-.

Substrate - On rock and moss; subalpine; mossy boulders and outcrops in Rhododendron Juniperus scrub and on open slopes with dwarf bamboo, 3500-4200 m. 
Known distribution - Yunnan and Sichuan Provinces.

Notes - The general morphology of this species suggests a saxicolous morph of $H$. irregularis or $H$. vittata. From $H$. irregularis, $H$. saxicola is distinguished by sparse, mostly centered holes in the lower surface, dark brown lobe tips, fragile texture, and (so far) absence of pycnidia and apothecia. In contrast, $H$. irregularis has numerous perforations that are irregular in placement on the lower surface, and often staggered side to side. Furthermore, H. irregularis is not particularly fragile, seldom has a brown upper surface, and commonly produces both pycnidia and apothecia. Although $H$. vittata is occasionally found on rock, and shares with $H$. saxicola the tendency to produce slender, perpendicular, adventitious side-branches, $H$. saxicola is distinguished by the absence of soredia, its fragile lobes, and the absence of 3-hydroxyphysodic acid.

Hypogymnia saxicola often has laminal lobules reminiscent of $H$. subobscura, the lobules being pointed or tear-drop shaped. However the two species have markedly different appearances, with $H$. subobscura having contiguous rather appressed lobes while $H$. saxicola has separate imbricate lobes. The dark lobe cavities of $H$. saxicola separate that species from $H$. subobscura, which has white or darkening ceilings and white to dark grayish floors.

The reproductive mode of $H$. saxicola appears to be similar to $H$. fragillima and $H$. duplicata; all three are characteristically vegetative with slender lobes, presumably relying on fragmentation for reproduction. This is aided by the open branching and fragility of the lobes in all three species. Both of the latter species have white to pale greenish gray lobes, in contrast with the brown color of $H$. saxicola. Furthermore, $H$. fragillima is readily distinguished by the extremely heavy perforations on the lower surface, while $H$. duplicata, a North American endemic, differs in its $\mathrm{P}+$ chemistry and its nodulose (alternating pinched and swollen) lobes.

Additional material examined - CHINA. Sichuan: Jiulong County, Ji Chou Mt., $29.75^{\circ} \mathrm{N}$ $101.50^{\circ} \mathrm{E}, 4300$ m, L. S. Wang 96-17426 (KUN). Yunnan: Luquan County, Jiaozixue Mt., 4100 m, 31 January 1992, L. S. Wang 93-12923 (KUN); mossy boulder on open slope with dwarf bamboo, 3500 m, Sep 2000, McCune 25644 (OSC).

Hypogymnia sinica J.C.Wei \& Y.M.Jiang, Acta Phytotax. Sin. 18:386. 1980.

Fig. $11 b$.

Type - CHINA. Xizang: Nyalam, Qüxiang, DeQingtang, $3660 \mathrm{~m}$, on bark of Betula, 21

May 1966. T. C. Wei and J. B. Chen 1110 (HMAS-L!).

Synopsis - Appears like an usnic-deficient $H$. hypotrypa; lobes broad, appressed to planarextended, somewhat separate, isotomic-dichotomously branched, with laminal soredia and schizidia; perforations in the lower surface large and conspicuous; pycnidia and apothecia absent; $\mathrm{P}-, \mathrm{K}+$ slowly reddish brown, $\mathrm{KC}+$ orange red.

Description - Thallus appressed, to $8 \mathrm{~cm}$ broad or long; texture cartilaginous; branching mostly isotomic dichotomous, budding occasional; upper surface smooth to rugose, pale gray to pale greenish gray, dark mottles occasional, black border often present, epruinose; lobes contiguous or separate; lobe outline even, 1-5(7)mm wide; lobe width:height ratio 1:1-4:1; lobe tips and axils perforate, lower surface conspicuously perforate with large, gaping holes; medulla hollow, ceiling of cavity dark, floor of cavity dark; soredia present, laminal, produced along the edges of schizidia and cracks in the upper cortex; isidia lacking; lobules rare; apothecia unknown; pycnidia unknown.

Chemistry - Containing atranorin (major), physodic acid (major), 3-hydroxyphysodic acid (major), vittatolic acid (minor accessory), and unknown "C22" (minor); medulla $\mathrm{P}-$, $\mathrm{K}+$ slowly reddish brown, $\mathrm{C}-, \mathrm{KC}+$ orange-red. Unknown $\mathrm{C} 22$ appears constant in TLC of $H$. sinica as a brownish spot just above the starting line and slightly lower than vittatolic acid in solvents $\mathrm{A}$ and $\mathrm{C}$, conspicuously lower than vittatolic acid in solvent G. Unknown C22 appears in Culberson Rf classes A1-2, B1-2, C1, and G2.

Substrate - On bark and wood, especially Rhododendron; also Abies, Hypericum, Juniperus, Salix, Sorbus, and bamboo.

Known distribution - Endemic to SW China, occurring in Xizang and Yunnan Provinces. 

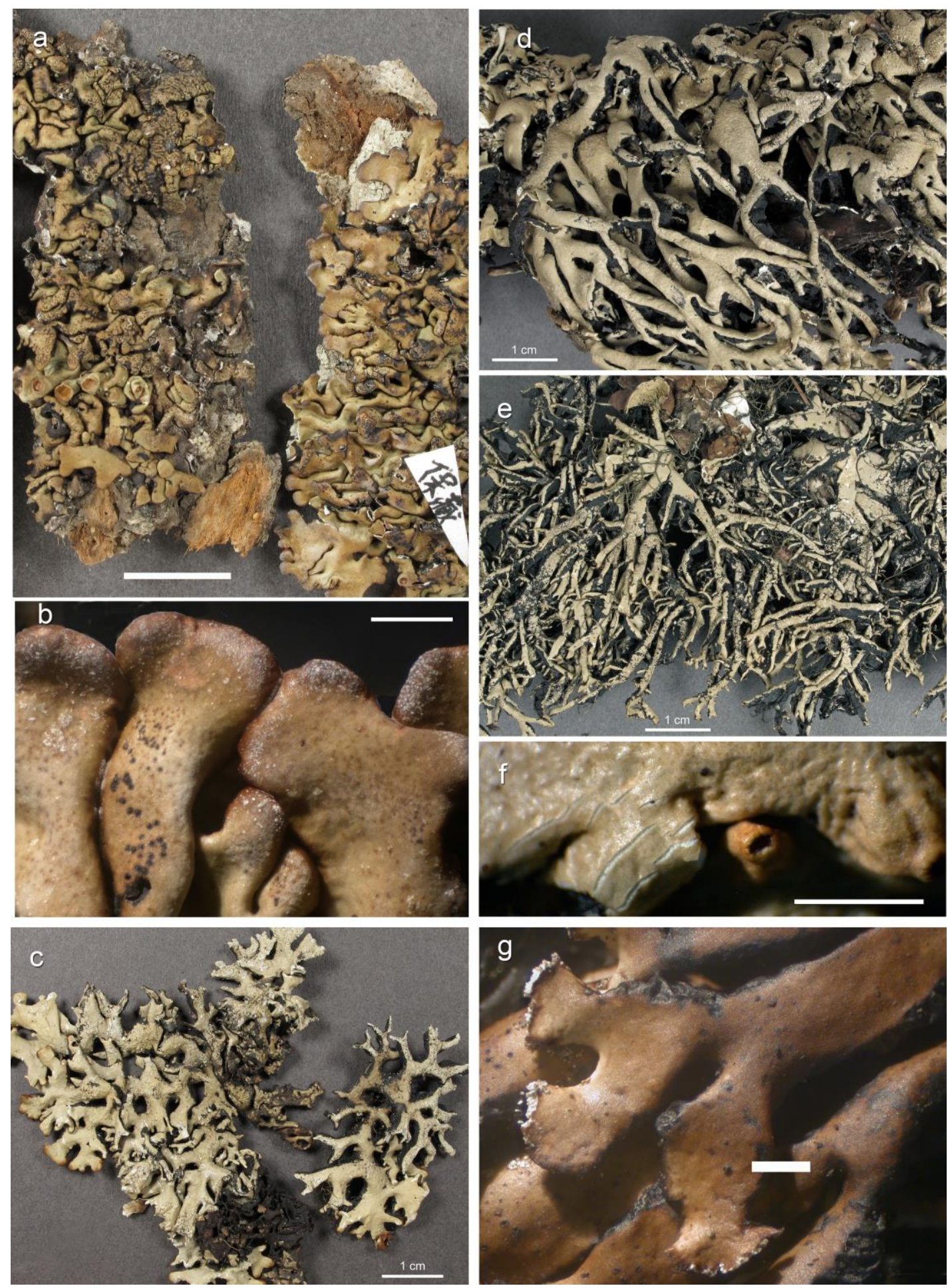

Fig. 11 - a Hypogymnia pseudopruinosa, habit (X. L. Wei 11143). b H. pseudopruinosa, lobe tips (X. L. Wei 11143). с H. sinica, habit (McCune 25523). d H. stricta, habit (L. S. Wang 01-20658). e H. stricta, habit (L. S. Wang 01-20659) f H. stricta, cracks in upper cortex (L. S. Wang 831806). g H. subarticulata, lobes (McCune 25598). Scale bars $1 \mathrm{~mm}$ unless otherwise indicated.

Notes $-H$. sinica was treated as a synonym of the esorediate Hypogymnia pseudohypotrypa by Wei (1991), while McCune \& Obermayer (2001) accepted H. sinica as a distinct, sorediate species.

The type specimen of $H$. sinica consists of three small pieces. On these, soredia are formed by small puckered to rugose spots on upper cortex near the lobe tips, the rugose areas then breaking into schizidia edged with soredia. 

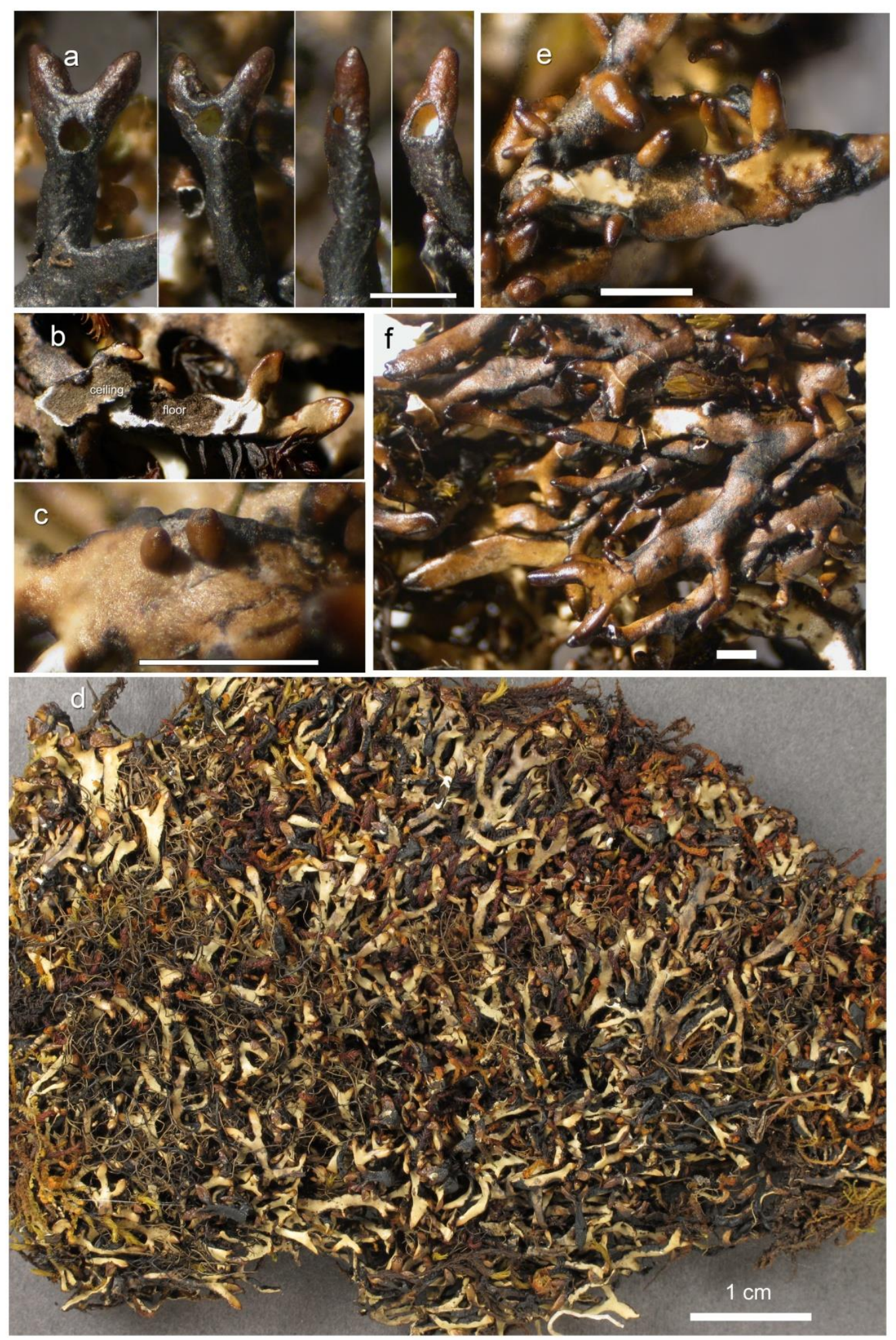

Fig. 12 - Hypogymnia saxicola. a Perforations (McCune 25561). b Lobe cavity (McCune 25644). c Laminal budding (Wang 92-1293). d.Habit (McCune 25644). e. Marginal budding (Wang 921293). f Lobes (Wang 92-1293). Scale bars $1 \mathrm{~mm}$ unless otherwise indicated.

Small individuals resemble $H$. pseudophysodes in the appressed habit and the combination of schizidia and soredia, often flaking off to expose the blackish medulla, but the lobe width of $H$. sinica is typically twice that of $H$. pseudophysodes. While both species are perforate below, the holes in $H$. sinica are large and gaping, similar to H. hypotrypa and $H$. flavida, while those in $H$. pseudophysodes are usually easily found but more moderate in size. 
Material examined - CHINA. Yunnan: Bijiang County, Gaoligong Shan, Pianma, $26.017^{\circ} \mathrm{N}$ 98.633 ${ }^{\circ} \mathrm{E}$, Zang Mu 7273 (KUN); Caojian County, Zi ben Mountain, $25.7367^{\circ} \mathrm{N} 99.0583^{\circ} \mathrm{E}$, L. S. Wang 00-18841 (KUN); Zi ben Mountain, 24.9267 ${ }^{\circ} \mathrm{N} 98.7517^{\circ} \mathrm{E}, 2390 \mathrm{~m}$, L. S. Wang 00-19533 (KUN); Dali County, trail to Mt. Cang Shan, $25.685^{\circ} \mathrm{N} 100.102^{\circ} \mathrm{E}, 3500 \mathrm{~m}$, McCune 26773, 26781 (OSC); Luquan County, Jiaozixue Mt., 3700-4100 m, L. S. Wang 92-12984, 96-16731, 00-20378, 00-20432 (KUN); McCune 25521, 25523, 25531, 25545, 25549, 25628, 25636, 25649, 25676 (OSC); Yunlong County, Zi Ben Shan, top of ridge, $25.733^{\circ} \mathrm{N} 99.067^{\circ} \mathrm{E}, 3200 \mathrm{~m}$, McCune 26819, 26828 (OSC).

Hypogymnia stricta (Hillmann) K. Yoshida, Bull. Nat. Science Museum Tokyo 27:36. 2001.

Parmelia elongata var. stricta Hillmann, Fedde Repert. Sp. Nov. 45:171. 1938. Holotype destroyed in Berlin; lectotype in TNS chosen by Yoshida (2001). Fig. 11c.

Hypogymnia vittata f. stricta (Hillmann) Kurok., Misc. Bryol. Lich. 5:130. 1971.

Synopsis - Appears like an esorediate $H$. vittata but ceiling of the lobe cavity is light brown to white (sometimes dark) and the upper cortex has faint to prominent transverse cracks; lobes often with adventitious buds and branches.

Description - Thallus appressed to pendulous, to $12 \mathrm{~cm}$ broad or long; texture cartilaginous; branching variable, budding present; upper surface smooth to weakly rugose, white to pale greenish gray, dark mottles sometimes present, black border sometimes present; lobes separate to \pm imbricate; lobe outline pinched and swollen; lobes 0.5-4(5) $\mathrm{mm}$ wide; lobe width:height ratio 0.5:14:1; lobe tips and axils sparsely perforate, lower surface perforate; medulla hollow, ceiling of cavity brownish to white, floor of cavity dark; soredia and isidia lacking, lobules often present; apothecia occasional, substipitate, to $9 \mathrm{~mm}$ diam, receptacle urn or funnel shaped, stipe hollow; hypothecium POL-; ascospores 5.5-7.0 $\times 4.3-5.6 \mu \mathrm{m}$, pycnidia common, spermatia weakly bifusiform, 4.7-5.3 $\times$ $0.9-1.1 \mu \mathrm{m}$.

Chemistry - Containing atranorin (major), physodic (major), 3-hydroxyphysodic (major), 2'$O$-methylphysodic (minor), and vittatolic (minor accessory) acids; medulla $\mathrm{K}+$ slowly reddish brown, $\mathrm{C}-\mathrm{KC}+$ orange red, $\mathrm{P}$-. The substance 2'-O-methylphysodic acid is apparently constant in H. stricta, although sometimes present in only trace amounts and therefore can be missed by TLC.

Substrate - On bark and wood, including Juniperus, Larix, Picea, Quercus, and Rhododendron.

Known distribution - China, Japan (including type locality), Taiwan

Notes - See comparison with $H$. irregularis and $H$. vittata in McCune (2011). This normally distinctive species has a long history of confusion with $H$. vittata. In routine identifications of $H$. stricta, we recommend confirming the pale ceilings, fine transverse cracks in the upper cortex, absence of soredia, and presence of 2'-O-methylphysodic acid.

Selected material examined - CHINA. Sichuan: Xiaojin County, Rilong Village, Sigouniangshan, $30.033^{\circ} \mathrm{N} 102.867^{\circ} \mathrm{E}, 3600 \mathrm{~m}$, L. S. Wang 02-21051 (KUN). Yunnan: Deqin County, Mei Li Xue Mt, Xio-Nang Village, $28.4^{\circ} \mathrm{N} 98.75^{\circ} \mathrm{E}, 3300 \mathrm{~m}, \mathrm{~L}$. S. Wang 94-15101c (KUN); Bai-ma-xue-shan, $28.35^{\circ} \mathrm{N} 99.033^{\circ} \mathrm{E}, 3500 \mathrm{~m}$, L. S. Wang 2420 (KUN); Gong Shan County, Qinatong, Songtaxue Mountain, $28.1883^{\circ} \mathrm{N} 98.5317^{\circ} \mathrm{E}, 3300 \mathrm{~m}$, L. S. Wang 00-19614 (KUN); Qiqi to Dongshaofang, $27.703^{\circ} \mathrm{N} 98.495^{\circ} \mathrm{E}, 2500 \mathrm{~m}$, L. S. Wang 00-19041 (KUN); Lijiang County, Laojuen Mountain, Jiushijiulong Lake, $28.5017^{\circ} \mathrm{N} 99.8177^{\circ} \mathrm{E}, 3800 \mathrm{~m}$, L. S. Wang 0019819 (KUN); Yuhaizi, 27.083 ${ }^{\circ} \mathrm{N} 100.25^{\circ} \mathrm{E}, 3800 \mathrm{~m}, \mathrm{~L} . \mathrm{S}$. Wang 83-1806 (KUN); Li-di-ping, $27.15^{\circ} \mathrm{N} 99.417^{\circ} \mathrm{E}, 3200 \mathrm{~m}, \mathrm{~J} . \mathrm{X}$. Xi 0172 (KUN); Zhongdian County, Daxue Shan, $28.575^{\circ} \mathrm{N}$ $99.834^{\circ} \mathrm{E}, 4000 \mathrm{~m}$, L. S. Wang 00-19997 (KUN); Wengshuei Village, Daxue Shan, $28.502^{\circ} \mathrm{N}$ $99.818^{\circ} \mathrm{E}, 3800 \mathrm{~m}$, L. S. Wang 00-19845 (KUN); Wengshuei Village, $28.575^{\circ} \mathrm{N} 99.834^{\circ} \mathrm{E}, 4000 \mathrm{~m}$, L. S. Wang 00-20027 (KUN); Tian-bao-shan, $27.583^{\circ} \mathrm{N} 99.917^{\circ} \mathrm{E}, 3700 \mathrm{~m}, \mathrm{~L}$. S. Wang 2008a (KUN). TAIWAN. (see citations in McCune 2009), also: Hualien County, Taroko NP, Hohuan Shan, $24.15^{\circ} \mathrm{N} 121.283^{\circ} \mathrm{E}, 3000 \mathrm{~m}$, Aptroot 53686 (F); Hohuan Shan, near field station, $24.156^{\circ} \mathrm{N}$ $121.288^{\circ} \mathrm{E}, 3200 \mathrm{~m}$, Aptroot 52395, 52615, 52662, 52397 (F); Pa-tung-kuan, Hsin-kao Shan (Yu Shan), $23.467^{\circ} \mathrm{N} 120.95^{\circ} \mathrm{E}, 3110 \mathrm{~m}$, Nakanishi 13125, 13184, (TNS); Taichung County, Hsueshan, 
Da-Syue National Forest Recreation Area, $24.283^{\circ} \mathrm{N} 121.030^{\circ} \mathrm{E}, 2603 \mathrm{~m}$, Wetmore 90406 (MIN); Hsueshan Mountains, Tahsuehshan Forest Park, Anmashan, $24.268^{\circ} \mathrm{N} 121.033^{\circ} \mathrm{E}, 2600 \mathrm{~m}$, Wetmore 85302 (MIN) JAPAN. (see citations in McCune 2009).

Hypogymnia subarticulata (J.D.Zhao, L.W.Hsu \& Z.M.Sun) J.C.Wei \& Y.M.Jiang, Lichens of Xizang, p. 37. 1986.

Fig. 11d.

Parmelia vittata var. subarticulata J.D.Zhao, L.W.Hsu \& Z.M.Sun, Acta Phytotax. Sin. 16:96. 1978.

Type - CHINA. Yunnan: Lijiang, 3000 m, J. D. Zhao 4410 (HMAS-L!).

Synopsis - Lobes short, broad, brownish to dark brown; soralia apical, labriform; perforations large, below the sorediate lobe tips, the lobes often terminating in a gaping hole.

Description - Thallus appressed to suberect, to $4 \mathrm{~cm}$ broad or long; texture cartilaginous; branching variable, budding occasional; upper surface smooth to weakly rugose, pale greenish gray to brown, dark mottles none or rare, black border often present; lobes 0.7-3(4)mm broad, often constricted at the nodes, separate to imbricate; lobe outline pinched and swollen; lobe width:height ratio 0.5:1-2.5:1; lobe tips and axils perforate, lower surface sparsely perforate; medulla hollow, ceiling of cavity dark, floor of cavity dark; soredia terminal, labriform, isidia and lobules lacking; apothecia unknown; pycnidia occasional; spermatia not seen.

Chemistry - Containing atranorin (major), 2'-O-methylphysodic acid (minor, accessory), physodic acid (major), physodalic acid (major), protocetraric acid (minor); medulla $\mathrm{K}-, \mathrm{C}-, \mathrm{KC}+$ orange red, $\mathrm{P}+$ orange-red.

Substrate - On bark and wood, rarely on rock or mossy rock; hosts include Abies, Betula, Picea, Pinus, Quercus, Rhododendron, Salix, bamboo, and various evergreen and sclerophyllous shrubs.

Known distribution - Common in Sichuan and Yunnan Provinces, with disjuncts in Taiwan and India (Sikkim).

Notes - The epithet refers to the tendency for the branch points to be strongly constricted ("subarticulate"). This distinctive species shares with $H$. vittata soralia that are terminal and labriform. Furthermore, both species solarize to brown. Hypogymnia subarticulata differs in more readily solarizing to dark brown, a $\mathrm{P}+$ orange red medulla, and relatively short, broad lobes, in contrast to $H$. vittata having a pale greenish gray to brownish upper surface, P- medulla, and relatively elongate, narrow lobes.

Material examined - CHINA. Sichuan: Er Mei Mountain, $29.50^{\circ} \mathrm{N} 103.33^{\circ} \mathrm{E}, 2900 \mathrm{~m}, \mathrm{Yu} \mathrm{Si}$ Min 696a (KUN); Hengduan Mountains, Daxue Shan, SE of the pass, $30.0153^{\circ} \mathrm{N} 101.8589^{\circ} \mathrm{E}$, 3570 m, Obermayer 9804 (GZU); Luding County, Gongga Mountain, 29.4167 $\mathrm{N} 101.833^{\circ} \mathrm{E}, 2450-$ 3000 m, L. S. Wang 96-16175, 96-17268 (KUN); Mi Yi County, Ma Long Village, Bei Puo Mountain, $26.83^{\circ} \mathrm{N} 102.0^{\circ} \mathrm{E}, 3200 \mathrm{~m}$, L. S. Wang 83-753a, 83-755, 83-784, 83-814 (KUN); Mu Li

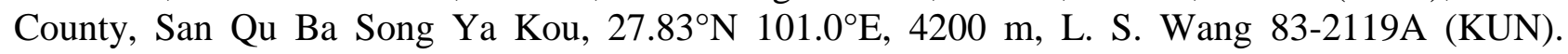
Yunnan: Caojian County, Zi ben Mt, $25.737^{\circ} \mathrm{N} 99.058^{\circ} \mathrm{E}, \mathrm{L}$. S. Wang 00-18803, 00-18816, 0018840 (KUN); Dali County, trail to Mountain, Cang Shan, $25.685^{\circ} \mathrm{N} 100.102^{\circ} \mathrm{E}, 3500 \mathrm{~m}$, McCune 26786, 26798 (OSC); Deqin County, Bei Ma Xue Shan, $28.383^{\circ} \mathrm{N} 99.0^{\circ} \mathrm{E}, 4200 \mathrm{~m}$, L. S. Wang HKAS2222 (KUN); Fu Gong County, Lu Ma Den Village, Qu Lu Di unit, 27.033 $\mathrm{N} 98.883^{\circ} \mathrm{E}$, $3500 \mathrm{~m}$, L. S. Wang 82-437 (KUN); Gongshan County, Qiqi to Dongshaofang, $27.7^{\circ} \mathrm{N} 98.5^{\circ} \mathrm{E}$, $2500 \mathrm{~m}, \mathrm{~L}$. S. Wang 00-19070 (KUN); Jianchuan County, ridge on trail to Laojuen Shan, $26.6317^{\circ} \mathrm{N} 99.7183^{\circ} \mathrm{E}, 3980 \mathrm{~m}$, McCune 26724 (OSC); San Jiang Bin Liu area, $26.6625^{\circ} \mathrm{N}$ $99.7217^{\circ} \mathrm{E}, 3110 \mathrm{~m}$, McCune 26702 (OSC). Lijiang County, Jiushijiulong Lake, Maan Mountain, $26.6512^{\circ} \mathrm{N} 99.775^{\circ} \mathrm{E}, 3500 \mathrm{~m}$, L. S. Wang 00-20173, 00-20200 (KUN); Yu Lake, $27.083^{\circ} \mathrm{N}$ $100.167^{\circ} \mathrm{E}, 3100-3400 \mathrm{~m}, \mathrm{~L}$. S. Wang 82-941, 82-987 (KUN); Yu Long Shan, $27.083^{\circ} \mathrm{N}$ $100.167^{\circ} \mathrm{E}, 3200 \mathrm{~m}$, L. S. Wang 82-885 (KUN); Ganheba, $27.083^{\circ} \mathrm{N} 100.233^{\circ} \mathrm{E}, 2600 \mathrm{~m}$, L. S. Wang 10269 (KUN); Tie-jia-shan, 26.8 ${ }^{\circ} \mathrm{N} 100.05^{\circ} \mathrm{E}, \mathrm{L}$. S. Wang 10265 (KUN); Yulong Shan, $27.10^{\circ} \mathrm{N} 100.23^{\circ} \mathrm{E}, 2900 \mathrm{~m}$, Moberg 7853 (UPS); Lijiang Pref., Yu Long Xue Shan, $27.133^{\circ} \mathrm{N}$ $100.167^{\circ} \mathrm{E}, 2400 \mathrm{~m}, \mathrm{~L}$. S. Wang 82-246 (KUN); Yu Long Xue Shan, $27.083^{\circ} \mathrm{N} 100.167^{\circ} \mathrm{E}, 4200 \mathrm{~m}$, 
L. S. Wang 85-243 (KUN); Luquan County, Jiaozixue Mt., $26.083^{\circ} \mathrm{N} 102.867^{\circ} \mathrm{E}, 3700 \mathrm{~m}$, L. S. Wang 13052, 00-20371, 00-20369, 00-20372, 00-20410 (KUN); McCune 25524, 25530, 25544,

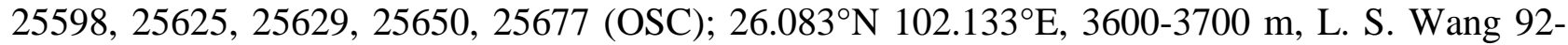
13052, 93-13051, 96-17054 (KUN); Yunlong County, road to Zi Ben Shan, 25.7658 ${ }^{\circ} \mathrm{N} 99.1067^{\circ} \mathrm{E}$, $2500 \mathrm{~m}$, McCune 26810 (OSC); Zi Ben Shan, top of ridge, $25.733^{\circ} \mathrm{N} 99.067^{\circ} \mathrm{E}, 3200 \mathrm{~m}$, McCune 26818, 26815, 26821 (OSC); Zhongdian County, Daxueshan, Ya Kou, $28.667^{\circ} \mathrm{N} 99.834^{\circ} \mathrm{E}, 4260$ m, C. C. Hu 2736 (KUN); Daxueshan, 28.567 ${ }^{\circ}$ 99.817 ${ }^{\circ}$, 4200-4400 m, L. S. Wang 01-20794, 01-20816, 01-20991 (KUN); Pa Cha Cao Dian, 27.833 ${ }^{\circ} \mathrm{N} 99.717^{\circ} \mathrm{E}, 3450 \mathrm{~m}, \mathrm{~L}$. S. Wang 93-13775 (KUN); Wengshuei Village, Daxueshan, $28.575^{\circ} \mathrm{N} 99.835^{\circ} \mathrm{E}, 4250 \mathrm{~m}$, L. S. Wang 00-19944 (KUN). TAIWAN. (see citations in McCune 2009).

Hypogymnia subfarinacea X. L. Wei \& J. C. Wei, Mycotaxon 94:156.

Fig. 14a.

Type - CHINA. Sichuan: Nanping County, Jiuzhai Gou, on trunk of Tsuga, $2550 \mathrm{~m}, 10 \mathrm{Jun}$ 1983, X. Y. Wang 10582 (HMAS-L!).

Synopsis - Lobes sorediate and patchily pruinose along the margins and lobe tips, lobe cavity with white ceiling and dark floor, lower surface with indistinctly rimmed holes; appears like a P+ $H$. sinica but has white ceilings rather than dark.

Description - Thallus appressed, to $8 \mathrm{~cm}$ broad; texture cartilaginous; branching isotomic dichotomous, budding occasional; upper surface smooth to weakly rugose, pale gray to greenish gray, black border not visible, dark mottles none or rare; lobes contiguous or separate, 1-3 mm broad, outline even; lobe width:height ratio 1:1-4:1; lobe tips and axils perforate, lower surface perforate; medulla hollow, ceiling of cavity white, floor of cavity dark; soredia present, laminal, produced along the edges of schizidia and cracks in the upper cortex; isidia lacking; lobules rare; apothecia unknown; pycnidia unknown.

Chemistry (based on holotype) - Atranorin, physodic, physodalic, 3-hydroxyphysodic, and protocetraric acids; thallus $\mathrm{K}+$ slowly red brown, $\mathrm{C}-, \mathrm{KC}+$ orange red, $\mathrm{P}+$ orange red.

Substrate - On Quercus and conifers.

Known distribution - SW China (Sichuan, Yunnan) at lower elevations (2000-3000 m) than most Hypogymnia species in this region. The original description cites three locations: Sichuan Province (Jioushai Gou, the type locality) and Yunnan Province (Yulong Shan, 2900 and 3100 m, Lijiang area).

Notes - See Table 1 for comparison with other pruinose Hypogymnia species.

Material examined - Only type specimen seen.

Hypogymnia subpruinosa J.B.Chen, Acta Mycologica Sinica 13:107.

Fig. 14b.

Type - CHINA. Yunnan: Zhongdian, Xiaozhongdian, in Sabina [Juniperus] squamata, 3600 m, 22 Aug 1981, X. Y. Wang 7094 (HMAS-L!).

Synopsis - Similar to $H$. pruinosa but lacking alectoronic acid and pruinose parts lighter; habit rosettiform rather like $H$. metaphysodes, but lobe tips perforate and lobe cavity dark above and below.

Description - Thallus appressed, to $7 \mathrm{~cm}$ broad; texture cartilaginous; branching variable, budding occasional; upper surface smooth, becoming rugose, white to pale greenish gray, dark mottles sometimes present, black border not visible; lobes contiguous, 1-3(4)mm wide; lobe tips and axils often perforate, lower surface sparsely perforate, medulla hollow, ceiling of cavity dark to grayish, floor of cavity dark; soredia and isidia lacking; lobules rare; apothecia common, substipitate, to $2 \mathrm{~mm}$ diam, receptacle urn or funnel shaped, stipe hollow; hypothecium weakly POL+; ascospores 6.0-7.3 $\times$ 4.9-5.5 $\mu \mathrm{m}$ (from original description; spores not seen by us); spermatia not seen.

Chemistry - Atranorin (major), 2'-O-methylphysodic acid (minor accessory, usually present), physodic acid (major), physodalic acid (major), 3-hydroxyphysodic acid (major, accessory), protocetraric acid (minor); medulla $\mathrm{K}$ - or $\mathrm{K}+$ slowly reddish brown, $\mathrm{C}-, \mathrm{KC}+$ orange red, $\mathrm{P}+$ orange red. 
Substrate - On bark and wood.

Known distribution - Yunnan Province.

Notes - The description above is based on the holotype. We could not evaluate the lower surface well on the holotype without dissecting it further. The apothecia on the holotype are small and no ascospores were found.

Hypogymnia subpruinosa is similar in chemistry and morphology to $H$. laccata, except that the latter is epruinose and has a paler ceiling (grayish or brownish to white). We are doubtful about maintaining this species as separate from $H$. laccata.

Material examined - CHINA. Sichuan: Litang County (= Batang, County), Jinsha (Yangtze) tributary, $30.30^{\circ} \mathrm{N} 99.283^{\circ} \mathrm{E}, 4220 \mathrm{~m}, \mathrm{G}$. \& S. Miehe 94-12-23/02 (GZU); Xiangchen County, Rewu village, $28.833^{\circ} \mathrm{N} 99.80^{\circ} \mathrm{E}, 4400 \mathrm{~m}$, J. K. Yang 2364 (KUN); Xizang: East Xizang, Upper Mekong basin, Mekong-Zi Qu divide, $31.083^{\circ} \mathrm{N} 96.967^{\circ} \mathrm{E}, 4245 \mathrm{~m}, \mathrm{G}$. \& S. Miehe 94-316/04 (GZU).

Hypogymnia tenuispora McCune \& L. S. Wang, sp. nov.

Fig 13 MycoBank MB 807352

Etymology - The epithet "tenuispora" refers to ascospores that are proportionately narrower than all other Hypogymnia species.

Type - CHINA. Yunnan: Luquan County, Jiaozixue Mt., north of Kunming, high plateau, with outcrops and scrub Rhododendron; on Sorbus in steep, shrubby riparian gully on mountain slope; $26.10^{\circ} \mathrm{N} 102.87^{\circ} \mathrm{E}, 4100 \mathrm{~m}$, Sep 2000, McCune 25573 (holotype KUN).

Synopsis - Thallus appressed, with short congested lobes; upper surface matte, brownish tinged, lobe cavity with white to brown ceiling and dark floor, spores over $10 \mu \mathrm{m}$ long, narrowly elliptical, length/width ratio about 2:1.

Description - Thallus appressed, to $7 \mathrm{~cm}$ broad; texture cartilaginous; branching variable, budding occasional; upper surface smooth to rugose, matte, greenish gray to brown, dark mottles sometimes present, black border not visible; lobes 1-3(4) $\mathrm{mm}$ broad, contiguous to imbricate; lobe width:height ratio 0.5:1-3:1; lobe tips and axils often perforate, lower surface perforate; medulla hollow, ceiling of cavity brownish to white, floor of cavity dark; soredia and isidia lacking, lobules rare; apothecia common, substipitate, to $6(11) \mathrm{mm}$, receptacle urn or funnel shaped, stipe hollow; hypothecium POL-; ascospores 10.8-11.8 × 4.1-5.4 $\mu \mathrm{m}$, pycnidia common, spermatia not seen.

Chemistry - Atranorin (major), physodic (major), 2'- $O$-methylphysodic, and \pm vittatolic (minor) acids; cortex $\mathrm{K}+$ yellow, $\mathrm{C}-, \mathrm{KC}-, \mathrm{P}-$; medulla $\mathrm{K}-, \mathrm{C}-, \mathrm{KC}+$ orange red, $\mathrm{P}-$.

Substrate - So far known from bark of hardwoods (Sorbus and Rhododendron).

Known distribution - Yunnan. Rare.

Notes - The congested lobes and apothecia of this species and brownish tone of the thallus suggest $H$. bulbosa or $H$. congesta, but the spores of $H$. tenuispora are longer and narrower than in those species and its lobe perforations are not typically rimmed. Most Hypogymnia species have spores $<10 \mu \mathrm{m}$ long and with a length:width ratio of 1.0:1 to 1.5:1. Spores of $H$. tenuispora are not only longer than that, but they are unusually narrow. The other species of Hypogymnia that have spores $>10 \mu \mathrm{m}$ are $H$. macrospora and H. pendula. However, their spores are longer $(12-17 \mu \mathrm{m})$, wider $(9-14 \mu \mathrm{m})$, and with a length:width ratio typically 1.3:1. If spores are not present, they can still potentially be differentiated by an apothecial section, with the hypothecium being POL+ in $H$. macrospora while POL- in $H$. tenuispora and $H$. pendula.

Only two collections are known at this time and they differ considerably in outward appearance. The holotype has darker thalli wrapped around twigs. In contrast, McCune 25572 has bigger, paler thalli that are not tightly wrapped around twigs, but still appressed (Fig. 13).

Additional specimen examined - CHINA. Yunnan: Luquan County, Jiaozixue Mt., $26.10^{\circ} \mathrm{N}$ 102.867 $\mathrm{E}, 4100 \mathrm{~m}$, Sep 2000, McCune 25572 (OSC).

Hypogymnia thomsoniana (Müll. Arg.) Awasthi, Kavaka 12(2):94. 1984.

Fig. 14c.

Parmelia thomsoniana Müll. Arg., Flora 74:379. 1891. 
Parmelia pseudohypotrypa Asahina apud Nuno, J. Jap. Bot. 39:99. 1964.

Hypogymnia pseudohypotrypa (Asah.) A. Singh, Lichenol. Ind. Subcontinent 1966-1977. Eco. Bot. Inform. Serv. Nat. Bot. Res. Inst. Lucknow 2. 1980.

Type - INDIA. Sikkim: no precise locality, T. Thomson 277, Holotype (G) photograph in Awasthi (1984); isotype (H-NYL!).

Synopsis - Lobes broad, either short or elongate, with large perforations below; lobe cavity with dark ceilings and floors; perpendicular bud-like side lobes infrequent or absent; thallus to 10 $\mathrm{cm}$ or more broad; spores $9-10 \times 7--7.5 \mu \mathrm{m}$; thallus similar to $H$. flavida except with atranorin instead of usnic acid and lacking physodalic acid.

Description - Thallus appressed to pendulous, to $7(14) \mathrm{cm}$ broad or long; texture cartilaginous; branching isotomic dichotomous, budding absent or rare; upper surface smooth to weakly rugose, pale gray to greenish gray, dark mottles sometimes present, black border often present; lobes 0.5-2.5(3) mm wide, contiguous to imbricate; lobe outline even to \pm nodulose; lobe width:height ratio $0.5: 1-2: 1$; lobe tips and axils perforate, lower surface perforate; medulla hollow, ceiling of cavity dark, floor of cavity dark; soredia, isidia, and lobules lacking; apothecia occasional, substipitate to stipitate, to $11(15) \mathrm{mm}$, receptacle urn or funnel shaped, stipe hollow; ascospores 9-10 × 7-7.5 $\mu \mathrm{m}$; pycnidia common, spermatia weakly bifusiform, 5-6 $\times 0.7-1.0 \mu \mathrm{m}$.

Chemistry - atranorin (major), 2'- $O$-methylphysodic acid (minor, accessory), physodic acid (major), 3-hydroxyphysodic acid (major, accessory), and vittatolic acid (minor accessory, usually present); medulla $\mathrm{K}$ - or $\mathrm{K}+$ slowly reddish brown, $\mathrm{C}$ - $\mathrm{KC}+$ orange red, $\mathrm{P}$-.

Substrate - On bark and wood, especially Rhododendron, also on Abies, Juniperus, twigs of shrubs near the ground, rarely on mossy rock or terricolous.

Known distribution - Sikkim, India, and SW China.

Notes - The type of $H$. pseudohypotrypa contains physodic acid, trace of 3-hydroxyphysodic acid, and 2'-O-methylphysodic acid (J. Elix HPLC). McCune et al (2012) synonymized $H$. pseudohypotrypa with $H$. thomsoniana, the former apparently just a short-lobed morph.

Material examined - CHINA. Sichuan: Luding County, Gongga Mountain, Hai Luo Gou, $29.833^{\circ} \mathrm{N} 102.333^{\circ} \mathrm{E}, 3000 \mathrm{~m}, \mathrm{~L}$. S. Wang 96-16976 (KUN); Muli County, Ning-lang shan, $27.317^{\circ} \mathrm{N} 100.883^{\circ} \mathrm{E}, 3900 \mathrm{~m}$, Xuan Yu 4264 (KUN). Xizang: Nyainqentanglha Shan, $29.908^{\circ} \mathrm{N}$ $94.875^{\circ} \mathrm{E}, 3500 \mathrm{~m}$, Obermayer 6772 (GZU). Yunnan: Lijiang, Handel-Mazzetti 3561 (US); eastern slopes Likiang Snow Range, J. F. Rock 8564 (US); Ning Lang County, Wei Yi, $27.67^{\circ} \mathrm{N} 100.75^{\circ} \mathrm{E}$, Han Yu Fen 81-1559 (KUN). INDIA. West Bengal: Darjeeling District, way from Sandakhpoo to Phalut, Awasthi 67-498 (LWG).

Hypogymnia vittata (Ach.) Parrique, Act. Soc. Linn. Bordeaux 53:66. 1898. Note that Parrique and Gasilien are the same person; Parrique is the currently accepted form of his name. Fig. 14d.

Hypogymnia vittata (Ach.) Gasilien, Act. Soc. Linn. Bordeaux 53:66. 1898. (listed this way in Lamb's Index Lich. Nom. and in Awasthi 1984)

Parmelia physodes var. vittata Ach., Meth. Lich. 250. 1803.

Parmelia vittata (Ach.) Nyl.

Parmelia vittata (Ach.) Röhl., Deutsch F. 3:2 Ab. 109. 1813. (listed this way in Awasthi 1984)

Synopsis - Branching open, with occasional to abundant adventitious lobes; lobe cavity with dark ceilings and floors, lower surface and lobe tips conspicuously perforate with large holes, soralia sparse to abundant, labriform beneath the lobe tips.

Description - Thallus appressed to suberect, to $10(15) \mathrm{cm}$ broad or long; texture cartilaginous; branching variable, but often with narrow adventitious side branches and lateral budding frequent; upper surface smooth to weakly rugose, white to greenish gray or brown, dark mottles sometimes present, black border often present; lobes $0.5-3 \mathrm{~mm}$ broad, separate to centrally subcontiguous; lobe outline even to \pm pinched and swollen; lobe width:height ratio 0.5:1-2.0:1; lobe tips and axils perforate, lower surface sparsely perforate; medulla hollow, ceiling of cavity dark, floor of cavity dark; soredia terminal, labriform, lining the burst-open lobe tips; isidia and lobules lacking; 
apothecia rare, substipitate, to $6(8) \mathrm{mm}$ diam, receptacle urn- or funnel-shaped, stipe hollowhypothecium weakly POL+; ascospores 4.8-6.0 $\times 4.8-5.4 \mu \mathrm{m}$, pycnidia sparse and infrequent, spermatia narrowly cylindrical to weakly bifusiform, 4.9-5.7 $\times 0.8-1.0 \mu \mathrm{m}$

Chemistry - Atranorin (major), physodic acid (major), 3-hydroxyphysodic acid (major, usually present), vittatolic acid (minor accessory); medulla $\mathrm{K}$ - or $\mathrm{K}+$ slowly reddish brown, $\mathrm{C}-$, $\mathrm{KC}+$ orange red, P-. Vittatolic and 3-hydroxyphysodic acids each occur in about $85 \%$ of Asian specimens.

Substrate - On bark, wood, mosses, mossy rock, and rock.

Known distribution - Hypogymnia vittata is one of the most broadly distributed species of Hypogymnia, occurring in Asia, North America, and Europe. Thus it is widespread in the northern Hemisphere, but has large disjunctions and gaps in its distribution, and in many areas it is locally rare.

Notes - See McCune (2011) for a detailed comparison of $H$. vittata, $H$. irregularis, and $H$. stricta.

Selected material examined - CHINA. Sichuan: Dao Chen, mountain behind village, $29.0^{\circ} \mathrm{N}$ $100.17^{\circ} \mathrm{E}, 4200$ m, L. S. Wang 2416 (KUN); Du Kou County, Yan Di, Yan Kou Village, Shi Bo Shan, $27.5^{\circ} \mathrm{N} 101.5^{\circ} \mathrm{E}, 2800-2900 \mathrm{~m}$, L. S. Wang 83-571, 83-572, 93-590, Kirkpatrick 83-623 (KUN); Er Mei Mountain, 29.50 ${ }^{\circ} \mathrm{N} 103.33^{\circ} \mathrm{E}, 2900 \mathrm{~m}$, Yu Si Min 696b (KUN); Hengduan Mountains, Daxue Shan, SE of the pass, $30.0153^{\circ} \mathrm{N} 101.8589^{\circ} \mathrm{E}, 3570 \mathrm{~m}$, Obermayer $9974-1$, 9974-2 (GZU); Shaluli Shan, $50 \mathrm{~km} \mathrm{~S}$ Litang, $29.5514^{\circ} \mathrm{N} 100.2903^{\circ} \mathrm{E}, 4270 \mathrm{~m}$, Obermayer 9681 (GZU); Hueli County, Long Zhou Mountain, TV tower, $26.7^{\circ} \mathrm{N} 102.0^{\circ} \mathrm{E}, 3250 \mathrm{~m}$, L. S. Wang 9618024 (KUN); Jiulong County, Jiulong to Liu Ba Xiang, $29.25^{\circ} \mathrm{N} 101.5^{\circ} \mathrm{E}, 4200 \mathrm{~m}, \mathrm{~L}$. S. Wang 96-16508, 96-17514 (KUN); Liu Ba Xiang, 29.25 ${ }^{\circ} \mathrm{N} 101.50^{\circ} \mathrm{E}, 3100 \mathrm{~m}$, L. S. Wang 96-16454 (KUN); Tang Gu Xiang, $29.17^{\circ} \mathrm{N} 101.50^{\circ} \mathrm{E}, 3000 \mathrm{~m}$, L. S. Wang 96-17453b (KUN); Kangding County, Zhe Duo Mountain, $30^{\circ} \mathrm{N} 102^{\circ} \mathrm{E}, 4000 \mathrm{~m}$, L. S. Wang 96-16325 (KUN); Luding County, Gongga Mountain, Hai Luo Gou, Camp, $29.83^{\circ} \mathrm{N} 102.33^{\circ} \mathrm{E}, 3000 \mathrm{~m}$, L. S. Wang 96-16184 (KUN); Mi Yi County, Ma Long Village, Bei Puo Mountain, $26.833^{\circ} \mathrm{N} 102^{\circ} \mathrm{E}, 2900 \mathrm{~m}$, L. S. Wang 83-971 (KUN); Mu Li County, Ka La Village, $28.083^{\circ} \mathrm{N} 101.333^{\circ} \mathrm{E}, 3300 \mathrm{~m}$, L. S. Wang 83-1977 (KUN); Ka La Village, Shao Xian Liang Zi, 28.083 ${ }^{\circ}$ 101.333 ${ }^{\circ}$ E, 3800 m, L. S. Wang 83-1743 (KUN); road from $\mathrm{Yi} \mathrm{Qu}$ to $\mathrm{Wo} \mathrm{Ya}, 27.83^{\circ} \mathrm{N} 101.0^{\circ} \mathrm{E}, 3750 \mathrm{~m}$, L. S. Wang 83-2394 (KUN); Nanping County, Jui Zhai Gou, Tian Er Lake, $33.0^{\circ} \mathrm{N} 103.83^{\circ} \mathrm{E}, 3200 \mathrm{~m}, \mathrm{~L}$. S. Wang 86-2671 (KUN); reg. bor. Dongrergo, Huang-lung-ssu, H. Smith 5239 (UPS); reg .bor--occid., Somo, H. Smith 5190, (UPS); Xiang Chen County, near Da Xue Shan, Ya Kou, $28.67^{\circ} \mathrm{N} 99.83^{\circ} \mathrm{E}, 4000 \mathrm{~m}, \mathrm{~L}$. S. Wang 2337 (KUN); Xiao Jin County, Shuang Qiao Gou, 31.0 ${ }^{\circ} \mathrm{N} 102.5^{\circ} \mathrm{E}, 3300 \mathrm{~m}, \mathrm{~L}$. S. Wang 96-17711, 96-17720 (KUN); Xing Chen County, Re Ru Village, near Ba Lang pasture, $28.83^{\circ} \mathrm{N} 99.83^{\circ} \mathrm{E}$, 4100 m, L. S. Wang 2337 (KUN); Yanyuan County, Beiling Village, Si Da Unit, 27.5 ${ }^{\circ} 101.5^{\circ} \mathrm{E}$, 3550 m, L. S. Wang 83-1367 (KUN). Sikang: Kangting (Tachienlu) District, Yulingkong, Gomba La, 3700 m, H. Smith 5190 (UPS). Xizang: Bomi County, near Pa Ju Village, 3100 m, Su Yong Ge 947a (KUN); Cha Yu Ca, Cawarong, Song Ta Xue Shan, N slope, $28.667^{\circ} \mathrm{N} 97.833^{\circ} \mathrm{E}, 2600 \mathrm{~m}$, L. S. Wang s.n. (KUN); Nie La Mu County, $28.1^{\circ} \mathrm{N} 85.9^{\circ} \mathrm{E}, \mathrm{S}$. K. Chen 23 (KUN); Nie La Mu to Zhang Mu, S. K. Chen 52 (KUN); Qan Ning, Zang Mu 1159 (KUN); Ri Dong County, Qi Ma La, $31.3^{\circ} \mathrm{N} 97.2^{\circ} \mathrm{E}, 3460 \mathrm{~m}$, Zang Mu 6284 (KUN); Nyainqentanglha Shan, $29.950^{\circ} \mathrm{N} 94.892^{\circ} \mathrm{E}, 3400$ $\mathrm{m}$, Obermayer 6935 (GZU); S Xizang, west of Sakyetang, $27.967^{\circ} \mathrm{N} 87.217^{\circ} \mathrm{E}, 4140 \mathrm{~m}$, Dickore K84-10 (GZU); SE Xizang, Tsangpo tributary, Nangxian-Mainling, $29.05^{\circ} \mathrm{N} 93.93^{\circ} \mathrm{E}, 4140 \mathrm{~m}$, Dickore 94-181-14E (GZU). Yunnan: Dali County, trail to Cang Shan, $25.685^{\circ} \mathrm{N} 100.102^{\circ} \mathrm{E}, 3500$ m, McCune 26792 (OSC); Deqin County, Bei Ma Xue Shan, Ya Kou, 28.38 ${ }^{\circ} \mathrm{N} 99.0^{\circ} \mathrm{E}, 4200 \mathrm{~m}, \mathrm{~L}$. S. Wang 93-13534, 93-13560b (KUN); Fu Gong County, Lu Ma Den Village, Qu Lu Di unit, $27.033^{\circ} \mathrm{N} 98.883^{\circ} \mathrm{E}, 3700 \mathrm{~m}, \mathrm{~L}$. S. Wang 82-457 (KUN); Gong Shan County, Bing Zhong Luo,

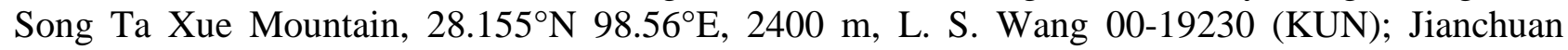
County, San Jiang Bin Liu area, $26.6625^{\circ} \mathrm{N} 99.7217^{\circ} \mathrm{E}, 3110 \mathrm{~m}$, McCune 26705 (OSC); Shi Bao Shan Park, $75 \mathrm{~km} \mathrm{~S}$ of Lijiang, $26.3589^{\circ} \mathrm{N} 99.8403^{\circ} \mathrm{E}, 2490 \mathrm{~m}$, McCune 26734 (OSC); Lijiang County, Bei Pu Lin, Yu Long Mountain, 27.083 $\mathrm{N} 100.167^{\circ} \mathrm{E}, 3050$ m, Xi Jian Xun 67b, 69, 70c 

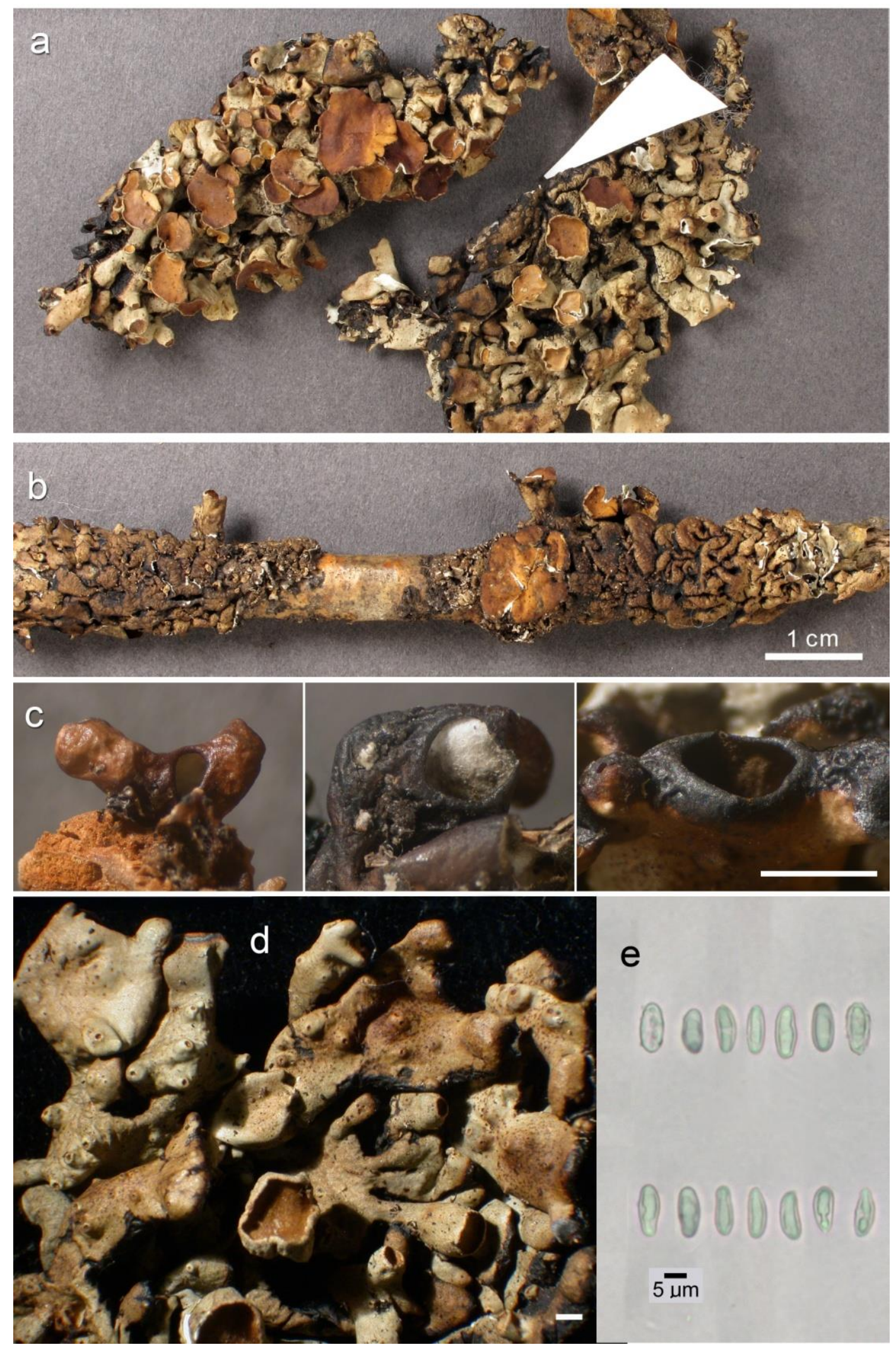

Fig. 13 - Hypogymnia tenuispora. a Habit (McCune 25572). b Habit (McCune 25573). c Perforations (McCune 25572). d Lobes (McCune 25572). e Ascospores (McCune 25573). Scale bars $1 \mathrm{~mm}$ unless otherwise indicated.

(KUN); Yulong Shan, Yu Feng Temple, 26.97 $\mathrm{N} 100.20^{\circ} \mathrm{E}, 2500 \mathrm{~m}$, Moberg 32217 (UPS); Luquan County, Jiaozixue Mt., $26.083^{\circ} \mathrm{N} 102.133^{\circ} \mathrm{E}, 3700-4000 \mathrm{~m}$, L. S. Wang 92-12928, 9213117, 93-1357400-20367 (KUN); Jiaozixue Mt., $26.100^{\circ} \mathrm{N} 102.867^{\circ} \mathrm{E}, 3500-3700 \mathrm{~m}$, McCune 

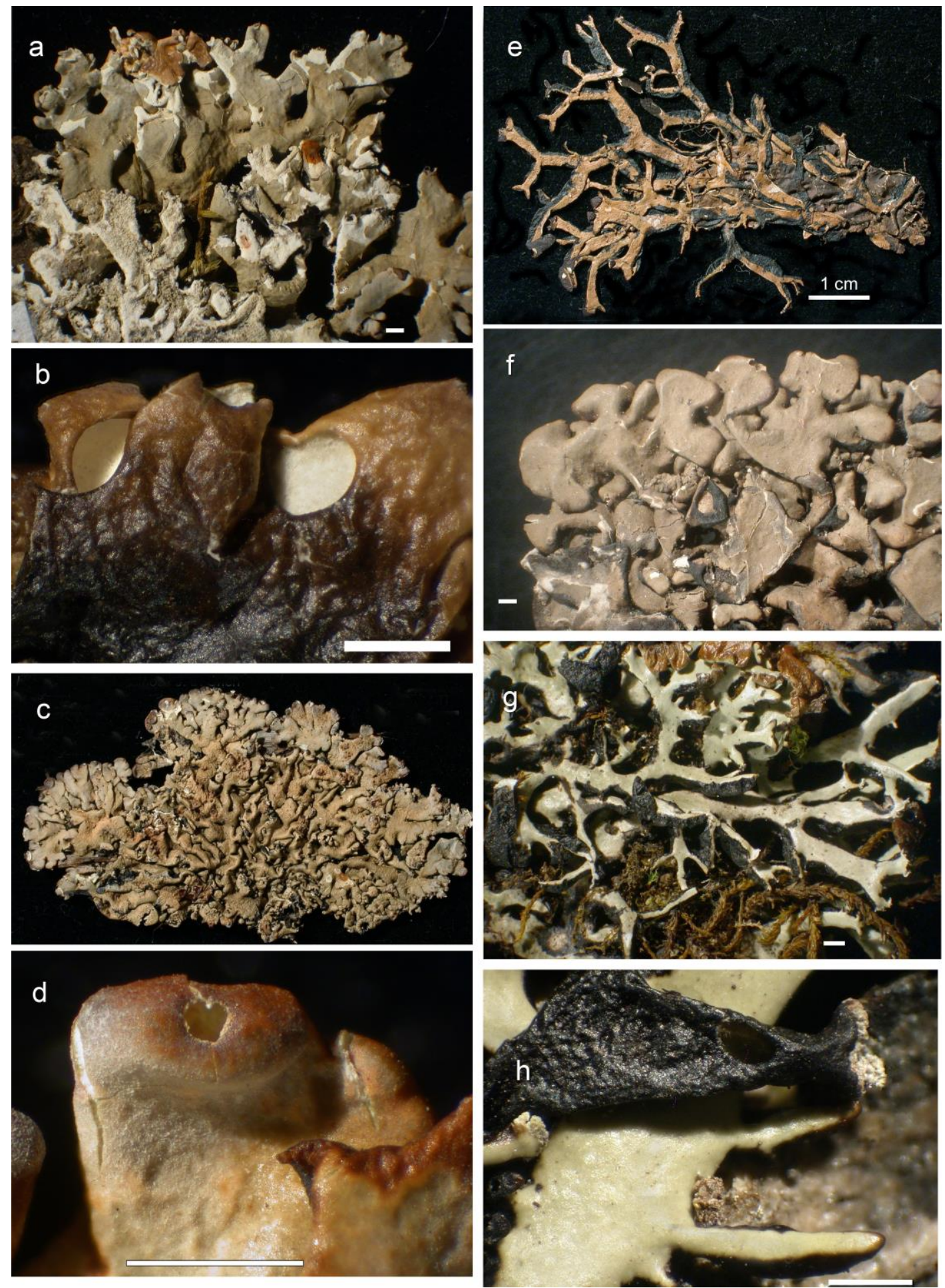

Fig. 14 - a Hypogymnia subfarinacea, habit (holotype, X. Y. Wang 10582). b H. subfarinacea, lower surface with perforations (X. L. Wei 11143). c H. subpruinosa, habit (holotype, X. Y. Wang 7094). d H. subpruinosa, lobe tips and perforation ( X. Y. Wang 7094). e H. thomsoniana, habit (type, Thomson 277, H-Nyl) f. H. thomsoniana, short-lobed "pseudohypotrypa" morph (Awasthi 67-498). g H. vittata, lobes (McCune 25623). h H. vittata, lobes showing soralia, narrow adventitious lobes, and perforations (McCune 26705). Scale bars $1 \mathrm{~mm}$ unless otherwise indicated.

25623, 25661 (OSC); Wei Xi County, Ye Zhi Village, Ba Di, $27.72^{\circ} \mathrm{N} 99.05^{\circ} \mathrm{E}, 3500-3800 \mathrm{~m}$, L. S. Wang 82-196, 82-213F, 82-1817 (KUN); Yi Liang County, small meadow, 27.62 ${ }^{\circ} \mathrm{N} 104.0^{\circ} \mathrm{E}, 1700$ m, L. S. Wang 96-16649 (KUN); Zhongdian County, Daxue Shan, $28.503^{\circ} \mathrm{N} 99.817^{\circ} \mathrm{E}, 3800 \mathrm{~m}, \mathrm{~L}$. S. Wang 00-19824b, 00-19850 (KUN); Zhongdian County, Wengshuei Village, Daxue Shan, 
$28.575^{\circ} \mathrm{N} 99.834^{\circ} \mathrm{E}, 4000-4250 \mathrm{~m}, \mathrm{~L} . \mathrm{S}$. Wang 00-19849, 00-19938b, 00-19952, 00-19991, 0020010 (KUN); Zhongdian County, Xiozhongdian, Tianchi, $27.833^{\circ} \mathrm{N} 99.717^{\circ} \mathrm{E}, 3700-3800 \mathrm{~m}$, L. S. Wang 93-13655C, 93-13681 (KUN). TAIWAN. Hualien County, Taroko NP, Shan, $24.150^{\circ} \mathrm{N}$ 121.283 ${ }^{\circ} \mathrm{E}, 3000 \mathrm{~m}$, Aptroot 53685 (F); Nantou County, Patungkuan, Mount Pa-tung-kuan, 3280 m, Nakanishi 13675, 13677 (TNS); Taichung County, between Ssu-yuan \& To-chia-tun Shan, Nanhuta Shan, 2825 m, Kashiwadani 36019 (TNS).

Unresolved species. A number of problem specimens remain. Notable among these, but represented by a single specimen, is L. S. Wang 82-735 (see key; Yunnan, Gong Shan Co., Bin Zhong Juo Village, south slope Song Ta, $28.033^{\circ} \mathrm{N} 98.616^{\circ} \mathrm{W}, 3600 \mathrm{~m}$, on Abies (KUN)). Briefly, the specimen is characterized by small thalli, about $1-2 \mathrm{~cm}$ broad; upper surface brownish; lobes short, appressed to slightly ascending, with large holes below; lobe cavities with pale ceilings and dark floors; apothecia abundant; epithecium thinly POL+ with K-soluble granules; spores subspherical, 4.5-7 $\mu \mathrm{m}$; hypothecium weakly POL+; thallus containing atranorin, physodic acid, and 2'-O-methylphysodic acid. The POL+ epithecium is highly unusual in Hypogymnia (but see $H$. crystallina from the Himalayas of India; McCune et al. 2012), and this is perhaps the only species of Hypogymnia in SW China with this character state.

\section{Acknowledgements}

We thank curators of BM, CANL, DUKE, E, F, GZU, H, H-NYL, HMAS, KUN, LWG, MIN, NY, OSC, PC, S, TNS, UPS, US, and WTU who kindly cooperated with loans and visits; Olivia Lee for translations of label data and assistance with data entry, and Elisa Alphandary, Lalita Calabria, Corinne Duncan, Erin Martin, Christina Wesseler for assistance with TLC. We thank Chicita Culberson and Jack Elix for identifying selected lichen substances, Svetlana Tchabanenko for sharing her knowledge and specimens of Hypogymnia in the Russian Far East, Toby Spribille for sharing specimens from Russia, Walter Obermayer for sharing specimens from Sichuan and Tibet, Hiroyuki Kashiwadani for facilitating field and herbarium work in Japan, and Xin-Li Wei and Jiang-Chun Wei for correspondence and specimens. We thank two anonymous reviewers for numerous useful comments and corrections to the manuscript. Collections were supported by The National Natural Science Foundation of China (No. 31170023 and 31370069) and Flora Lichenum Sinicorum (KSCX2-EW-Z-9).

\section{References}

Awasthi DD. 1984 - The lichen genera Hypogymnia and Menegazzia from India and Nepal. Kavaka 12(2), 87-97.

Chen JB. 1994 - Two new species of Hypogymnia (Nyl.) Nyl. (Hypogymniaceae, Ascomycotina). Acta Mycologica Sinica 13, 107-110.

Culberson CF. 1972 - Improved conditions and new data for the identification of lichen products by a standardized thin-layer chromatographic method. Journal of Chromatography 72, 113 125.

Culberson CF, Johnson A. 1982 - Substitution of methyl tert.-butyl ether for diethyl ether in the standardized thin-layer chromatographic method for lichen products. Journal of Chromatography A 238, 483-487.

Goward T, Ahti T, Elix JA, Spribille T. 2010 - Hypogymnia recurva and Hypogymnia wilfiana spp. nov., two new lichens from western North America. Botany 88, 345-361.

Hansen ES, McCune B. 2010 - The lichen genus Hypogymnia in Greenland. Folia Cryptogamica Estonica 47, 13-20.

Herner G. 1988 - Harry Smith in China: Routes of his botanical travels. Taxon 37, 299-308.

Lai MJ. 1980 - Notes on some Hypogymniae (Parmeliaceae) from East Asia. Quarterly Journal of the Taiwan Museum 33, 209-214. 
McCune B. 2009 - Hypogymnia (Parmeliaceae) species new to Japan and Taiwan. Bryologist 112, $823-826$.

McCune B. 2011 - Hypogymnia irregularis (Ascomycota: Parmeliaceae) - a new species from Asia. Mycotaxon 115, 485-494.

McCune B 2012 - The identity of Hypogymnia delavayi (Parmeliaceae) and its impact on H. alpina and H. yunnanensis. Opuscula Philolichenum 11, 11-18.

McCune B, Divakar PK, Upreti DK. 2012 - Hypogymnia in the Himalayas of India and Nepal. The Lichenologist 44, 595-609.

McCune B, Martin E, Wang LS. 2002 - Five new species of Hypogymnia with rimmed holes, from the Chinese Himalayas. The Bryologist 106, 226-234.

McCune B, Obermayer W. 2001 - Typification of Hypogymnia hypotrypa and H. sinica. Mycotaxon 79, 23-27.

Obermayer W. 2002 - Dupla Graecensia Lichenum 2002. Fritschiana 33, 15-31.

Obermayer W. 2004 - Additions to the lichen flora of the Tibetan region. Bibliotheca Lichenologica 88, 479-526.

Rassadina KA 1971 - Hypogymnia. Pages 285-301 in Kopaczevskaja EG, Makarevicz MF, Oxner AN, and Rassadina KA, Handbook of the Lichens of the U.S.S.R. 1. Pertusariaceae, Lecanoraceae and Parmeliaceae. Nauka. Leningrad. 412 pages. (See also English translation by Alexander Mikulin, (1996), "The genus Hypogymnia in the former Soviet Union.").

Tchabanenko S, McCune B. 2001 - Hypogymnia arcuata and H. sachalinensis, two new lichens from east Asia. The Bryologist 104, 146-150.

Upreti DK, Divakar PK. 2008 - Notes on some interesting macrolichens from India. Nova Hedwigia 86, 525-528.

Wei JC. 1984 - A new isidiate species of Hypogymnia in China. Acta Mycologica Sinica 3, 214-216.

Wei JC. 1991 - An Enumeration of Lichens in China. International Academic Publishers, Beijing.

Wei JC, Bi WF. 1998 - Chemical revision of Hypogymnia hengduanensis. The Bryologist 101, $556-557$.

Wei JC, Jiang YM. 1980 - (Species novae lichenum e Parmeliaceis in regione xizangensi). Acta Phytotaxonomica Sinica 18(3), 386-388.

Wei XL, Wei JC. 2005 - Two new species of Hypogymnia (Lecanorales, Ascomycota) with pruinose lobe tips from China. Mycotaxon 94, 155-158.

Wei XL, Wei JC. 2012 - A study of the pruinose species of Hypogymnia (Parmeliaceae, Ascomycota) from China. The Lichenologist 44, 783-793.

Wei XL, McCune B, Wang LS, Wei JC. 2010 - Hypogymnia magnifica (Parmeliaceae), a new lichen from southwest China. The Bryologist 113, 120-123.

Yoshida K, Kashiwadani H. 2001 - Typification of taxa of Hypogymnia (Parmeliaceae) described from Japan and Sakhalin. Bulletin of the National Science Museum, Tokyo, Series B $27(2,3), 35-46$.

Zahlbruckner A. 1930 - Lichenes. In H. Handel-Mazzetti. Symbolae sinicae: botanische Ergebnisse der Expedition der Akademie der Wissenschaften in Wein nach Südwest-China, 1914-1918. 3: $1-254$.

Zhao JD (= Chao CD). 1964 - A preliminary study on Chinese Parmelia. Acta Phytotaxonomica Sinica 9, 139-166. 